\title{
THE MASLOV DEQUANTIZATION, IDEMPOTENT AND TROPICAL MATHEMATICS: A BRIEF INTRODUCTION
}

\author{
G. L. LITVINOV \\ To Anatoly Vershik with admiration and gratitude
}

\begin{abstract}
This paper is a brief introduction to idempotent and tropical mathematics. Tropical mathematics can be treated as a result of the so-called Maslov dequantization of the traditional mathematics over numerical fields as the Planck constant $\hbar$ tends to zero taking imaginary values.
\end{abstract}

This paper is a brief introduction, practically without exact theorems and proofs, to the Maslov dequantization and idempotent and tropical mathematics. Our list of references is not complete (not at all). Additional references can be found, e.g., in the electronic archive

$$
\text { http://arXiv.org }
$$

and in $[9,17,21,25,28-31,37,38,51,62,64-70,84,87,89,93,96,102,104$, $110,115,137,187]$. The present brief survey is an extended version of the paper [101].

The author thanks M. Akian, Ya. I. Belopolskaya, P. Butkovič, G. Cohen, S. Gaubert, R. A. Cuninghame-Green, P. Del Moral, W. H. Fleming, J. S. Golan, M. Gondran, I. Itenberg, Y. Katsov, V. N. Kolokoltsov, P. Loreti, Yu. I. Manin, G. Mascari, W. M. MacEneaney, G. Panina, E. Pap, M. Pedicini, H. Prade, A. A. Puhalskii, J.-P. Quadrat, M. A. Roytberg, G. B. Shpiz, I. Singer, and O. Viro for useful contacts and references. Special thanks are due to V. P. Maslov for his crucial help and support and to A. N. Sobolevskiu for his great help including, but not limited to, three pictures presented below.

2000 Mathematics Subject Classification. Primary 00A05, 81Q20, 14P99, 51P05, 46S10, 49L99; Secondary 06A99, 06F07, 14N10, 81S99.

Key words and phrases. The Maslov dequantization, idempotent mathematics, tropical mathematics, idempotent semirings, idempotent analysis, idempotent functional analysis, dequantization of geometry.

This work has been supported by the RFBR grant 05-01-00824 and the Erwin Schrödinger International Institute for Mathematical Physics (ESI).

To be published in Journal of Mathematical Sciences. 


\section{SOME BASIC IDEAS}

Idempotent mathematics is based on replacing the usual arithmetic operations with a new set of basic operations (such as maximum or minimum), that is on replacing numerical fields by idempotent semirings and semifields. Typical examples are given by the so-called max-plus algebra $\mathbf{R}_{\text {max }}$ and the min-plus algebra $\mathbf{R}_{\text {min. }}$. Let $\mathbf{R}$ be the field of real numbers. Then $\mathbf{R}_{\max }=\mathbf{R} \cup\{-\infty\}$ with operations $x \oplus y=\max \{x, y\}$ and $x \odot y=x+y$. Similarly $\mathbf{R}_{\text {min }}=\mathbf{R} \cup\{+\infty\}$ with the operations $\oplus=\min , \odot=+$. The new addition $\oplus$ is idempotent, i.e., $x \oplus x=x$ for all elements $x$.

Many authors (S. C. Kleene, S. N. N. Pandit, N. N. Vorobjev, B. A. Carre, R. A. Cuninghame-Green, K. Zimmermann, U. Zimmermann, M. Gondran, F. L. Baccelli, G. Cohen, S. Gaubert, G. J. Olsder, J.P. Quadrat, and others) used idempotent semirings and matrices over these semirings for solving some applied problems in computer science and discrete mathematics, starting from the classical paper of S. C. Kleene [88]. The modern idempotent analysis (or idempotent calculus, or idempotent mathematics) was founded by V. P. Maslov and his collaborators in the 1980s in Moscow; see, e.g., [96, 119-124]. Some preliminary results are due to E. Hopf and G. Choquet, see [24,71].

Idempotent mathematics can be treated as a result of a dequantization of the traditional mathematics over numerical fields as the Planck constant $\hbar$ tends to zero taking imaginary values. This point of view was presented by G. L. Litvinov and V. P. Maslov [102-104], see also $[110,111]$. In other words, idempotent mathematics is an asymptotic version of the traditional mathematics over the fields of real and complex numbers.

The basic paradigm is expressed in terms of an idempotent correspondence principle. This principle is closely related to the well-known correspondence principle of N. Bohr in quantum theory. Actually, there exists a heuristic correspondence between important, interesting, and useful constructions and results of the traditional mathematics over fields and analogous constructions and results over idempotent semirings and semifields (i.e., semirings and semifields with idempotent addition).

A systematic and consistent application of the idempotent correspondence principle leads to a variety of results, often quite unexpected. As a result, in parallel with the traditional mathematics over fields, its "shadow," the idempotent mathematics, appears. This "shadow" stands approximately in the same relation to the traditional mathematics as does classical physics to quantum theory, see Fig. 1. In many 


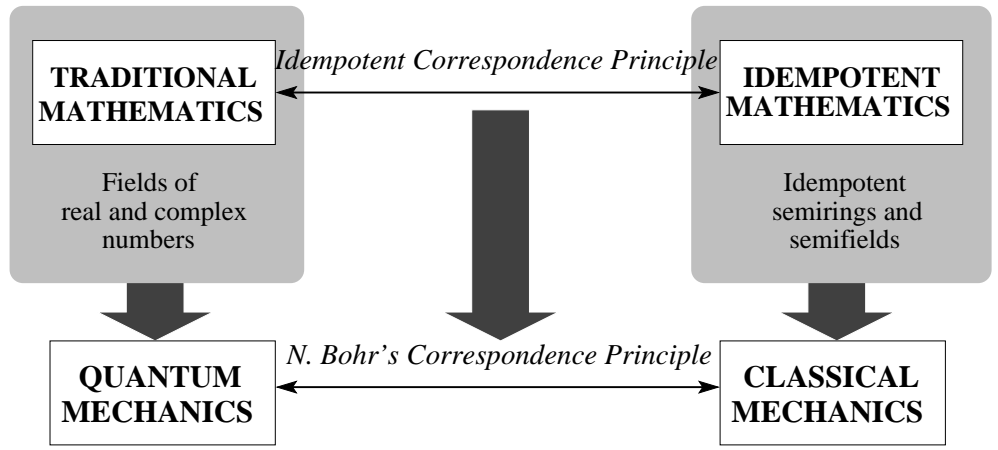

Figure 1. Relations between idempotent and traditional mathematics.

respects idempotent mathematics is simpler than the traditional one. However the transition from traditional concepts and results to their idempotent analogs is often nontrivial.

\section{SEMIRINGS, SEMIFIELDS, AND DEQUANTIZATION}

Consider a set $S$ equipped with two algebraic operations: addition $\oplus$ and multiplication $\odot$. It is a semiring if the following conditions are satisfied:

- the addition $\oplus$ and the multiplication $\odot$ are associative;

- the addition $\oplus$ is commutative;

- the multiplication $\odot$ is distributive with respect to the addition $\oplus$ :

$x \odot(y \oplus z)=(x \odot y) \oplus(x \odot z) \quad$ and $\quad(x \oplus y) \odot z=(x \odot z) \oplus(y \odot z)$

for all $x, y, z \in S$.

A unity of a semiring $S$ is an element $\mathbf{1} \in S$ such that $\mathbf{1} \odot x=x \odot \mathbf{1}=x$ for all $x \in S$. A zero of a semiring $S$ is an element $\mathbf{0} \in S$ such that $\mathbf{0} \neq \mathbf{1}$ and $\mathbf{0} \oplus x=x, \mathbf{0} \odot x=x \odot \mathbf{0}=\mathbf{0}$ for all $x \in S$. A semiring $S$ is called an idempotent semiring if $x \oplus x=x$ for all $x \in S$. A semiring $S$ with neutral elements $\mathbf{0}$ and $\mathbf{1}$ is called a semifield if every nonzero element of $S$ is invertible. Note that dioïds in the sense of $[9,67,68]$, quantales in the sense of $[147,148]$, and inclines in the sense of [84] are examples of idempotent semirings.

Let $\mathbf{R}$ be the field of real numbers and $\mathbf{R}_{+}$the semiring of all nonnegative real numbers (with respect to the usual addition and multiplication). The change of variables $x \mapsto u=h \ln x, h>0$, defines a map $\Phi_{h}: \mathbf{R}_{+} \rightarrow S=\mathbf{R} \cup\{-\infty\}$. Let the addition and multiplication operations be mapped from $\mathbf{R}$ to $S$ by $\Phi_{h}$, i.e., let $u \oplus_{h} v=h \ln (\exp (u / h)+$ 


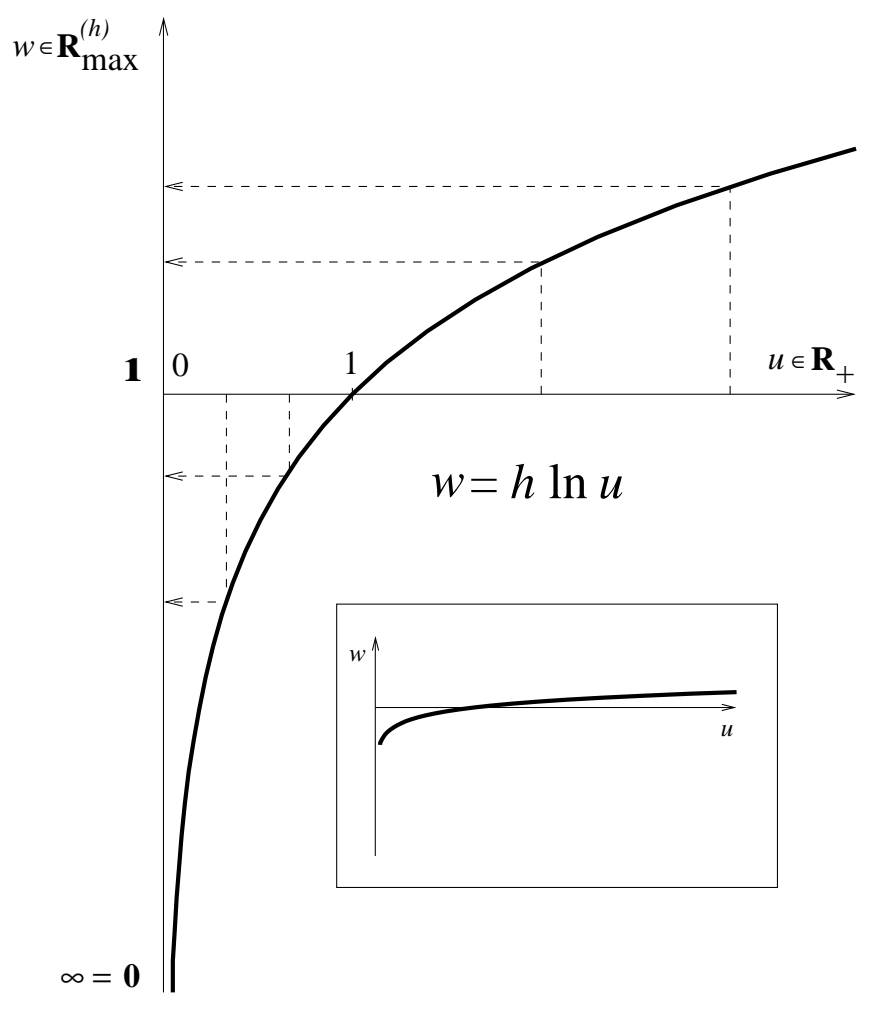

Figure 2. Deformation of $\mathbf{R}_{+}$to $\mathbf{R}^{(h)}$. Inset: same for a small value of $h$.

$\exp (v / h)), u \odot v=u+v, \mathbf{0}=-\infty=\Phi_{h}(0), \mathbf{1}=0=\Phi_{h}(1)$, so $S$ has a structure of a semiring $\mathbf{R}^{(h)}$ isomorphic to $\mathbf{R}_{+}$; see Fig. 2 .

It can easily be checked that $u \oplus_{h} v \rightarrow \max \{u, v\}$ as $h \rightarrow 0$ and that $S$ forms a semiring with respect to addition $u \oplus v=\max \{u, v\}$ and multiplication $u \odot v=u+v$ with zero $\mathbf{0}=-\infty$ and unit $\mathbf{1}=0$. Denote this semiring by $\mathbf{R}_{\max }$; it is idempotent, i.e., $u \oplus u=u$ for all its elements. The semiring $\mathbf{R}_{\max }$ is actually a semifield. The analogy with quantization is obvious; the parameter $h$ plays the rôle of the Planck constant, so $\mathbf{R}_{+}$can be viewed as a "quantum object" and $\mathbf{R}_{\max }$ as the result of its "dequantization." A similar procedure (for $h<0$ ) gives the semiring $\mathbf{R}_{\text {min }}=\mathbf{R} \cup\{+\infty\}$ with the operations $\oplus=\min , \odot=+$; in this case $\mathbf{0}=+\infty, \mathbf{1}=0$. The semirings $\mathbf{R}_{\max }$ and $\mathbf{R}_{\min }$ are isomorphic. This passage to $\mathbf{R}_{\max }$ or $\mathbf{R}_{\text {min }}$ is called the Maslov dequantization. It is clear that the corresponding passage from $\mathbf{C}$ or $\mathbf{R}$ to $\mathbf{R}_{\max }$ is generated by the Maslov dequantization and the map $x \mapsto|x|$. By misuse of language, we shall also call this passage the Maslov dequantization. Connections with physics and the meaning of imaginary values of the 
Planck constant are discussed below (Section 6) and in $[110,111]$. The idempotent semiring $\mathbf{R} \cup\{-\infty\} \cup\{+\infty\}$ with the operations $\oplus=\max$, $\odot=$ min can be obtained as a result of a "second dequantization" of $\mathbf{C}$, $\mathbf{R}$ or $\mathbf{R}_{+}$. Dozens of interesting examples of nonisomorphic idempotent semirings may be cited as well as a number of standard methods of deriving new semirings from these (see, e.g., [26,64,66-70,104,110]). The so-called idempotent dequantization is a generalization of the Maslov dequantization; this is a passage from fields to idempotent semifields and semirings in mathematical constructions and results.

The Maslov dequantization is related to the well-known logarithmic transformation that was used, e.g., in the classical papers of E. Schrödinger [153] and E. Hopf [71]. The term 'Cole-Hopf transformation' is also used. The subsequent progress of E. Hopf's ideas has culminated in the well-known vanishing viscosity method and the method of viscosity solutions, see, e.g., [10, 19, 54, 122, 125, 149, 167].

\section{Terminology: Tropical SEMirings And tropical MATHEMATICS}

The term 'tropical semirings' was introduced in computer science to denote discrete versions of the max-plus algebra $\mathbf{R}_{\max }$ or min-plus algebra $\mathbf{R}_{\text {min }}$ and their subalgebras; (discrete) semirings of this type were called tropical semirings by Dominic Perrin in honour of Imre Simon (who is a Brasilian mathematician and computer scientist) because of his pioneering activity in this area, see [140].

More recently the situation and terminology have changed. For the most part of modern authors 'tropical' means 'over $\mathbf{R}_{\max }$ (or $\mathbf{R}_{\min }$ )'

and tropical semirings are idempotent semifields $\mathbf{R}_{\max }$ and $\mathbf{R}_{\min }$. The terms 'max-plus' and 'min-plus' are often used in the same sense. Now the term 'tropical mathematics' usually means 'mathematics over $\mathbf{R}_{\max }$ or $\mathbf{R}_{\text {min }}$ ', see, e.g., [7, 11, 12, 14, 39, 41, 55, 56, 59, 60, 72-78, 85, 86, 126$129,131,132,134,135,146,155,156,161-165,169-171]$. Terms 'tropicalization' and 'tropification' (see, e.g., [87]) mean exactly dequantization and quantization in our sense. In any case, tropical mathematics is a natural and very important part of idempotent mathematics. Some well known constructions and results of idempotent mathematics were repeated in the framework of tropical mathematics (and especially tropical linear algebra).

Note that in papers [174-176] N. N. Vorobjev developed a version of idempotent linear algebra (with important applications, e.g., to mathematical economics) and predicted many aspects of the future extended 
theory. He used the terms 'extremal algebras' and 'extremal mathematics' for idempotent semirings and idempotent mathematics. Unfortunately, N. N. Vorobjev's papers and ideas were forgotten for a long period, so his remarkable terminology is not in use any more.

\section{IDEmpotent ALGEBRA AND LineAR ALGEBRA}

The first known paper on idempotent linear algebra is due to S. Kleene [88]. Systems of linear algebraic equations over an exotic idempotent semiring of all formal languages over a fixed finite alphabet are examined in this work; however, S. Kleene's ideas are very general and universal. Since then, dozens of authors investigated matrices with coefficients belonging to an idempotent semiring and the corresponding applications to discrete mathematics, computer science, computer languages, linguistic problems, finite automata, optimization problems on graphs, discrete event systems and Petry nets, stochastic systems, computer performance evaluation, computational problems etc. This subject is very well known and well presented in the corresponding literature, see, e.g., $[9,17,18,21,25,28-30,44,62,64-70,84,93,96,102,104-$ $107,114,115,122,174-177,187]$.

Idempotent abstract algebra is not so well developed yet (on the other hand, from a formal point of view, the lattice theory and the theory of ordered groups and semigroups are parts of idempotent algebra). However, there are many interesting results and applications presented, e.g., in [29-31, 81, 147, 148, 154].

In particular, an idempotent version of the main theorem of algebra holds $[31,154]$ for radicable idempotent semifields (a semiring $A$ is radicable if the equation $x^{n}=a$ has a solution $x \in A$ for any $a \in A$ and any positive integer $n$ ). It is proved that $\mathbf{R}_{\max }$ and other radicable semifields are algebraically closed in a natural sense [154].

Over the last years, tropical algebraic geometry attracted a lot of attention. This subject will be briefly discussed below (Section 11).

\section{IDEMPOTENT ANALYSIS}

Idempotent analysis was initially constructed by V. P. Maslov and his collaborators and then developed by many authors. The subject is presented in the book of V. N. Kolokoltsov and V. P. Maslov [96] (a version of this book in Russian [122] was published in 1994).

Let $S$ be an arbitrary semiring with idempotent addition $\oplus$ (which is always assumed to be commutative), multiplication $\odot$, zero $\mathbf{0}$, and unit 1 . The set $S$ is supplied with the standard partial order $\preceq$ : by definition, $a \preceq b$ if and only if $a \oplus b=b$. Thus all elements of $S$ are 
nonnegative: $\mathbf{0} \preceq a$ for all $a \in S$. Due to the existence of this order, idempotent analysis is closely related to the lattice theory, theory of vector lattices, and theory of ordered spaces. Moreover, this partial order allows to model a number of basic "topological" concepts and results of idempotent analysis at the purely algebraic level; this line of reasoning was examined systematically in [108-112] and [26].

Calculus deals mainly with functions whose values are numbers. The idempotent analog of a numerical function is a map $X \rightarrow S$, where $X$ is an arbitrary set and $S$ is an idempotent semiring. Functions with values in $S$ can be added, multiplied by each other, and multiplied by elements of $S$ pointwise.

The idempotent analog of a linear functional space is a set of $S$ valued functions that is closed under addition of functions and multiplication of functions by elements of $S$, or an $S$-semimodule. Consider, e.g., the $S$-semimodule $B(X, S)$ of all functions $X \rightarrow S$ that are bounded in the sense of the standard order on $S$.

If $S=\mathbf{R}_{\text {max }}$, then the idempotent analog of integration is defined by the formula

$$
I(\varphi)=\int_{X}^{\oplus} \varphi(x) d x=\sup _{x \in X} \varphi(x)
$$

where $\varphi \in B(X, S)$. Indeed, a Riemann sum of the form $\sum_{i} \varphi\left(x_{i}\right) \cdot \sigma_{i}$ corresponds to the expression $\bigoplus_{i} \varphi\left(x_{i}\right) \odot \sigma_{i}=\max _{i}\left\{\varphi\left(x_{i}\right)+\sigma_{i}\right\}$, which tends to the right-hand side of (1) as $\sigma_{i} \rightarrow 0$. Of course, this is a purely heuristic argument.

Formula (1) defines the idempotent (or Maslov) integral not only for functions taking values in $\mathbf{R}_{\max }$, but also in the general case when any of bounded (from above) subsets of $S$ has the least upper bound.

An idempotent (or Maslov) measure on $X$ is defined by $m_{\psi}(Y)=$ $\sup \psi(x)$, where $\psi \in B(X, S), Y \subseteq X$. The integral with respect to $x \in Y$

this measure is defined by

$$
I_{\psi}(\varphi)=\int_{X}^{\oplus} \varphi(x) d m_{\psi}=\int_{X}^{\oplus} \varphi(x) \odot \psi(x) d x=\sup _{x \in X}(\varphi(x) \odot \psi(x)) .
$$

Obviously, if $S=\mathbf{R}_{\text {min }}$, then the standard order $\preceq$ is opposite to the conventional order $\leq$, so in this case equation (2) assumes the form

$$
\int_{X}^{\oplus} \varphi(x) d m_{\psi}=\int_{X}^{\oplus} \varphi(x) \odot \psi(x) d x=\inf _{x \in X}(\varphi(x) \odot \psi(x)),
$$

where inf is understood in the sense of the conventional order $\leq$. 
Note that the so-called pseudo-analysis (see, e.g., the survey paper of E. Pap [138]) is related to a special part of idempotent analysis; however, this pseudo-analysis is not a proper part of idempotent mathematics in the general case. Some generalizations of Maslov measures are discussed in $[89,137]$.

\section{THE SUPERPOSITION PRINCIPLE AND LINEAR PROBLEMS}

Basic equations of quantum theory are linear; this is the superposition principle in quantum mechanics. The Hamilton-Jacobi equation, the basic equation of classical mechanics, is nonlinear in the conventional sense. However, it is linear over the semirings $\mathbf{R}_{\max }$ and $\mathbf{R}_{\min }$. Similarly, different versions of the Bellman equation, the basic equation of optimization theory, are linear over suitable idempotent semirings; this is V. P. Maslov's idempotent superposition principle, see [119-123]. For instance, the finite-dimensional stationary Bellman equation can be written in the form $X=H \odot X \oplus F$, where $X, H, F$ are matrices with coefficients in an idempotent semiring $S$ and the unknown matrix $X$ is determined by $H$ and $F$ [20]. In particular, standard problems of dynamic programming and the well-known shortest path problem correspond to the cases $S=\mathbf{R}_{\max }$ and $S=\mathbf{R}_{\text {min }}$, respectively. In [20], it was known that principal optimization algorithms for finite graphs correspond to standard methods for solving systems of linear equations of this type (over semirings). Specifically, Bellman's shortest path algorithm corresponds to a version of Jacobi's algorithm, Ford's algorithm corresponds to the Gauss-Seidel iterative scheme, etc.

The linearity of the Hamilton-Jacobi equation over $\mathbf{R}_{\min }$ and $\mathbf{R}_{\max }$, which is the result of the Maslov dequantization of the Schrödinger equation, is closely related to the (conventional) linearity of the Schrödinger equation and can be deduced from this linearity. Thus, it is possible to borrow standard ideas and methods of linear analysis and apply them to a new area.

Consider a classical dynamical system specified by the Hamiltonian

$$
H=H(p, x)=\sum_{i=1}^{N} \frac{p_{i}^{2}}{2 m_{i}}+V(x),
$$

where $x=\left(x_{1}, \ldots, x_{N}\right)$ are generalized coordinates, $p=\left(p_{1}, \ldots, p_{N}\right)$ are generalized momenta, $m_{i}$ are masses, and $V(x)$ is the potential. In this case the Lagrangian $L(x, \dot{x}, t)$ has the form

$$
L(x, \dot{x}, t)=\sum_{i=1}^{N} m_{i} \frac{\dot{x}_{i}^{2}}{2}-V(x),
$$


where $\dot{x}=\left(\dot{x}_{1}, \ldots, \dot{x}_{N}\right), \dot{x}_{i}=d x_{i} / d t$. The value function $S(x, t)$ of the action functional has the form

$$
S=\int_{t_{0}}^{t} L(x(t), \dot{x}(t), t) d t
$$

where the integration is performed along the factual trajectory of the system. The classical equations of motion are derived as the stationarity conditions for the action functional (the Hamilton principle, or the least action principle).

For fixed values of $t$ and $t_{0}$ and arbitrary trajectories $x(t)$, the action functional $S=S(x(t))$ can be considered as a function taking the set of curves (trajectories) to the set of real numbers which can be treated as elements of $\mathbf{R}_{\text {min }}$. In this case the minimum of the action functional can be viewed as the Maslov integral of this function over the set of trajectories or an idempotent analog of the Euclidean version of the Feynman path integral. The minimum of the action functional corresponds to the maximum of $e^{-S}$, i.e. idempotent integral $\int_{\{\text {paths }\}}^{\oplus} e^{-S(x(t))} D\{x(t)\}$ with respect to the max-plus algebra $\mathbf{R}_{\max }$. Thus the least action principle can be considered as an idempotent version of the well-known Feynman approach to quantum mechanics. The representation of a solution to the Schrödinger equation in terms of the Feynman integral corresponds to the Lax-Oleĭnik solution formula for the Hamilton-Jacobi equation.

Since $\partial S / \partial x_{i}=p_{i}, \partial S / \partial t=-H(p, x)$, the following HamiltonJacobi equation holds:

$$
\frac{\partial S}{\partial t}+H\left(\frac{\partial S}{\partial x_{i}}, x_{i}\right)=0
$$

Quantization (see, e.g., [48]) leads to the Schrödinger equation

$$
-\frac{\hbar}{i} \frac{\partial \psi}{\partial t}=\widehat{H} \psi=H\left(\hat{p}_{i}, \hat{x}_{i}\right) \psi
$$

where $\psi=\psi(x, t)$ is the wave function, i.e., a time-dependent element of the Hilbert space $L^{2}\left(\mathbf{R}^{N}\right)$, and $\widehat{H}$ is the energy operator obtained by substitution of the momentum operators $\widehat{p}_{i}=\frac{\hbar}{i} \frac{\partial}{\partial x_{i}}$ and the coordinate operators $\widehat{x}_{i}: \psi \mapsto x_{i} \psi$ for the variables $p_{i}$ and $x_{i}$ in the Hamiltonian function, respectively. This equation is linear in the conventional sense (the quantum superposition principle). The standard procedure of limit transition from the Schrödinger equation to the HamiltonJacobi equation is to use the following ansatz for the wave function: $\psi(x, t)=a(x, t) e^{i S(x, t) / \hbar}$, and to keep only the leading order as $\hbar \rightarrow 0$ (the 'semiclassical' limit). 
Instead of doing this, we switch to imaginary values of the Planck constant $\hbar$ by the substitution $h=i \hbar$, assuming $h>0$. Thus the Schrödinger equation (4) turns to the following generalized heat equation:

$$
h \frac{\partial u}{\partial t}=H\left(-h \frac{\partial}{\partial x_{i}}, \hat{x}_{i}\right) u
$$

where the real-valued function $u$ corresponds to the wave function $\psi$ (or, rather, to $|\psi|$ ). A similar idea (the switch to imaginary time) is used in the Euclidean quantum field theory (see, e.g., [130]); let us remember that time and energy are dual quantities.

Linearity of equation (4) implies linearity of equation (5). Thus if $u_{1}$ and $u_{2}$ are solutions of (5), then so is their linear combination

$$
u=\lambda_{1} u_{1}+\lambda_{2} u_{2} \text {. }
$$

Let $S=h \ln u$ or $u=e^{S / h}$ as in Section 2 above. It can easily be checked that equation (5) thus turns to

$$
\frac{\partial S}{\partial t}=V(x)+\sum_{i=1}^{N} \frac{1}{2 m_{i}}\left(\frac{\partial S}{\partial x_{i}}\right)^{2}+h \sum_{i=1}^{n} \frac{1}{2 m_{i}} \frac{\partial^{2} S}{\partial x_{i}^{2}} .
$$

Thus we have a passage from (4) to (7) by means of the change of variables $\psi=e^{S / h}$. Note that $|\psi|=e^{\operatorname{Re} S / h}$, where $\operatorname{Re} S$ is the real part of $S$. Now let us consider $S$ as a real variable. The equation (7) is nonlinear in the conventional sense. However, if $S_{1}$ and $S_{2}$ are its solutions, then so is the function

$$
S=\lambda_{1} \odot S_{1} \oplus_{h} \lambda_{2} \odot S_{2}
$$

obtained from (6) by means of our substitution $S=h \ln u$. Here the generalized multiplication $\odot$ coincides with the ordinary addition and the generalized addition $\oplus_{h}$ is the image of the conventional addition under the above change of variables. As $h \rightarrow 0$, we obtain the operations of the idempotent semiring $\mathbf{R}_{\max }$, i.e., $\oplus=\max$ and $\odot=+$, and equation (7) turns to the Hamilton-Jacobi equation (3), since the third term in the right-hand side of equation (7) vanishes.

Thus it is natural to consider the limit function $S=\lambda_{1} \odot S_{1} \oplus \lambda_{2} \odot S_{2}$ as a solution of the Hamilton-Jacobi equation and to expect that this equation can be treated as linear over $\mathbf{R}_{\max }$. This argument (clearly, a heuristic one) can be extended to equations of a more general form. For a rigorous treatment of (semiring) linearity for these equations see $[52,96,122,123]$ and also [120]. Notice that if $h$ is changed to $-h$, then we have that the resulting Hamilton-Jacobi equation is linear over $\mathbf{R}_{\text {min }}$. 
The idempotent superposition principle indicates that there exist important nonlinear (in the traditional sense) problems that are linear over idempotent semirings. The liner idempotent functional analysis (see below) is a natural tool for investigation of those nonlinear infinitedimensional problems that possess this property.

\section{Convolution And the Fourier-Legendre transform}

Let $G$ be a group. Then the space $\mathcal{B}\left(X, \mathbf{R}_{\max }\right)$ of all bounded functions $G \rightarrow \mathbf{R}_{\max }$ (see above) is an idempotent semiring with respect to the following analog $\circledast$ of the usual convolution:

$$
(\varphi(x) \circledast \psi)(g)=\int_{G}^{\oplus} \varphi(x) \odot \psi\left(x^{-1} \cdot g\right) d x=\sup _{x \in G}\left(\varphi(x)+\psi\left(x^{-1} \cdot g\right)\right) .
$$

Of course, it is possible to consider other "function spaces" (and other basic semirings instead of $\left.\mathbf{R}_{\max }\right)$. In [96,122] "group semirings" of this type are referred to as convolution semirings.

Let $G=\mathbf{R}^{n}$, where $\mathbf{R}^{n}$ is considered as a topological group with respect to the vector addition. The conventional Fourier-Laplace transform is defined as

$$
\varphi(x) \mapsto \tilde{\varphi}(\xi)=\int_{G} e^{i \xi \cdot x} \varphi(x) d x
$$

where $e^{i \xi \cdot x}$ is a character of the group $G$, i.e., a solution of the following functional equation:

$$
f(x+y)=f(x) f(y) .
$$

The idempotent analog of this equation is

$$
f(x+y)=f(x) \odot f(y)=f(x)+f(y),
$$

so "continuous idempotent characters" are linear functions of the form $x \mapsto \xi \cdot x=\xi_{1} x_{1}+\cdots+\xi_{n} x_{n}$. As a result, the transform in (8) assumes the form

$$
\varphi(x) \mapsto \tilde{\varphi}(\xi)=\int_{G}^{\oplus} \xi \cdot x \odot \varphi(x) d x=\sup _{x \in G}(\xi \cdot x+\varphi(x)) .
$$

The transform in (9) is nothing but the Legendre transform (up to some notation) [121]; transforms of this kind establish the correspondence between the Lagrangian and the Hamiltonian formulations of classical mechanics. The Legendre transform generates an idempotent version of harmonic analysis for the space of convex functions, see, e.g., [118].

Of course, this construction can be generalized to different classes of groups and semirings. Transformations of this type convert the generalized convolution $\circledast$ to the pointwise (generalized) multiplication and possess analogs of some important properties of the usual Fourier 
transform. For the case of semirings of Pareto sets, the corresponding version of the Fourier transform reduces the multicriterial optimization problem to a family of singlecriterial problems [152].

The examples discussed in this sections can be treated as fragments of an idempotent version of the representation theory, see, e.g., [111]. In particular, "idempotent" representations of groups can be examined as representations of the corresponding convolution semirings (i.e. idempotent group semirings) in semimodules.

\section{Correspondence to Stochastics And A DuAlity Between PROBABILITY AND OPTIMIZATION}

Maslov measures are nonnegative (in the sense of the standard order) just as probability measures. The analogy between idempotent and probability measures leads to important relations between optimization theory and probability theory. By the present time idempotent analogues of many objects of stochastic calculus have been constructed and investigated, such as max-plus martingales, max-plus stochastic differential equations, and others. These results allow, for example, to transfer powerful stochastic methods to the optimization theory. This was noticed and examined by many authors (G. Salut, P. Del Moral, M. Akian, J.-P. Quadrat, V. P. Maslov, V. N. Kolokoltsov, P. Bernhard, W. A. Fleming, W. M. McEneaney, A. A. Puhalskii and others), see the survey paper of W. A. Fleming and W. M. McEneaney [53] and $[1,6,13,28,35-38,50-52,69,122,141,143,144]$. For relations and applications to large deviations see $[1,35-38,142]$ and especially the book of A. A. Puhalskii [141].

\section{IDEMPOTENT FUNCTIONAL ANALYSIS}

Many other idempotent analogs may be given, in particular, for basic constructions and theorems of functional analysis. Idempotent functional analysis is an abstract version of idempotent analysis. For the sake of simplicity take $S=\mathbf{R}_{\max }$ and let $X$ be an arbitrary set. The idempotent integration can be defined by the formula (1), see above. The functional $I(\varphi)$ is linear over $S$ and its values correspond to limiting values of the corresponding analogs of Lebesgue (or Riemann) sums. An idempotent scalar product of functions $\varphi$ and $\psi$ is defined by the formula

$$
\langle\varphi, \psi\rangle=\int_{X}^{\oplus} \varphi(x) \odot \psi(x) d x=\sup _{x \in X}(\varphi(x) \odot \psi(x)) .
$$


So it is natural to construct idempotent analogs of integral operators in the form

$$
\varphi(y) \mapsto(K \varphi)(x)=\int_{Y}^{\oplus} K(x, y) \odot \varphi(y) d y=\sup _{y \in Y}\{K(x, y)+\varphi(y)\}
$$

where $\varphi(y)$ is an element of a space of functions defined on a set $Y$, and $K(x, y)$ is an $S$-valued function on $X \times Y$. Of course, expressions of this type are standard in optimization problems.

Recall that the definitions and constructions described above can be extended to the case of idempotent semirings which are conditionally complete in the sense of the standard order. Using the Maslov integration, one can construct various function spaces as well as idempotent versions of the theory of generalized functions (distributions). For some concrete idempotent function spaces it was proved that every 'good' linear operator (in the idempotent sense) can be presented in the form (10); this is an idempotent version of the kernel theorem of L. Schwartz; results of this type were proved by V. N. Kolokoltsov, P. S. Dudnikov and S. N. Samborskiur, I. Singer, M. A. Shubin and others, see, e.g., [44,96,122,123,158]. So every 'good' linear functional can be presented in the form $\varphi \mapsto\langle\varphi, \psi\rangle$, where $\langle$,$\rangle is an idempotent scalar$ product.

In the framework of idempotent functional analysis results of this type can be proved in a very general situation. In [108-112] an algebraic version of the idempotent functional analysis is developed; this means that basic (topological) notions and results are simulated in purely algebraic terms. The treatment covers the subject from basic concepts and results (e.g., idempotent analogs of the well-known theorems of Hahn-Banach, Riesz, and Riesz-Fisher) to idempotent analogs of A. Grothendieck's concepts and results on topological tensor products, nuclear spaces and operators. An abstract version of the kernel theorem is formulated. Note that the passage from the usual theory to idempotent functional analysis may be very nontrivial; for example, there are many non-isomorphic idempotent Hilbert spaces. Important results on idempotent functional analysis (duality and separation theorems) are recently published by G. Cohen, S. Gaubert, and J.P. Quadrat [26]; see also a finite dimensional version of the separation theorem in [183]. Idempotent functional analysis has received much attention in the last years, see, e.g., $[2-5,27,68,105,113,149,158,159,178]$ and works cited above. 


\section{The Dequantization transform And Generalization of THE NEWTON POLYTOPES}

In this section we briefly discuss results proved in the paper [113]. For functions defined on $\mathbf{C}^{n}$ almost everywhere (a.w.) it is possible to construct a dequantization transform $f \rightarrow \hat{f}$ generated by the Maslov dequantization. If $f$ is a polynomial, then the subdifferential $\partial \hat{f}$ of $\hat{f}$ at the origin coincides with the Newton polytope of $f$. For the semiring of polynomials with nonnegative coefficients, the dequantization transform is a homomorphism of this semiring to the idempotent semiring of convex polytopes with respect to the well-known Minkovski operations. These results can be generalized to a wide class of functions and convex sets.

10.1. The dequntization transform. Let $X$ be a topological space. For functions $f(x)$ defined on $X$ we shall say that a certain assertion is valid almost everywhere (a.e.) if it is valid for all elements $x$ of an open dense subset of $X$. Suppose $X$ is $\mathbf{C}^{n}$ or $\mathbf{R}^{n}$; denote by $\mathbf{R}_{+}^{n}$ the set $x=\left\{\left(x_{1}, \ldots, x_{n}\right) \in X \mid x_{i} \geq 0\right.$ for $\left.i=1,2, \ldots, n\right\}$. For $x=\left(x_{1}, \ldots, x_{n}\right) \in X$ we set $\exp (x)=\left(\exp \left(x_{1}\right), \ldots, \exp \left(x_{n}\right)\right)$; so if $x \in \mathbf{R}^{n}$, then $\exp (x) \in \mathbf{R}_{+}^{n}$.

Denote by $\mathcal{F}\left(\mathbf{C}^{n}\right)$ the set of all functions defined and continuous on an open dense subset $U \subset \mathbf{C}^{n}$ such that $U \supset \mathbf{R}_{+}^{n}$. In all the examples below we consider even more regular functions, which are holomorphic in $U$. It is clear that $\mathcal{F}\left(\mathbf{C}^{n}\right)$ is a ring (and an algebra over $\mathbf{C}$ ) with respect to the usual addition and multiplications of functions.

For $f \in \mathcal{F}\left(\mathbf{C}^{n}\right)$ let us define the function $\hat{f}_{h}$ by the following formula:

$$
\hat{f}_{h}(x)=h \log |f(\exp (x / h))|,
$$

where $h$ is a (small) real parameter and $x \in \mathbf{R}^{n}$. Set

$$
\hat{f}(x)=\lim _{h \rightarrow 0} \hat{f}_{h}(x),
$$

if the right-hand part of (12) exists almost everywhere. We shall say that the function $\hat{f}(x)$ is a dequantization of the function $f(x)$ and the map $f(x) \mapsto \hat{f}(x)$ is a dequantization transform. By construction, $\hat{f}_{h}(x)$ and $\hat{f}(x)$ can be treated as functions taking their values in $\mathbf{R}_{\max }$. Note that in fact $\hat{f}_{h}(x)$ and $\hat{f}(x)$ depend on the restriction of $f$ to $\mathbf{R}_{+}^{n}$ only; so in fact the dequantization transform is constructed for functions defined on $\mathbf{R}_{+}^{n}$ only. It is clear that the dequantization transform is generated by the Maslov dequantization and the map $x \mapsto|x|$. Of course, similar definitions can be given for functions defined on $\mathbf{R}^{n}$ and $\mathbf{R}_{+}^{n}$. 
Denote by $V$ the set $\mathbf{R}^{n}$ treated as a linear Euclidean space (with the scalar product $\left.(x, y)=x_{1} y_{1}+x_{2} y_{2}+\cdots+x_{n} y_{n}\right)$ and set $V_{+}=\mathbf{R}_{+}^{n}$. We shall say that a function $f \in \mathcal{F}\left(\mathbf{C}^{n}\right)$ is dequantizable whenever its dequantization $\hat{f}(x)$ exists (and is defined on an open dense subset of $V)$. By $\mathcal{D}\left(\mathbf{C}^{n}\right)$ denote the set of all dequantizable functions and by $\widehat{\mathcal{D}}(V)$ denote the set $\left\{\hat{f} \mid f \in \mathcal{D}\left(\mathbf{C}^{n}\right)\right\}$. Recall that functions from $\mathcal{D}\left(\mathbf{C}^{n}\right)$ (and $\widehat{\mathcal{D}}(V)$ ) are defined almost everywhere and $f=g$ means that $f(x)=g(x)$ a.e., i.e., for $x$ ranging over an open dense subset of $\mathbf{C}^{n}$ (resp., of $\left.V\right)$. Denote by $\mathcal{D}_{+}\left(\mathbf{C}^{n}\right)$ the set of all functions $f \in \mathcal{D}\left(\mathbf{C}^{n}\right)$ such that $f\left(x_{1}, \ldots, x_{n}\right) \geq 0$ if $x_{i} \geq 0$ for $i=1, \ldots, n$; so $f \in \mathcal{D}_{+}\left(\mathbf{C}^{n}\right)$ if the restriction of $f$ to $V_{+}=\mathbf{R}_{+}^{n}$ is a nonnegative function. By $\widehat{\mathcal{D}}_{+}(V)$ denote the image of $\mathcal{D}_{+}\left(\mathbf{C}^{n}\right)$ under the dequantization transform. We shall say that functions $f, g \in \mathcal{D}\left(\mathbf{C}^{n}\right)$ are in general position whenever $\hat{f}(x) \neq \widehat{g}(x)$ for $x$ running an open dense subset of $V$.

For functions $f, g \in \mathcal{D}\left(\mathbf{C}^{n}\right)$ and any nonzero constant $c$, the following equations are valid:

1) $\widehat{f g}=\hat{f}+\widehat{g}$

2) $|\hat{f}|=\hat{f} ; \widehat{c f}=f ; \widehat{c}=0$;

3) $(\widehat{f+g})(x)=\max \{\hat{f}(x), \widehat{g}(x)\}$ a.e. if $f$ and $g$ are nonnegative on $V_{+}$(i.e., $\left.f, g \in \mathcal{D}_{+}\left(\mathbf{C}^{n}\right)\right)$ or $f$ and $g$ are in general position.

Left-hand sides of these equations are well-defined automatically.

The set $\mathcal{D}_{+}\left(\mathbf{C}^{n}\right)$ has a natural structure of a semiring with respect to the usual addition and multiplication of functions taking their values in C. The set $\widehat{\mathcal{D}}_{+}(V)$ has a natural structure of an idempotent semiring with respect to the operations $(f \oplus g)(x)=\max \{f(x), g(x)\},(f \odot$ $g)(x)=f(x)+g(x)$; elements of $\widehat{\mathcal{D}}_{+}(V)$ can be naturally treated as functions taking their values in $\mathbf{R}_{\max }$. The dequantization transform generates a homomorphism from $\mathcal{D}_{+}\left(\mathbf{C}^{n}\right)$ to $\widehat{\mathcal{D}}_{+}(V)$.

10.2. Simple functions. For any nonzero number $a \in \mathbf{C}$ and any vector $d=\left(d_{1}, \ldots, d_{n}\right) \in V=\mathbf{R}^{n}$ we set $m_{a, d}(x)=a \prod_{i=1}^{n} x_{i}^{d_{i}}$; functions of this kind we shall call generalized monomials. Generalized monomials are defined a.e. on $\mathbf{C}^{n}$ and on $V_{+}$, but not on $V$ unless the numbers $d_{i}$ take integer or suitable rational values. We shall say that a function $f$ is a generalized polynomial whenever it is a finite sum of linearly independent generalized monomials. For instance, Laurent polynomials are examples of generalized polynomials.

As usual, for $x, y \in V$ we set $(x, y)=x_{1} y_{1}+\cdots+x_{n} y_{n}$. It is easy to prove that if $f$ is a generalized monomial $m_{a, d}(x)$, then $\hat{f}$ is a linear 
function $x \mapsto(d, x)$. If $f$ is a generalized polynomial, then $\hat{f}$ is a sublinear function.

Recall that a real function $p$ defined on $V=\mathbf{R}^{n}$ is sublinear if $p=\sup _{\alpha} p_{\alpha}$, where $\left\{p_{\alpha}\right\}$ is a collection of linear functions. Sublinear functions defined everywhere on $V=\mathbf{R}^{n}$ are convex; thus these functions are continuous. We discuss sublinear functions of this kind only. Suppose $p$ is a continuous function defined on $V$, then $p$ is sublinear whenever

1) $p(x+y) \leq p(x)+p(y)$ for all $x, y \in V$;

2) $p(c x)=c p(x)$ for all $x \in V, c \in \mathbf{R}_{+}$.

So if $p_{1}, p_{2}$ are sublinear functions, then $p_{1}+p_{2}$ is a sublinear function.

We shall say that a function $f \in \mathcal{F}\left(\mathbf{C}^{n}\right)$ is simple, if its dequantization $\hat{f}$ exists and a.e. coincides with a sublinear function; by misuse of language, we shall denote this (uniquely defined verywhere on $V$ ) sublinear function by the same symbol $\hat{f}$.

Recall that simple functions $f$ and $g$ are in general position if $\hat{f}(x) \neq$ $\widehat{g}(x)$ for all $x$ belonging to an open dense subset of $V$. In particular, generalized monomials are in general position whenever they are linearly independent.

Denote by $\operatorname{Sim}\left(\mathbf{C}^{n}\right)$ the set of all simple functions defined on $V$ and denote by $\operatorname{Sim}_{+}\left(\mathbf{C}^{n}\right)$ the set $\operatorname{Sim}\left(\mathbf{C}^{n}\right) \cap \mathcal{D}_{+}\left(\mathbf{C}^{n}\right)$. By $\operatorname{Sbl}(V)$ denote the set of all (continuous) sublinear functions defined on $V=\mathbf{R}^{n}$ and by $S_{b l}(V)$ denote the image $\widehat{\operatorname{Sim}_{+}}\left(\mathbf{C}^{n}\right)$ of $\operatorname{Sim}_{+}\left(\mathbf{C}^{n}\right)$ under the dequantization transform.

The set $\operatorname{Sim}_{+}\left(\mathbf{C}^{n}\right)$ is a subsemiring of $\mathcal{D}_{+}\left(\mathbf{C}^{n}\right)$ and $S b l_{+}(V)$ is an idempotent subsemiring of $\widehat{\mathcal{D}_{+}}(V)$. The dequantization transform generates an epimorphism of $\operatorname{Sim}_{+}\left(\mathbf{C}^{n}\right)$ onto $S b l_{+}(V)$. The set $S b l(V)$ is an idempotent semiring with respect to the operations $(f \oplus g)(x)=$ $\max \{f(x), g(x)\},(f \odot g)(x)=f(x)+g(x)$.

Of course, polynomials and generalized polynomials are simple functions.

We shall say that functions $f, g \in \mathcal{D}(V)$ are asymptotically equivalent whenever $\hat{f}=\widehat{g}$; any simple function $f$ is an asymptotic monomial whenever $\hat{f}$ is a linear function. A simple function $f$ will be called an asymptotic polynomial whenever $\hat{f}$ is a sum of a finite collection of nonequivalent asymptotic monomials. Every asymptotic polynomial is a simple function.

Example. Generalized polynomials, logarithmic functions of (generalized) polynomials, and products of polynomials and logarithmic functions are asymptotic polynomials. This follows from our definitions and formula (11). 
10.3. Subdifferentials of sublinear functions and Newton sets for simple functions. It is well known that all the convex compact subsets in $\mathbf{R}^{n}$ form an idempotent semiring $\mathcal{S}$ with respect to the Minkowski operations: for $A, B \in \mathcal{S}$ the sum $A \oplus B$ is the convex hull of the union $A \cup B$; the product $A \odot B$ is defined in the following way: $A \odot B=\{x \mid x=a+b$, where $a \in A, b \in B\}$. In fact $\mathcal{S}$ is an idempotent linear space over $\mathbf{R}_{\max }$ (see, e.g., [110]). Of course, the Newton polytopes in $V$ form a subsemiring $\mathcal{N}$ in $\mathcal{S}$.

We shall use some elementary results from convex analysis. These results can be found, e.g., in [118].

For any function $p \in \operatorname{Sbl}(V)$ we set

$$
\partial p=\{v \in V \mid(v, x) \leq p(x) \forall x \in V\} .
$$

It is well known from convex analysis that for any sublinear function $p$ the set $\partial p$ is exactly the subdifferential of $p$ at the origin. The following proposition is also known in convex analysis.

Proposition 1. Suppose $p_{1}, p_{2} \in \operatorname{Sbl}(V)$, then

$$
\begin{gathered}
\partial\left(p_{1}+p_{2}\right)=\partial p_{1} \odot \partial p_{2}= \\
\left\{v \in V \mid v=v_{1}+v_{2}, \text { where } v_{1} \in \partial p_{1}, v_{2} \in \partial p_{2}\right\} ; \\
\partial\left(\max \left\{p_{1}(x), p_{2}(x)\right\}\right)=\partial p_{1} \oplus \partial p_{2} .
\end{gathered}
$$

Suppose $p \in \operatorname{Sbl}(V)$. Then $\partial p$ is a nonempty convex compact subset of $V$.

Corollary 1. The map $p \mapsto \partial p$ is a homomorphism of the idempotent semiring $\operatorname{Sbl}(V)$ to the idempotent semiring $\mathcal{S}$ of all convex compact subsets of $V$.

For any simple function $f \in \operatorname{Sim}\left(\mathbf{C}^{n}\right)$ let us denote by $N(f)$ the set $\partial(\hat{f})$. We shall call $N(f)$ the Newton set of the function $f$. It follows from this proposition that for any simple function $f$, its Newton set $N(f)$ is a nonempty convex compact subset of $V$.

Theorem. Suppose that $f$ and $g$ are simple functions. Then

1) $N(f g)=N(f) \odot N(g)=\left\{v \in V \mid v=v_{1}+v_{2}\right.$ with $v_{1} \in$ $\left.N(f), v_{2} \in N(g)\right\}$

2) $N(f+g)=N(f) \oplus N(g)$, if $f_{1}$ and $f_{2}$ are in general position or $f_{1}, f_{2} \in \operatorname{Sim}_{+}\left(\mathbf{C}^{n}\right)$ (recall that $N(f) \oplus N(g)$ is the convex hull of $N(f) \cup N(g)$ ).

Corollary 2. The map $f \mapsto N(f)$ generates a homomorphism from $\mathrm{Sim}_{+}\left(\mathbf{C}^{n}\right)$ to $\mathcal{S}$. 
Proposition 2. Let $f=m_{a, d}(x)=a \prod_{i=1}^{n} x_{i}^{d_{i}}$ be a generalized monomial; here $d=\left(d_{1}, \ldots, d_{n}\right) \in V=\mathbf{R}^{n}$ and $a$ is a nonzero complex number. Then $N(f)=\{d\}$.

Corollary 3. Let $f=\sum_{d \in D} m_{a_{d}, d}$ be a generalized polynomial. Then $N(f)$ is the polytope $\oplus_{d \in D}\{d\}$, i.e. the convex hull of the finite set $D$.

This statement follows from Theorem and Proposition 2. Thus in this case $N(f)$ is the well-known classical Newton polytope of the polynomial $f$.

Now the following corollary is obvious.

Corollary 4. Let $f$ be a generalized or asymptotic polynomial. Then its Newton set $N(f)$ is a convex polytope.

Example. Consider the one dimensional case, i.e., $V=\mathbf{R}$ and suppose $f_{1}=a_{n} x^{n}+a_{n-1} x^{n-1}+\cdots+a_{0}$ and $f_{2}=b_{m} x^{m}+b_{m-1} x^{m-1}+$ $\cdots+b_{0}$, where $a_{n} \neq 0, b_{m} \neq 0, a_{0} \neq 0, b_{0} \neq 0$. Then $N\left(f_{1}\right)$ is the segment $[0, n]$ and $N\left(f_{2}\right)$ is the segment $[0, m]$. So the map $f \mapsto N(f)$ corresponds to the map $f \mapsto \operatorname{deg}(f)$, where $\operatorname{deg}(f)$ is a degree of the polynomial $f$. In this case Theorem means that $\operatorname{deg}(f g)=\operatorname{deg} f+\operatorname{deg} g$ and $\operatorname{deg}(f+g)=\max \{\operatorname{deg} f, \operatorname{deg} g\}=\max \{n, m\}$ if $a_{i} \geq 0, b_{i} \geq 0$ or $f$ and $g$ are in general position.

\section{Dequantization of GeOmetry}

An idempotent version of real algebraic geometry was discovered in the report of O. Viro for the Barcelona Congress [172]. Starting from the idempotent correspondence principle O. Viro constructed a piecewise-linear geometry of polyhedra of a special kind in finite dimensional Euclidean spaces as a result of the Maslov dequantization of real algebraic geometry. He indicated important applications in real algebraic geometry (e.g., in the framework of Hilbert's 16th problem for constructing real algebraic varieties with prescribed properties and parameters) and relations to complex algebraic geometry and amoebas in the sense of I. M. Gelfand, M. M. Kapranov, and A. V. Zelevinsky (see their book [61] and [173]). Then complex algebraic geometry was dequantized by G. Mikhalkin and the result turned out to be the same; this new 'idempotent' (or asymptotic) geometry is now often called the tropical algebraic geometry, see, e.g., [47,72, 126-129, 146, 155, 164,166].

There is a natural relation between the Maslov dequantization and amoebas. Suppose $\left(\mathbf{C}^{*}\right)^{n}$ is a complex torus, where $\mathbf{C}^{*}=\mathbf{C} \backslash\{0\}$ is the group of nonzero complex numbers under multiplication. For $z=$ $\left(z_{1}, \ldots, z_{n}\right) \in\left(\mathbf{C}^{*}\right)^{n}$ and a positive real number $h$ denote by $\log _{h}(z)=$ 


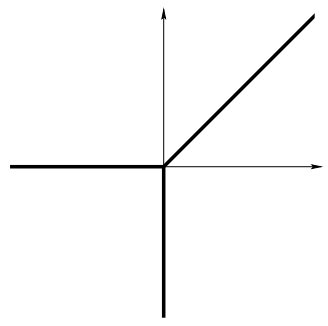

(a)

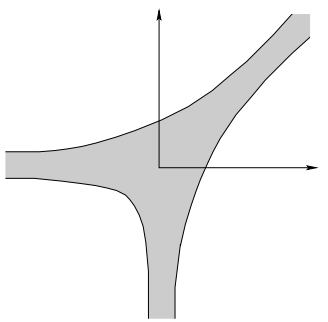

(b)

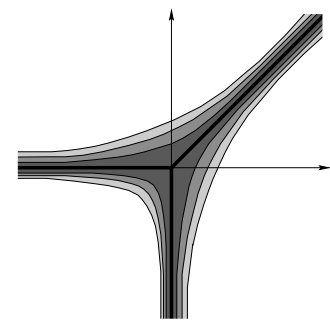

(c)

Figure 3. A tropical line and amoebas.

$h \log (|z|)$ the element

$$
\left(h \log \left|z_{1}\right|, h \log \left|z_{2}\right|, \ldots, h \log \left|z_{n}\right|\right) \in \mathbf{R}^{n} .
$$

Suppose $V \subset\left(\mathbf{C}^{*}\right)^{n}$ is a complex algebraic variety; denote by $\mathcal{A}_{h}(V)$ the set $\log _{h}(V)$. If $h=1$, then the set $\mathcal{A}(V)=\mathcal{A}_{1}(V)$ is called the amoeba of $V$ in the sense of [61], see also [7,126,128,129,139,155,161,173]; the amoeba $\mathcal{A}(V)$ is a closed subset of $\mathbf{R}^{n}$ with a non-empty complement. Note that this construction depends on our coordinate system.

For the sake of simplicity suppose $V$ is a hypersurface in $\left(\mathbf{C}^{*}\right)^{n}$ defined by a polynomial $f$; then there is a deformation $h \mapsto f_{h}$ of this polynomial generated by the Maslov dequantization and $f_{h}=f$ for $h=1$. Let $V_{h} \subset\left(\mathbf{C}^{*}\right)^{n}$ be the zero set of $f_{h}$ and set $\mathcal{A}_{h}\left(V_{h}\right)=$ $\log _{h}\left(V_{h}\right)$. Then there exists a tropical variety $\operatorname{Tro}(V)$ such that the subsets $\mathcal{A}_{h}\left(V_{h}\right) \subset \mathbf{R}^{n}$ tend to Tro $(V)$ in the Hausdorff metric as $h \rightarrow 0$, see $[126,151]$. The tropical variety $\operatorname{Tro}(V)$ is a result of a deformation of the amoeba $\mathcal{A}(V)$ and the Maslov dequantization of the variety $V$. The set $\operatorname{Tro}(V)$ is called the skeleton of $\mathcal{A}(V)$.

Example [126]. For the line $V=\left\{(x, y) \in\left(\mathbf{C}^{*}\right)^{2} \mid x+y+1=0\right\}$ the piecewise-linear graph $\operatorname{Tro}(V)$ is a tropical line, see Fig. 111(a). The amoeba $\mathcal{A}(V)$ is represented in Fig. 11(b), while Fig. 11(c) demonstrates the corresponding deformation of the amoeba.

In the important paper [80] (see also $[47,126,128,146])$ tropical varieties appeared as amoebas over non-Archimedean fields. In 2000 M. Kontsevich noted that it is possible to use non-Arhimedean amoebas in enumerative geometry, see [126, section 2.4, remark 4]. In fact methods of tropical geometry lead to remarkable applications to the algebraic enumerative geometry, Gromov-Witten and Welschinger invariants, see $[59,72-75,126-129,155,156]$. In particular, G. Mikhalkin presented and proved in $[127,129]$ a formula enumerating curves of arbitrary genus in toric surfaces. See also the papers $[60,72,73,131,155]$. 
Last time many other papers on tropical algebraic geometry and its applications to the conventional (e.g., complex) algebraic geometry and other areas appeared, see, e.g., [7, 55, 56,76, 131, 134, 135, 168, 169, 171]. The thing is that some difficult traditional problems can be reduced to their tropical versions which are hopefully not so difficult.

Note that tropical geometry is closely related to the well-known program of M. Kontsevich and Y. Soibelman, see, e.g., [98, 99].

There is an introductory paper [146] (see also [166]) on tropical algebraic geometry. However, on the whole, only first steps in idempotent/tropical geometry have been made and the problem of systematic construction of idempotent versions of algebraic and analytic geometries is still open.

\section{THE CORRESPONDENCE PRINCIPLE FOR ALGORITHMS AND THEIR COMPUTER IMPLEMENTATIONS}

There are many important applied algorithms of idempotent mathematics, see, e.g., [9, 18, 21,30,31, 49, 52, 53, 67-69, 72, 84, 87, 93, 96, 102 , $104,106,107,114-116,127,129,146,150,166,174-176,179,186,187]$.

The idempotent correspondence principle is valid for algorithms as well as for their software and hardware implementations [102-104,106, 107]. In particular, according to the superposition principle, analogs of linear algebra algorithms are especially important. It is well-known that algorithms of linear algebra are convenient for parallel computations; so their idempotent analogs accept a parallelization. This is a regular way to use parallel computations for many problems including basic optimization problems. It is convenient to use universal algorithms which do not depend on a concrete semiring and its concrete computer model. Software implementations for universal semiring algorithms are based on object-oriented and generic programming; program modules can deal with abstract (and variable) operations and data types, see $[102,104,106,107,116]$.

The most important and standard algorithms have many hardware implementations in the form of technical devices or special processors. These devices often can be used as prototypes for new hardware units generated by substitution of the usual arithmetic operations for its semiring analogs, see $[102,104,107]$. Good and efficient technical ideas and decisions can be transposed from prototypes into new hardware units. Thus the correspondence principle generates a regular heuristic method for hardware design. 


\section{IDEMPOTENT INTERVAL ANALYSIS}

An idempotent version of the traditional interval analysis is presented in $[114,115]$. Let $S$ be an idempotent semiring equipped with the standard partial order. A closed interval in $S$ is a subset of the form $\mathbf{x}=[\underline{\mathbf{x}}, \overline{\mathbf{x}}]=\{x \in S \mid \underline{\mathbf{x}} \preceq x \preceq \overline{\mathbf{x}}\}$, where the elements $\underline{\mathbf{x}} \preceq \overline{\mathbf{x}}$ are called lower and upper bounds of the interval $\mathbf{x}$. A weak interval extension $I(S)$ of the semiring $S$ is the set of all closed intervals in $S$ endowed with operations $\oplus$ and $\odot$ defined as $\mathbf{x} \oplus \mathbf{y}=[\underline{\mathbf{x}} \oplus \underline{\mathbf{y}}, \overline{\mathbf{x}} \oplus \overline{\mathbf{y}}]$, $\mathbf{x} \odot \mathbf{y}=[\underline{\mathbf{x}} \odot \underline{\mathbf{y}}, \overline{\mathbf{x}} \odot \overline{\mathbf{y}}]$; the set $I(S)$ is a new idempotent semiring with respect to these operations. It is proved that basic interval problems of idempotent linear algebra are polynomial, whereas in the traditional interval analysis problems of this kind are generally NP-hard. Exact interval solutions for the discrete stationary Bellman equation (see the matrix equation discussed in section 8 above) and for the corresponding optimization problems are constructed and examined by G. L. Litvinov and A. N. Sobolevskiü in [114,115]. Similar results are presented by K. Cechlárová and R. A. Cuninghame-Green in [22].

\section{Relations to the KAM theory and optimal transport}

The subject of the Kolmogorov-Arnold-Moser (KAM) theory may be formulated as the study of invariant subsets in phase spaces of nonintegrable Hamiltonian dynamical systems where the dynamics displays the same degree of regularity as that of integrable systems (quasiperiodic behaviour). Recently, a considerable progress was made via a variational approach, where the dynamics is specified by the Lagrangian rather than Hamiltonian function. The corresponding theory was initiated by S. Aubry and J. N. Mather and recently dubbed weak KAM theory by A. Fathi (see his monograph "Weak KAM Theorems in Lagrangian Dynamics," in preparation, and also $[82,83,159,160])$. Minimization of a certain functional along trajectories of moving particles is a central feature of another subject, the optimal transport theory, which also has undergone a rapid recent development. This theory dates back to G. Monge's work on cuts and fills (1781). A modern version of the theory is known now as the so-called Monge-AmpèreKantorovich (MAK) optimal transport theory (after the work of L. Kantorovich [79]). There is a similarity between the two theories and there are relations to problems of the idempotent functional analysis (e.g., the problem of eigenfunctions for "idempotent" integral operators, see [159]). Applications of optimal transport to data processing in cosmology are presented in $[15,58]$. 


\section{RELATIONS TO LOGIC, FUZZY SETS, AND POSSIBILITY THEORY}

Let $S$ be an idempotent semiring with neutral elements $\mathbf{0}$ and $\mathbf{1}$ (recall that $\mathbf{0} \neq \mathbf{1}$, see section 2 above). Then the Boolean algebra $\mathbf{B}=\{\mathbf{0}, \mathbf{1}\}$ is a natural idempotent subsemiring of $S$. Thus $S$ can be treated as a generalized (extended) logic with logical operations $\oplus$ (disjuction) and $\odot$ (conjunction). Ideas of this kind are discussed in many books and papers with respect to generalized versions of logic and especially quantum logic, see, e.g., [42,64, 90, 147, 148].

Let $\Omega$ be the so-called universe consisting of "elementary events." Denote by $\mathcal{F}(S)$ the set of functions defined on $\Omega$ and taking their values in $S$; then $\mathcal{F}(S)$ is an idempotent semiring with respect to the pointwise addition and multiplication of functions. We shall say that elements of $\mathcal{F}(S)$ are generalized fuzzy sets, see $[64,100]$. We have the well-known classical definition of fuzzy sets (L. A. Zadeh [180]) if $S=\mathbf{P}$, where $\mathbf{P}$ is the segment $[0,1]$ with the semiring operations $\oplus=\max$ and $\odot=$ min. Of course, functions from $\mathcal{F}(\mathbf{P})$ taking their values in the Boolean algebra $\mathbf{B}=\{0,1\} \subset \mathbf{P}$ correspond to traditional sets from $\Omega$ and semiring operations correspond to standard operations for sets. In the general case functions from $\mathcal{F}(S)$ taking their values in $\mathbf{B}=\{\mathbf{0}, \mathbf{1}\} \subset S$ can be treated as traditional subsets in $\Omega$. If $S$ is a lattice (i.e. $x \odot y=\inf \{x, y\}$ and $x \oplus y=\sup \{x, y\}$ ), then generalized fuzzy sets coincide with $L$-fuzzy sets in the sense of J. A. Goguen [63]. The set $I(S)$ of intervals is an idempotent semiring (see section 11), so elements of $\mathcal{F}(I(S))$ can be treated as interval (generalized) fuzzy sets.

It is well known that the classical theory of fuzzy sets is a basis for the theory of possibility $[43,181]$. Of course, it is possible to develop a similar generalized theory of possibility starting from generalized fuzzy sets, see, e.g., [43, 90, 100]. Generalized theories can be noncommutative; they seem to be more qualitative and less quantitative with respect to the classical theories presented in $[180,181]$. We see that idempotent analysis and the theories of (generalized) fuzzy sets and possibility have the same objects, i.e. functions taking their values in semirings. However, basic problems and methods could be different for these theories (like for the measure theory and the probability theory).

\section{Relations to other AREAS AND MiscellaneOUS APPLICATIONS}

Many relations and applications of idempotent mathematics to different theoretical and applied areas of mathematical sciences are discussed above. Of course, optimization and optimal control problems form a very natural field for applications of ideas and methods of 
idempotent mathematics. There is a very good survey paper [93] of V. N. Kolokoltsov on the subject, see also [9, 18, 21, 25, 28-31,35, 37,38, 50-53, 67-69, 102, 104, 114, 115, 117, 119-124, 144, 174-176, 179, 186, 187].

There are many applications to differential equations and stochastic differential equations, see, e.g., [50-53, 69, 91, 92, 94, 96, 119-123, 138, $159,160]$.

Applications to the game theory are discussed, e.g., in [95, 96, 122]. There are interesting applications in biology (bioinformatics), see, e.g., $[49,135,150]$. Applications and relations to mathematical morphology are examined the paper [38] of P. Del Moral and M. Doisy and especially in an extended preprint version of this article. There are many relations and applications to physics (quantum and classical physics, statistical physics, cosmology etc.) see, e.g., Section 6 above and $[23,92,96,110$, $111,117,133,145]$.

There are important relations and applications to purely mathematical areas. The so-called tropical combinatorics is discussed in a large survey paper [87] of A. N. Kirillov, see also $[18,187]$. Interesting applications of tropical semirings to the traditional representation theory are presented in $[11,12,87]$. Tropical mathematics is closely related to the very attractive and popular theory of cluster algebras founded by S. Fomin and A. Zelevinsky, see their survey paper [57]. In both cases there are relations with the traditional theory of representations of Lie groups and related topics. There are important relations with convex analysis and discrete convex analysis, see, e.g., $[2,27,30,32,40,113,118,123,157,183-185]$. Some results on complexity of idempotent/tropical calculations can be found, e.g., in $[86,114,115,170]$. Interesting applications of tropical algebra to the theory of braids and the Yang-Baxter mappings (in the sense of [16]) can be found in $[34,45,46]$.

Many authors examine, explicitly or not, relations and applications of idempotent mathematics to mathematical economics starting from the classical papers of N. N. Vorobjev [174-176], see, e.g., [33, 95, 123, $182,187]$.

\section{REFERENCES}

[1] M. Akian, Densities of idempotent measures and large deviations, Trans. Amer. Math. Soc. 351 (1999), 4515-4543.

[2] M. Akian and S. Gaubert, Spectral theorem for convex monotone homogeneous maps and ergodic control, Nonlinear Analysis 52 (2003), 637-679. See also arXiv:math.SP/0110108. 
[3] M. Akian, S. Gaubert, and V. Kolokoltsov, Set Coverings and Invertibility of Functional Galois Connections. - In [105], p. 1952.

[4] M. Akian, S. Gaubert, and C. Walsh, The max-plus Martin boundary, arXiv:math.MG/0412408, 2004.

[5] M. Akian, S. Gaubert, and C. Walsh, Discrete Max-Plus Spectral Theory. - In [105], p. 53-78.

[6] M. Akian, J. P. Quadrat, and M. Viot, Duality between probability and optimization. - In [69], p. 331-353.

[7] D. Alessandrini, Amoebas, tropical varieties and compactification of Teichmüller spaces, arXiv:math.AG/0505269, 2005.

[8] S. M. Avdoshin, V. V. Belov, V. P. Maslov, and A. M. Chebotarev, Design of computational media: mathematical aspects. - In: [124], p. $9-145$.

[9] F. Baccelli, G. Cohen, G. J. Olsder, and J.-P. Quadrat, Synchronization and Linearity: An Algebra for Discrete Event Systems, John Wiley \& Sons Publishers, New York e.a., 1992.

[10] M. Bardi, I. Capuzzo-Dolcetta, Optimal Control and Viscosity Solutions of Hamilton-Jacobi-Bellman Equations, Birkhäuser, Boston-Basel-Berlin, 1997.

[11] A. Berenstein, S. Fomin, and A. Zelevinsky, Parametrizations of canonical bases and totally positive matrices, Adv. Math. 122 (1996), 49-149.

[12] A. Berenstein and A. Zelevinsky, Tenzor product multiplicities, canonical bases and totally positive varieties, Invent. Math. 143 (2001), 77-128.

[13] P. Bernhard, Minimax versus stochastic partial information control, Proceedings of the 33rd Conference on Decision and Control, Lake Buena Vista, FL, December 1994, IEEE, 1994, p. 2572-2577.

[14] F. Block and J. Yu, Tropical convexity via cellular resolutions, arXiv:math.MG/0503279, 2005.

[15] Y. Brenier, U. Frisch, M. Hénon, G. Loeper, S. Matarrese, R. Mohayaee, and A. Sobolevskil. Reconstruction of the early Universe as a convex optimization problem, Mon. Nat. R. Astron. Soc. 346 (2003), 501-524.

[16] V. M. Buhstaber, Mappings of Yang-Baxter, Uspekhi Mat. Nauk 53 (1998), no. 6, 241-242 [in Russian]. English version is published in Russian Math. Surveys 53 (1998), no. 6.

[17] P. Butkovič, Strong regularity of matrices - a survey of results, Discrete Applied Math. 48 (1994), 45-68.

[18] P. Butkovič, On the combinatorial aspects of max-algebra. - In [105], p. 93-104. 
[19] I. Capuzzo Dolcetta, P.-L. Lions (Eds.), Viscosity solutions and applications, Lectures given at the 2 nd Session of the C.I.M.E. held in Montecatini Terme, Italy, June 12-20, 1995. Lecture Notes in Mathematics 1660, 1997.

[20] B. A. Carré, An algebra for network routing problems, J. Inst. Appl. 7 (1971), 273-294.

[21] B. A. Carré, Graphs and networks, The Clarendon Press/Oxford University Press, Oxford, 1979.

[22] K. Cechlárová and R. A. Cuninghame-Green, Interval systems of max-separable linear equations, Linear Algebra and its Applications 340 (2002), 215-224.

[23] Weiren Chou and R. J. Duffin, An additive eigenvalue problem of physics related HJB equation to linear programming, Adv. in Applied Mathematics 8 (1987), 486-498.

[24] G. Choquet, Theory of capacities, Ann. Inst. Fourier 5 (1955), 131-295.

[25] G. Cohen, S. Gaubert, and J. P. Quadrat, Max-plus algebra and system theory: where we are and where to go now, Annual Reviews in Control 23 (1999), 207-219.

[26] G. Cohen, S. Gaubert, and J.-P. Quadrat, Duality and separation theorems in idempotent semimodules, Linear Algebra and its Applications 379 (2004), 395-422. Also arXiv:math.FA/0212294.

[27] G. Cohen, S. Gaubert, J.-P. Quadrat, and I. Singer, Max-plus convex sets and functions. - In [105], p. 105-130.

[28] G. Cohen and J.-P. Quadrat (Eds.), 11th International Conference on Analysis and Optimization Systems, Springer Lecture Notes on Control and Information Systems 199, 1994.

[29] R. A. Cuninghame-Green, Minimax algebra, Springer Lect. Notes in Economics and Mathematical Systems 166, Berlin et al., 1979.

[30] R. A. Cuninghame-Green, Minimax algebra and applications, Advances in Imaging and Electron Physics 90 (1995), 1-121. (Academic Press, New York).

[31] R. Cuninghame-Green and P. Meijer, An algebra for piesewiselinear minimax problems, Dicsrete Appl. Math. 2 (1980), 267-294.

[32] V. I. Danilov, G. A. Koshevoi, Discrete convexity, Zapiski nauchnyh seminarov POMI 312 (2004) [in Russian].

[33] V. Danilov, G. Koshevoi, and K. Murota, Discrete convexity and equilibria in economics with indivisible goods and money, Math. Soc. Sci. 11 (2001), 251-273.

[34] P. Dehornoy, I. Dynnikov, D. Rolfsen, and B. Wiest, Why are braids orderable? Panoramas et Synthèses 14, SMF, 2002. 
[35] P. Del Moral, A survey of Maslov optimization theory. - In: V. N. Kolokoltsov and V. P. Maslov, Idempotent Analysis and Applications, Kluwer Acad. Publ., Dordrecht, 1997, p. 243-302 (Appendix).

[36] P. Del Moral, Feynman-Kac formulae. Genealogical and interacting particle systems with applications, Springer, New York e.a., 2004.

[37] P. Del Moral and M. Doisy, Maslov idempotent probability calculus, I, II, Theory of Probability and its Applications 43 (1998), no. 4, 735-751 and 44 (1999), no. 2, 384-400.

[38] P. Del Moral and M. Doisy, On the applications of Maslov optimization theory, Mathematical Notes 69 (2001), no. 2, 232-244.

[39] M. Develin, The moduli space of $n$ tropically collinear points in $R^{d}$, arXiv:math.CO/0401224, 2004.

[40] M. Develin and B. Sturmfels, Tropical covexity, arXiv:math.MG/0308254, 2003.

[41] M. Develin, F. Santos, and B. Sturmfels, On the rank of a tropical matrix, arXiv:math.CO/0312114v2, 2004.

[42] A. Di Nola, B. Gerla, Algebras of Lukasiewicz's Logic and Their Semiring Reducts.. - In [105], p. 131-144.

[43] D. Dubois, H. Prade, and R. Sabbadin, Decision-theory foundations of qualitative possibility theory, European Journal of Operational Research 128 (2001), 459-478.

[44] P. S. Dudnikov and S. N. Samborskiu, Endomorphisms of semimodules over semirings with an idempotent operation, preprint of the Mathematical Institute of the Ukrainian Academy of Sciences, Kiev, 1987 (in Russian); Izv. Akad. Nauk SSSR, ser. math. 55 (1991), no. 1, 93-109; English transl. in Math. USSR Izvestiya 38 (1992), no. 1, 91-105.

[45] I. A. Dynnikov, On a Yang-Baxter mapping and the Dehornoy ordering, Uspekhi Mat. Nauk 57 (2002), no. 3, 151-152. English version see in Russian Math. Surveys 57 (2002), no. 3, 592-594.

[46] I. A. Dynnikov and B. Wiest, On the complexity of braids, arXiv: math.GT/0403177, 2004.

[47] M. Einsiedler, M. Kapranov, and D. Lind, Non-archimedean amoebas and tropical varieties, arXiv:math.AG/0408311, 2004.

[48] R. Feynman and A. Hibbs, Quantum mechanics and path integrals, McGraw-Hill, New-York, 1965.

[49] A. V. Finkelstein and M. A. Roytberg, Computation of biopolymers: a general approach to different problems, BioSystems 30 (1993), 1-20. 
[50] W. H. Fleming, Max-Plus Stochastic Control. — In: B. PasikDuncan, Ed., Stochastic Theory and Control, Lecture Notes in Control and Information Science 280 (2002), 111-119.

[51] W. H. Fleming, Max-plus stochastic processes, Applied Math. And Optim. 48 (2004), 159-181.

[52] W. H. Fleming and W. M. McEneaney, A max-plus-based algorithm for a Hamilton-Jacobi-Bellman equation of nonlinear filtering, SIAM J. Control Optim. 38 (2000), no. 3, 683-710.

[53] W. H. Fleming and W. M. McEneaney, Max-plus approaches to continuous space control and dynamic programming. - In [105], p. $145-160$.

[54] W. H. Fleming and H. M. Soner, Controlled Markov processes and viscosity solutions, Springer, New York, 1993.

[55] V. V. Fock, A. B. Goncharov, Moduli spaces of local systems and higher Teichmuller theory, arXiv:math.AG/0311149, 2003.

[56] V. V. Fock, A. B. Goncharov, Cluster ensembles, quantization and the dilogarithm, arXiv:math.AG/0311245, 2003.

[57] S. Fomin and A. Zelevinsky, Cluster algebras: Notes for the CDM-03 Conference, Conf. "Current Developments in Mathematics 2003" held at Harvard University on November 21-22, 2004, arXiv:math.RT/0311493, v. 2, 2004.

[58] U. Frisch, S. Matarrese, R. Mohayaee, and A. Sobolevskiu. A reconstruction of the initial conditions of the Universe by optimal mass transportation, Nature, 417 (May 2002), 260-262.

[59] A. Gathmann and H. Markwig, The Caporaso-Harris formula and plane relative Gromov-Witten invariants in tropical geometry, arXiv:math.AG/0504392,2005.

[60] A. Gathmann and H. Markwig, The numbers of tropical plane curves through points in general position arXiv:math.AG/0406099, 2005.

[61] I. M. Gelfand, M. M. Kapranov, and A. Zelevinsky, Discriminants, resultants, and multidimensional determinants, Birkhäuser, Boston, 1994.

[62] K. Glazek, A guide to the literature on semirings and their applications in mathematics and information sciences: with complete bibliography, Kluwer Acad. Publ., Dordrecht e.a., 2002.

[63] J. A. Goguen, L-fuzzy sets, J. of Math. Anal. Appl. 18 (1967), no. 1, 145-174.

[64] J. S. Golan, Semirings and their applications, Kluwer Acad. Publ., Dordrecht, 1999.

[65] J. S. Golan, Power algebras over semirings, Kluwer Acad. Publ., Dordrecht, 1999. 
[66] J. S. Golan, Semirings and affine equations over them: thery and applications, Kluwer Acad. Publ., Dordrecht, 2003.

[67] M. Gondran and M. Minoux, Graphes et algorithmes, Editions Eyrolles, Paris, 1979, 1988.

[68] M. Gondran and M. Minoux, Graphes, diö̈des et semi-anneaux, Editions TEC\&DOC, Paris e.a., 2001.

[69] J. Gunawardena (Ed.), Idempotency, Publ. of the Newton Institute, Vol. 11, Cambridge University Press, Cambridge, 1998.

[70] J. Gunawardena, An introduction to idempotency. — In [69], p. $1-49$.

[71] E. Hopf, The partial differential equation $u_{t}+u u_{x}=\mu u_{x x}$, Comm. Pure Appl. Math. 3 (1950), 201-230.

[72] I. Itenberg, V. Kharlamov, and E. Shustin, Welschinger invariant and enumeration of real rational curves, International Mathematics Research Notices 49 (2003), 26-39.

[73] I. Itenberg, V. Kharlamov, E. Shustin, Appendix to "Welschinger invariants and enumeration of real rational curves, arXiv:math.AG/0312142v2, 2003.

[74] I. Itenberg, V. Kharlamov, and E. Shustin, Logarithmic equivalence of Welschinger and Gromov-Witten invariants, Uspekhi Matem. Nauk 59 (2004), no. 6, 85-110 [in Russian]. English Version see in Russian Math. Surveys 59 (2004), no. 6 and arXiv:math.AG/0407188, 2004.

[75] I. Itenberg, V. Kharlamov, E. Shustin, Logarithmic asymptotics of the genus zero Gromov-Witten invariants of the blown up plane, Geometry \& Topology 9 (2005), 483-491; see also arXiv:math.AG/0412533, 2004.

[76] Z. Izhakian, Duality of tropical curves, arXiv:math.AG/0503691, 2005.

[77] Z. Izhakian, Tropical arithmetic \& algebra of tropical matrices, arXiv:math.AG/0505458, 2005.

[78] M. Joswig, Tropical halfspaces, arXiv:math.CO/0312068, 2004.

[79] L. V. Kantorovich, On the translocation of masses, Doklady AN SSSR 37 (1942), 227-229.

[80] M. M. Kapranov, Amoebas over non-Archimedian fields, Preprint, 2000.

[81] Y. Katsov, On flat semimodules over semirings, Algebra Universalis 51 (2004), 287-299.

[82] K. Khanin, D. Khmelëv, and A. Sobolevskiü, A blow-up phenomenon in the Hamilton-Jacobi equation in an unbounded domainIn [105], p. 161-180. 
[83] K. Khanin, D. Khmelëv, and A. Sobolevskiǔ, On velocities of lagrangian minimizers. Moscow Math. J., 2005 (in print).

[84] K. H. Kim and F. W. Roush, Inclines and incline matrices: a survey, Linear Algebra and its Applications 379 (2004), 457-473.

[85] K. H. Kim and F. W. Roush, Kapranov rank vs. tropical rank, arXiv:math.CO/0503044, 2005.

[86] K. H. Kim, F. W. Roush, Factorization of polynomials in one variable over the tropical semiring, arXiv:math.CO/0501167, 2005.

[87] A. N. Kirillov, Introduction to tropical combinatorics. - In: A. N. Kirillov and N. Liskova (Eds.), Physics and Combinatorics 2000, Proc. of the Nagoya 2000 Intern. Workshop, World Scientific, 2001, p. 82-150.

[88] S. C. Kleene, Representation of events in nerve sets and finite automata. - In: J. McCarthy and C. Shannon (Eds), Automata Studies, Princeton University Press, Princeton, 1956, pp. 3-40.

[89] E. P. Klement, R. Mesiar, and E.Pap, Triangular Norms, Kluwer Acad. Publ., Dordrecht, 2000.

[90] E. P. Klement and E. Pap (Eds.), Mathematics of Fuzzy Systems, 25th Linz Seminar on Fuzzy Set Theory, Linz, Austria, Feb. 3-7, 2004. Abstracts. J. Kepler Univ., Linz, 2004.

[91] V. N. Kolokoltsov, Stochastic Hamilton-Jacobi-Bellman equations and stochastic Hamiltonian systems, Journal of Control and Dynamic Systems 2 (1996), no. 3, 299-319.

[92] V. N. Kolokoltsov, Semiclassical analysis for diffusions and stochastic processes, Springer Lecture Notes in Math. 1724, 2000.

[93] V. N. Kolokoltsov, Idempotency structures in optimization, Journal Math. Sci. 104 (2001), no. 1, 847-880.

[94] V. N. Kolokoltsov, Small diffusion and fast dying out asymptotics for superprocesses as non-Hamiltonian quasiclassics for evalution equations, Electronic Journal of Probability 6 (2001), paper 21 (see http://www.math.washington.edu/ ejpecp/).

[95] V. N. Kolokoltsov and O. A. Malafeyev, A turnpike theorem in conflict-control processes with many participants. - In: O. Malafeyev (Ed.), Conflict Models in Economics and Finance, St. Petersburg Univ. Press, 1997 (in Russian).

[96] V. Kolokoltsov and V. Maslov, Idempotent analysis and applications, Kluwer Acad. Publ., 1997.

[97] V. Kolokoltsov and A. Tyukov, Small time amd semiclassical asymptotics for stochastic heat equation driven by Levi noise, Stochastics and Stochastics Reports 75 (2003), no. 1-2, 1-38. 
[98] M. Kontsevich and Y. Soibelman, Homological mirror symmetry and torus fibration. - In: Symplectic geometry and mirror symmetry (Seoul, 2000), World Sci. Publ., River Edge, N.J., 2001, pp. 203-263.

[99] M. Kontsevich and Y. Soibelman, Affine structures and nonarchimedean analytic spaces, arXiv:math.AG/0406564, 2004.

[100] G. L. Litvinov, Dequantization of mathematics, idempotent semirings and fuzzy sets. - In [90], p. 113-117.

[101] G. L. Litvinov, The Maslov dequantization, idempotent and tropical mathematics: a very brief introduction. - In [105], p. 1-17.

[102] G. L. Litvinov and V. P. Maslov, Correspondence principle for idempotent calculus and some computer applications, (IHES/M/95/33), Institut des Hautes Etudes Scientifiques, Buressur-Yvette, 1995. Also arXiv:math.GM/0101021.

[103] G. L. Litvinov and V. P. Maslov, Idempotent mathematics: correspondence principle and applications, Russian Mathematical Surveys 51 (1996), no. 6, 1210-1211.

[104] G. L. Litvinov and V. P. Maslov, The correspondence principle for idempotent calculus and some computer applications. — In [69], p. $420-443$.

[105] G. L. Litvinov and V. P. Maslov (Eds.), Idempotent mathematics and mathematical physics, Contemporary Mathematics, Vol. 377, AMS, Providence, RI, 2005.

[106] G. L. Litvinov and E. V. Maslova, Universal numerical algorithms and their software implementation, Programming and Computer Software 26 (2000), no. 5, 275-280. Also arXiv:math.SC/0102114.

[107] G. L. Litvinov, V. P. Maslov, and A. Ya. Rodionov, A unifying approach to software and hardware design for scientific calculations and idempotent mathematics, International Sophus Lie Centre, Moscow 2000. Also arXiv:math.SC/0101069.

[108] G. L. Litvinov, V. P. Maslov, and G. B. Shpiz, Linear functionals on idempotent spaces: an algebraic approach, Doklady Mathematics 58 (1998), no. 3, 389-391. Also arXiv:math.FA/0012268.

[109] G. L. Litvinov, V. P. Maslov, and G. B. Shpiz, Tensor products of idempotent semimodules. An algebraic approach, Mathematical Notes 65 (1999), no. 4, 497-489. Also arXiv:math.FA/0101153.

[110] G. L. Litvinov, V. P. Maslov, and G. B. Shpiz, Idempotent functional analysis. An algebraic approach, Mathematical Notes 69 (2001), no. 5, 696-729. Also arXiv:math.FA/0009128.

[111] G. L. Litvinov, V. P. Maslov, and G. B. Shpiz, Idempotent (asymptotic) analysis and the representation theory. - In: V. A. Malyshev and A. M. Vershik (Eds.), Asymptotic Combinatorics with 
Applications to Mathematical Physics. Kluwer Academic Publ., Dordrecht et al, 2002, p. 267-278. Also arXiv:math.RT/0206025.

[112] G. L. Litvinov and G. B. Shpiz, Nuclear semimodules and kernel theorems in idempotent analysis: an algebraic approach, Doklady Mathematics 66 (2002), no. 2, 197-199. Also arXiv math.FA/0202026.

[113] G. L. Litvinov and G. B. Shpiz, The dequantization transform and generalized Newton polytopes. - In [105], p. 181-186.

[114] G. L. Litvinov and A. N. Sobolevskiu, Exact interval solutions of the discrete Bellman equation and polynomial complexity of problems in interval idempotent linear algebra, Doklady Mathematics 62 (2000), no. 2, 199-201. Also arXiv:math.LA/0101041.

[115] G. L. Litvinov and A. N. Sobolevskiŭ, Idempotent interval analysis and optimization problems, Reliable Computing 7 (2001), no. 5, 353-377. Also arXiv:math.SC/0101080.

[116] P. Loreti and M. Pedicini, An object-oriented approach to idempotent analysis: integral equations as optimal control problems. In [105], p. 187-208.

[117] P. Lotito, J.-P. Quadrat, and E. Mancinelli, Traffic assignment \& Gibbs-Maslov semirings. - In [105], p. 209-220.

[118] G. G. Magaril-Il'yaev and V. M. Tikhomirov, Convex analysis: theory and applications, Translations of Mathematical Monographs, vol. 222, American Math. Soc., Providence, RI, 2003.

[119] V. P. Maslov, New superposition principle for optimization problems. - In: Seminaire sur les Equations aux Dérivées Partielles 1985/86, Centre Math. De l'Ecole Polytechnique, Palaiseau, 1986, exposé 24.

[120] V. P. Maslov, On a new superposition principle for optimization problems, Uspekhi Mat. Nauk, [Russian Math. Surveys], 42, no. 3 (1987), 39-48.

[121] V. P. Maslov, Méthodes opératorielles, Mir, Moscow, 1987.

[122] V. P. Maslov and V. N. Kolokoltsov, Idempotent analysis and its application in optimal control, Nauka, Moscow, 1994. (in Russian)

[123] V. P. Maslov and S. N. Samborskiǔ (Eds), Idempotent analysis, Adv. in Sov. Math., vol. 13, AMS, RI, 1992.

[124] V. P. Maslov and K. A. Volosov (Eds.), Mathematical aspects of computer engineering, MIR Publ., Moscow, 1988.

[125] D. McCaffrey, Viscosity solutions on Lagrangian manifolds and connections with tunneling operators. - In [105], p. 221-238.

[126] G. Mikhalkin, Amoebas of algebraic varieties, Notes for the Real Algebraic and Analytic Geometry Congress, June 11-15, 2001, Rennes, France. Also arXiv:math.AG/0108225, 2001. 
[127] G. Mikhalkin, Counting curves via lattice path in polygons, C.R. Acad. Sci. Paris 336 (2003), no. 8, 629-634.

[128] G. Mikhalkin, Amoebas of algebraic varieties and tropical geometry, to be published in volume "Different faces in Geometry." Also arXiv:math.AG/0403015, 2004.

[129] G. Mikhalkin, Enumerative tropical algebraic geometry in $\mathbf{R}^{\mathbf{2}}$, Journal of the ACM, 2005 (in press). Also arXiv:math.AG/0312530.

[130] E. Nelson, Probability theory and Euclidean field theory, Constructive quantum field theory, vol. 25, Springer, Berlin, 1973.

[131] T. Nishinou and B. Siebert, Toric degenerations of toric varieties and tropical curves, arXiv:math.AG/0409060, 2004.

[132] M. Noumi, Y. Yamada, Tropical Robinson-SchenstedKnuth correspondence and birational Weyl group actions, arXiv:math-ph/0203030, 2002.

[133] R. D. Nussbaum, Convergence of iterates of a nonlinear operator arising in statistical mechanics, Nonlinearity 4 (1991), 1223-1240.

[134] L. Pachter and B. Sturmfels, Tropical geometry of statistical models, arXiv:q-bio.QM/0311009v2, 2004.

[135] L. Pachter and B. Sturmfels, The mathematics of phylogenomics, arXiv:math.ST/0409132, 2004.

[136] S. N. N. Pandit, A new matrix calculus, SIAM J. Appl. Math. 9 (1961), 632-639.

[137] E. Pap, Pseudo-additive measures and their applications. - In: E. Pap, ed., Handbook of measure theory, Elsevier, Amsterdam, 2002, p. 1403-1465.

[138] E. Pap, Applications of the generated pseudo-analysis to nonlinear partial differential equations. - In [105], p. 239-260.

[139] M. Passare and A. Tsikh, Amoebas: their spines and their contours. - In [105], p. 275-288.

[140] J. E. Pin, Tropical semirings. - In [69], p. 50-60.

[141] A. A. Puhalskii, Large Deviations and Idempotent Probability, Chapman and Hall/CRC Press, London/Boka Raton, FL., 2001.

[142] A. A. Puhalskii, On large deviations convergence of invariant measures, Journal of Theoretical Probability 16 (2003), 689-724.

[143] J.-P. Quadrat, Théorèmes asymptotiques en programmation dynamique, Comptes Rendus Acad. Sci., Paris 311, (1990), 745-748.

[144] J.-P. Quadrat and Max-Plus working group, Max-plus algebra and applications to system theory and optimal control, - In: Proc. of the Internat. Congress of Mathematicians, Zürich, 1994. 
[145] J.-P. Quadrat and Max-Plus working group, Min-plus linearity and statistical mechanics, Markov Processes and Related Fields 3 (1997), no. 4, 565-587.

[146] J. Richter-Gebert, B. Sturmfels, and T. Theobald, First steps in tropical geometry. — In [105], p. 289-318. Also arXiv:math.AG/0306366.

[147] K. I. Rosenthal, Quantales and their applications, Pitman Research Notes in Mathematics Series, Longman Sci.\&Tech., 1990.

[148] K. I. Rosenthal, The theory of quantaloids, Pitman Research Notes in Mathematics Series 348, LongmanHarlow, 1996.

[149] I. V. Roublev, On minimax and idempotent generalized weak solutions to the Hamilton-Jacobi Equation. - In [105], p. 319-338.

[150] M. A. Roytberg, Fast algorithm for optimal aligning of symbol sequences, DIMACS Series in Mathematics and Theoretical Computer Science, 8 (1992), 113-126.

[151] H. Rullgård, Polynomial amoebas and convexity, Preprint, Stokholm University, 2001.

[152] S. N. Samborskii, A.A. Tarashchan, The Fourier transform and semirings of Pareto sets. - In: [123], p. 139-150.

[153] E. Schrödinger, Quantization as an eigenvalue problem, Annalen der Physik 364 (1926), 361-376 [in German].

[154] G. B. Shpiz, Solution of algebraic equations over idempotent semifields, Uspekhi Matem. Nauk [Russian Math. Surveys] 55 (2000), no. 5, 185-186.

[155] E. Shustin, Patchworking singular algebraic curves, non Archimedian amoebas and enumerative geometry, arXiv:math.AG/0211278.

[156] E. Shustin, A tropical calculation of the Welschinger invariants of real toric Del Pezzo surfaces, arXiv:math.AG/0504390, 2004.

[157] I. Singer, Abstract convex analysis, John Wiley\&Sons Inc., New York, 1997.

[158] I. Singer, Some relations between linear mappings and conjugations in idempotent analysis, J. Math. Sci. 115 (2003), no. 5, 26102630 .

[159] A. N. Sobolevskil, Aubry-Mather theory and idempotent eigenfunctions of Bellman operator, Commun. Contemp. Math. 1 (1999), no. 4, 517-533.

[160] A. N. Sobolevskil, Periodic solutions of the Hamilton-Jacobi equation with a periodic nonhomogeneity, and the Aubry-Mather theory, Mat. Sb. 190 (1999), no. 10, 87-104.

[161] F. Sottile, Tropical interpolation, arXiv:math.AG/0501146, 2005. 
[162] D. E. Speyer, Tropical linear spaces, arXiv:math.CO/0410455, 2004.

[163] D. Speyer, B. Sturmfels, The tropical Grassmannian, arXiv:math.AG/0304218, 2003.

[164] D. Speyer and B. Sturmfels, Tropical mathematics, arXiv:math.CO/0408099, 2004.

[165] D. Speyer, L. K. Williams, The tropical totally positive Grassmannian, arXiv:math.CO/0312297, 2003.

[166] B. Sturmfels, Solving systems of polynomial equations, CBMS Regional Conference Series in Mathematics, AMS, Providence, RI, 2002.

[167] A. I. Subbotin, Generalized solutions of first order PDEs: The dynamic optimization perspective. Birkhäuser, Boston, 1996.

[168] A. Szenes and M. Vergne, Mixed toric residues and tropical degenerations, arXiv:math.AG/0410064, 2004.

[169] J. Tevelev, Tropical compactifications, arXiv:math.AG/0412329, 2004.

[170] T. Theobald, On the frontiers of polynomial computations in tropical geometry, arXiv:math.CO/0411012, 2004.

[171] M. D. Vigeland, The group law on a tropical elliptic curve, arXiv:math.AG/0411485, 2004.

[172] O. Viro, Dequantization of real algebraic geometry on a logarithmic paper. - In: 3rd European Congress of Mathematics, Barcelona, 2000. Also arXiv:math/0005163.

[173] O. Viro, What is an amoeba?, Notices of the Amer. Math, Soc. 49 (2002), 916-917.

[174] N. N. Vorobjev, The extremal matrix algebra, Soviet Math. Dokl. 4 (1963), 1220-1223.

[175] N. N. Vorobjev, Extremal algebra of positive matrices, Elektronische Informationsverarbeitung und Kybernetik 3 (1967), 39-57. (in Russian)

[176] N. N. Vorobjev, Extremal algebra of nonnegative matrices, Elektronische Informationsverarbeitung und Kybernetik 6 (1970), 302-312. (in Russian)

[177] E. Wagneur, Dequantization: semi-direct sums of idempotent semimodules. - In [105], p. 339-357.

[178] C. Walsh, Minimum representing measures in idempotent analysis, arXiv:math.MG/0503716, 2005.

[179] J. van der Woude and G. J. Olsder, On (min, max, +)inequalities.-In [105], p. 358-363.

[180] L. A. Zadeh, Fuzzy sets, Information and Control 8 (1965), 338353. 
[181] L. A. Zadeh, Fuzzy sets as a basis for a theory of possibility, Fuzzy Sets and Systems, 1 (1978), 3-28.

[182] K. Zimmermann, Extremální Algebra, Ekonomický ùstav ČSAV, Praha 46 (1976). (in Czech).

[183] K. Zimmermann, A general separation theorem in extremal algebras, Ekonom.-Mat. Obzor 13 (1977), no. 2, 179-210.

[184] K. Zimmermann, Extremally convex functions, Wiss. Z. Päd. Hochschule "N. K. Krupskaya" 17 (1979), 147-158.

[185] K. Zimmermann, A generalization of convex functions, Ekonom.Mat. Obzor 15 (1979), no. 2, 147-158.

[186] K. Zimmermann, Solution of some max-separable optimization problems with inequality constraints. - In [105], p. 363-370.

[187] U. Zimmermann, Linear and combinatorial optimization in ordered algebraic structures, Ann. Discrete Math., 10 (1981), 1-380.

IndePendent University of Moscow, Bol'shoi Vlasievskil PeR., 11, Moscow 121002, Russia

E-mail address: islc@dol.ru 


\title{
ДЕКВАНТОВАНИЕ МАСЛОВА, ИДЕМПОТЕНТНАЯ И ТРОПИЧЕСКАЯ МАТЕМАТИКА: КРАТКОЕ ВВЕДЕНИЕ
}

\author{
Г. Л. Литвинов \\ Анатолию Моисеевичу Веричку с восхищением и благодарностью
}

\begin{abstract}
АннотАция. Эта статья является кратким введением в идемпотентную и тропическую математику. Тропическая математика может быть получена из традиционной математики над числовыми полями как результат деквантования Маслова, при котором постоянная Планка ћ стремится к нулю, принимая мнимые значения.

Ключевые слова: деквантование Маслова, идемпотентная математика, тропическая математика, идемпотентные полукольца, идемпотентный анализ, идемпотентный функциональный анализ, деквантование геометрии.
\end{abstract}

Эта статья практически не содержит строгих формулировок теорем и их доказательств, она является лишь кратким введением в деквантование Маслова, идемпотентную и тропическую математику. Список цитируемой литературы отнюдь не является полным. Дополнительные ссылки могут быть найдены, например, в электронном архиве

$$
\text { http://arXiv.org }
$$

и в работах $[9,17,21,25,28-31,37,38,51,62,64-70,84,87,89,93,96$, $102,104,110,115,137,187]$. Настоящий обзор является расширенной версией статьи [101].

Автор благодарен М. Акиан (M. Akian), Я. И. Белопольской, П. Бутковичу (P. Butkovič), Г. Коэну (G. Cohen), C. Гоберу (S. Gaubert), P. A. Канингхем-Грину (R. A. Cuninghame-Green), П. Дел Моралу (P. Del Moral), У. Х. Флемингу (W. H. Fleming), Дж. С. Голану (J. S. Golan), М. Гондрану (M. Gondran), И. Итенбергу (I. Itenberg), Е. Кацову (Y. Katsov), В. Н. Колокольцову, П. Лорети (P. Loreti),

Эта работа поддержана грантом РФФИ 05-01-00824 и Международным институтом математической физики им. Э. Шредингера в Вене (Erwin Schrödinger International Institute for Mathematical Physics).

Записки научных семинаров ПОМИ. Теория представлений, динамические системы XII, в печати. 
Ю. И. Манину, Дж. Маскари (G. Mascari), У. М. Макэнэни (W. M. MacEneaney), Г. Паниной, Е. Папу (Е. Рар), М. Педишини (M. Pedicini), А. Праду (H. Prade), А. А. Пухальскому (А. A. Puhalskii), Ж.-П. Квадра (J.-P. Quadrat), М. А. Ройтбергу, А. В. Чуркину, Г. Б. Шпизу, И. Зингеру (I. Singer), и О. Виро (O. Viro) за полезные добавления и замечания. Автор особенно благодарен В. П. Маслову за всестороннюю помощь и поддержку и А. Н. Соболевскому за большую помощь, включая три рисунка и многое другое.

\section{1. ОСНОВНЫЕ ИДЕИ}

В основе идемпотентной математики лежит замена обычных арифметических операций новым набором базовых операций (такими как максимум или минимум), при этом числовые поля заменяются идемпотентными полукольцами и полуполями. Типичные примеры так называемые алгебра макс-плюс $\mathbf{R}_{\max }$ и алгебра мин-плюс $\mathbf{R}_{\min }$. Пусть $\mathbf{R}$ - поле вещественных чисел. Тогда $\mathbf{R}_{\max }=\mathbf{R} \cup\{-\infty\}$ с операциями $x \oplus y=\max \{x, y\}$ и $x \odot y=x+y$. Аналогично $\mathbf{R}_{\text {min }}=\mathbf{R} \cup\{+\infty\}$ с операциями $\oplus=\min , \odot=+$. Новое сложение $\oplus$ является идемпотентной операцией, то есть $x \oplus x=x$ для всех $x$.

Начиная с классической работы С. Клини [88], многие авторы (С. Клини, С. Н. Н. Пандит, Н. Н. Воробьев, Б. А. Карре, Р. А. Канингхем-Грин, К. Циммерманн, У. Циммерманн, М. Гондран, Ф. Л. Баккелли, Г. Коэн, С. Гобер, Г. Дж. Олсдер, Ж.-П. Квадра и др.) использовали идемпотентные полукольца и матрицы над этими полукольцами для решения ряда прикладных задач дискретной математики и информатики. Современный идемпотентный анализ (или идемпотентное исчисление, или идемпотентная математика) был разработан В. П. Масловым и его сотрудниками в восьмидесятых годах в Москве, см., например, работы [96, 119-124]. Некоторые предварительные результаты сформулировали Э. Хопф и Г. Шоке, см. работы $[24,71]$.

Идемпотентную математику можно рассматривать как результат деквантования традиционной математики над числовыми полями, при котором постоянная Планка $\hbar$ стремится к нулю, принимая мнимые значения. Такая точка зрения была представлена Г. Л. Литвиновым и В. П. Масловым [102-104], см. также [110,111]. Иначе говоря, идемпотентная математика является асимптотической версией традиционной математики над полями вещественных и комплексных чисел. 


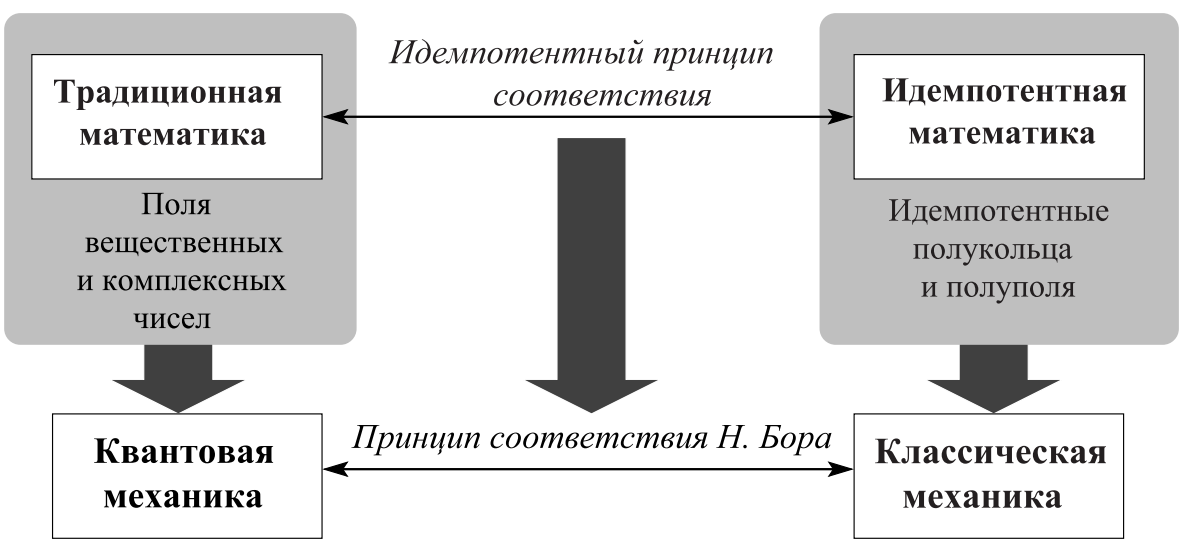

Рис. 1. Связь между идемпотентной и традиционной математикой.

Основную парадигму идемпотентной математики выражает идемпотентный принцип соответствия. Этот принцип тесно связан со знаменитым принципом соответствия Нильса Бора для квантовой теории. Оказывается, что существует эвристическое соответствие между рядом важных, интересных и полезных конструкций и результатов обычной математики над полями и аналогичными конструкциями и результатами над идемпотентными полуполями и полукольцами (полуполями и полукольцами с идемпотентными сложением).

Систематическое и последовательное использование идемпотентного принципа соответствия приводит к многообразным результатам, часто весьма неожиданным. В результате, наряду с традиционной математикой, возникает ее "теневая" идемпотентная версия. Эта “теневая" версия так же связана с традиционной математикой, как классическая физика с физикой квантовой, см. рис. 11.

Во многих отношениях идемпотентная математика проще традиционной. Однако переход от традиционных конструкций и результатов к их идемпотентным аналогам часто является нетривиальным.

\section{2. ПолУКОЛЬЦА, ПОЛУПОЛЯ И ДЕКВАНТОВАНИЕ}

Пусть на множестве $S$ заданы две алгебраические операции : сложение $\oplus$ и умножение $\odot$. Говорят, что на множестве $S$ задано полукольщо, если выполняются следующие условия: 
- сложение $\oplus$ и умножение $\odot$ ассоциативны;

- сложение $\oplus$ коммутативно;

- умножение $\odot$ дистрибутивно относительно сложения $\oplus$ :

$$
\begin{gathered}
x \odot(y \oplus z)=(x \odot y) \oplus(x \odot z) \quad \text { и } \quad(x \oplus y) \odot z=(x \odot z) \oplus(y \odot z) \\
\text { для любых } x, y, z \in S .
\end{gathered}
$$

Единицей полукольца $S$ называется такой элемент $1 \in S$, что $\mathbf{1} \odot x=x \odot \mathbf{1}=x$ для всех $x \in S$. Нулем полукольца $S$ называется такой элемент $\mathbf{0} \in S$, что $\mathbf{0} \neq \mathbf{1}$ и $\mathbf{0} \oplus x=x, \mathbf{0} \odot x=x \odot \mathbf{0}=\mathbf{0}$ для всех $x \in S$. Полукольцо $S$ называется идемпотентным полукольцом, если $x \oplus x=x$ для всех $x \in S$. Полукольцо $S$ с элементами 0 и 1 называется полуполем, если для любого ненулевого элемента множества $S$ существует обратный элемент. Заметим, что диоиды в смысле работ $[9,67,68]$, кванталы в смысле $[147,148]$, и инклайны в смысле [84] являются примерами идемпотентных полуколец.

Рассмотрим поле вещественных чисел $\mathbf{R}$ и полуполе всех неотрицательных вещественных чисел $\mathbf{R}_{+}$(относительно обычных операций сложения и умножения). Замена переменных $x \mapsto u=h \ln x, h>0$, задает отображение $\Phi_{h}: \mathbf{R}_{+} \rightarrow S=\mathbf{R} \cup\{-\infty\}$. Перенесем операции сложения и умножения из $\mathbf{R}$ в $S$ с помощью отображения $\Phi_{h}$, а именно, пусть $u \oplus_{h} v=h \ln (\exp (u / h)+\exp (v / h)), u \odot v=u+v, \mathbf{0}=-\infty=\Phi_{h}(0)$, $\mathbf{1}=0=\Phi_{h}(1)$, таким образом $S$ приобретает структуру полукольца $\mathbf{R}^{(h)}$ изоморфного $\mathbf{R}_{+}$; см. рис. 2

Несложно проверить, что $u \oplus_{h} v \rightarrow \max \{u, v\}$ при $h \rightarrow 0$ и что $S$ образует полукольцо относительно сложения $u \oplus v=\max \{u, v\}$ и умножения $u \odot v=u+v$ с нулевым элементом $\mathbf{0}=-\infty$ и единицей $\mathbf{1}=0$. Обозначим это полукольцо через $\mathbf{R}_{\max }$; оно идемпотентно, так как $u \oplus u=u$ для всех элементов. При этом полукольцо $\mathbf{R}_{\max }$ является полуполем. Аналогия с процедурой квантования здесь очевидна, параметр $h$ играет роль постоянной Планка, поэтому полуполе $\mathbf{R}_{+}$можно рассматривать как “квантовый” объект, а полукольцо $\mathbf{R}_{\text {max }}$ может рассматриваться как результат его "деквантования". Аналогичная процедура для $h<0$ дает полукольцо $\mathbf{R}_{\min }=\mathbf{R} \cup$ $\{+\infty\}$ с операциями $\oplus=\min , \odot=+$; в этом случае $\mathbf{0}=+\infty, \mathbf{1}$ $=0$. Полукольца $\mathbf{R}_{\max }$ и $\mathbf{R}_{\min }$ изоморфны. Переход к $\mathbf{R}_{\max }$ или $\mathbf{R}_{\min }$ называется деквантованием Маслова. Понятно, что соответствующий переход от $\mathbf{C}$ или $\mathbf{R}$ к $\mathbf{R}_{\max }$ осуществляется при помощи деквантования Маслова и отображения $x \mapsto|x|$. Допуская вольность речи, такой переход в дальнейшем мы также будем называть деквантованием Маслова.

Связь с физикой и роль мнимых значений постоянной Планка будут обсуждаться ниже, в разделе 6 , а также в работах $[110,111]$. 


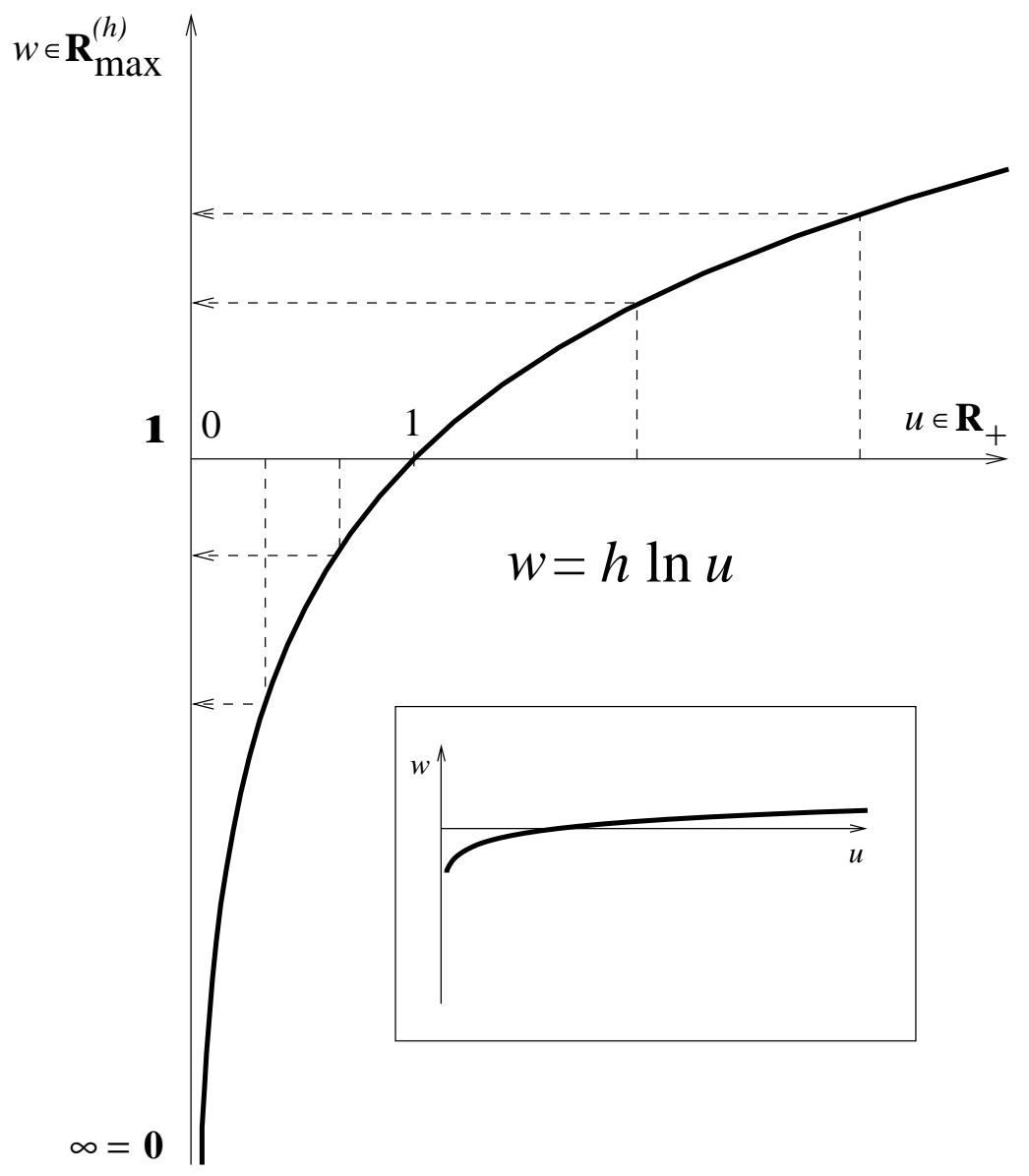

Рис. 2. Переход от $\mathbf{R}_{+}$к $\mathbf{R}^{(h)}$. На вставке: то же для малых $h$.

Идемпотентное полукольцо $\mathbf{R} \cup\{-\infty\} \cup\{+\infty\}$ с операциями $\oplus=$ $\max , \odot=\min$ может быть получено в результате "вторичного деквантования" полей $\mathbf{C}, \mathbf{R}$ или полуполя $\mathbf{R}_{+}$. Десятки интересных примеров неизоморфных идемпотентных полуколец, а также стандартные методы получения новых полуколец из исходных рассматриваются в следующих работах $[26,64,66-70,104,110]$. Так называемое идемпотентное деквантование является обобщением деквантования Маслова; это переход от полей к идемпотентным полуполям и полукольцам в математических конструкциях и результатах.

Деквантование Маслова связано с хорошо известным логарифмическим преобразованием, использованным, например, в классических работах Э. Шредингера [153] и Э. Хопфа [71]. Используется также термин “преобразование Коула-Хопфа". Идеи Э. Хопфа получили дальнейшее 
развитие в известном методе исчезающей вязкости и методе вязкостных решений, см., например, работы [10, 19, 54, 122, 125, 149, 167].

\section{3. ТЕРМИНОЛОГИЯ: ТРОПИЧЕСКИЕ ПОЛУКОЛЬЦА И ТРОПИЧЕСКАЯ МАТЕМАТИКА}

Термин “тропические полукольца" появился в информатике и теории алгоритмов для обозначения дискретной версии алгебры $\mathbf{R}_{\max }$ или $\mathbf{R}_{\text {min }}$ и их подалгебр; дискретные полукольца этого типа были названы “тропическими" Домиником Перрэном в честь бразильского специалиста по информатике и математике Имре Саймона, в знак признания его пионерской деятельности в данной области, см. [140].

В дальнейшем ситуация и терминология изменились. Для большинства современных авторов “тропический” означает "над полуполями $\mathbf{R}_{\text {max }}$ или $\mathbf{R}_{\text {min }}$ ", а тропические полукольца - это идемпотентные полуполя $\mathbf{R}_{\max }$ и $\mathbf{R}_{\min }$. В этом же смысле часто используются термины "максплюс" и "мин-плюс". В настоящее время термин "тропическая математика" обычно означает "математика над полуполями $\mathbf{R}_{\max }$ или $\mathbf{R}_{\min }$ ", см., например, [7,11,12,14,39,41,55,56,59,60,72-78,85,86,126-129,131,132, $134,135,146,155,156,161-165,169-171]$. Термины “тропикализация" и "тропификация" (например, в [87]) в точности означают деквантование и квантование в описанном выше смысле. В любом случае, тропическая математика является естественной и очень важной частью идемпотентной математики. Многие известные конструкции и результаты идемпотентной математики были повторены в рамках тропической математики (и, особенно, в тропической линейной алгебре).

Заметим, что в статьях [174-176] Н. Н. Воробьев развил некоторую версию идемпотентной линейной алгебры (с важными приложениями, в том числе для математической экономики), и предвидел многие аспекты будущей расширенной теории. Для обозначения идемпотентных полуколец и идемпотентной математики он использовал термины "экстремальные алгебры" и "экстремальная математика". К сожалению, идеи Н. Н. Воробьева в свое время не получили широкой известности, поэтому его терминология не прижилась и сейчас почти не используется.

\section{4. ИДЕМПОТЕНТНАЯ АЛГЕБРА И ЛИНЕЙНАЯ АЛГЕБРА}

Автором первой известной работы по идемпотентной линейной алгебре является С. Клини. В его работе [88] рассматриваются системы линейных алгебраических уравнений над несколько экзотическим идемпотентным полукольцом всех формальных языков с фиксированным конечным алфавитом. Однако идеи С. Клини оказались весьма общими и универсальными. После этого десятки авторов изучали 
матрицы с коэффициентами, принадлежащими идемпотентным полукольцам, а также соответствующие приложения к дискретной математике, информатике, языкам программирования, лингвистическим задачам, конечным автоматам, проблемам оптимизации на графах, теории оптимального управления, дискретным системам событий и сетям Петри, стохастическим системам, оценке производительности компьютеров, вычислительным проблемам и т.д. Эти направления хорошо известны и широко представлены в литературе, см., например $[9,17,18,21,25$, 28-30, 44, 62, 64-70, 84, 93, 96, 102, 104-107, 114, 115, 122, 174-177, 187].

Идемпотентная абстрактная алгебра пока не так хорошо развита, хотя с другой стороны, с формальной точки зрения теория решеток, теория упорядоченных групп и полугрупп входят в состав идемпотентной алгебры. Тем не менее, имеется много интересных результатов и приложений, см., например, [29-31, 81, 147, 148, 154].

В частности, идемпотентная версия основной теоремы алгебры сформулирована в $[31,154]$ для радикабельных идемпотентных полуколец (полукольцо $A$ называется радикабельным, если уравнение $x^{n}=a$ имеет решение $x \in A$ для любого $a \in A$ и любого положительного целого $n$ ). Доказано, что $\mathbf{R}_{\max }$ и другие радикабельные полуполя алгебраически замкнуты в естественном смысле [154].

В последние годы особое внимание привлекают к себе вопросы тропической алгебраической геометрии, которые будут рассмотрены ниже, в разделе 11.

\section{5. ИДЕМПОТЕНТНЫЙ АНАЛИЗ}

Идемпотентный анализ первоначально был построен В.П. Масловым и его сотрудниками, а затем развит в большом количестве публикаций различных авторов. Этому предмету посвящена книга В. Н. Колокольцова и В. П. Маслова [96] (русская версия [122] опубликована в 1994 году).

Пусть $S$ - произвольное полукольцо с идемпотентным сложением $\oplus$ (которое всегда предполагается коммутативным), умножением $\odot$, нулем 0, и единицей 1. Множество $S$ снабжено стандартным частичным порядком $\preceq:$ по определению, $a \preceq b$ тогда и только тогда, когда $a \oplus b=b$. Таким образом, все элементы множества $S$ неотрицательны: $\mathbf{0} \preceq a$ для всех $a \in S$. Благодаря существованию этого порядка, идемпотентный анализ тесно связан с теорией решеток, теорией векторных решеток и теорией упорядоченных пространств. Более того, этот частичный порядок позволяет моделировать основные топологические понятия и результаты на чисто алгебраическом уровне; 
систематическое изложение такого подхода можно найти в работах [108-112] и [26].

Анализ главным образом имеет дело с функциями, чьими значениями являются числа. Идемпотентным аналогом числовой функции является отображение $X \rightarrow S$, где $X$ - произвольное множество, а $S$ идемпотентное полукольцо. Функции со значениями в $S$ можно скадывать, умножать друг на друга, а также умножать на элементы $S$ поточечно.

Идемпотентным аналогом линейного функционального пространства является множество функций со значениями в $S$, замкнутое относительно сложения функций и умножения функций на элементы из $S$, или $S$-полумодуль. Рассмотрим, например, $S$-полумодуль $B(X, S)$ всех функций $X \rightarrow S$, которые ограничены в смысле стандартного порядка B $S$.

Пусть $S=\mathbf{R}_{\max }$, тогда идемпотентный аналог интеграла определяется формулой

$$
I(\varphi)=\int_{X}^{\oplus} \varphi(x) d x=\sup _{x \in X} \varphi(x),
$$

где $\varphi \in B(X, S)$. Действительно, риманова сумма вида $\sum_{i} \varphi\left(x_{i}\right) \cdot \sigma_{i}$ соответствует выражению $\bigoplus_{i} \varphi\left(x_{i}\right) \odot \sigma_{i}=\max _{i}\left\{\varphi\left(x_{i}\right)+\sigma_{i}\right\}$, которое сходится к правой части $(1)$ при $\sigma_{i} \rightarrow$ 0. Разумеется, это чисто эвристическое рассуждение.

Формула (1) определяет идемпотентный интеграл (или интеграл Маслова) не только для функций, принимающих значения в $\mathbf{R}_{\max }$, но также и в общем случае, при условии, что любое ограниченное сверху подмножество $S$ имеет точную верхнюю грань.

Идемпотентная мера (или мера Маслова) на $X$ определяется как $m_{\psi}(Y)=\sup _{x \in Y} \psi(x)$, где $\psi \in B(X, S), Y \subseteq X$. Интеграл по этой мере имеет вид

$$
I_{\psi}(\varphi)=\int_{X}^{\oplus} \varphi(x) d m_{\psi}=\int_{X}^{\oplus} \varphi(x) \odot \psi(x) d x=\sup _{x \in X}(\varphi(x) \odot \psi(x)) .
$$

Очевидно, что если $S=\mathbf{R}_{\min }$, то стандартный порядок $\preceq$ является противоположным по отношению к обычному порядку $\leq$, поэтому выражение (2) примет вид

$$
\int_{X}^{\oplus} \varphi(x) d m_{\psi}=\int_{X}^{\oplus} \varphi(x) \odot \psi(x) d x=\inf _{x \in X}(\varphi(x) \odot \psi(x)),
$$

где inf понимается в смысле обычного порядка $\leq$.

Отметим, что так называемый псевдо-анализ (см., например, обзор [138]) связан со специальной частью идемпотентного анализа; тем 
не менее, вообще говоря, этот псевдо-анализ выходит за рамки идемпотентной математики. Некоторые обобщения мер Маслова обсуждаются в работах [89, 137].

\section{6. ПРИНЦИП СУПЕРПОЗИЦИИ И ЛИНЕЙНЫЕ ЗАДАЧИ}

Основные уравнения квантовой теории линейны. Это утверждение составляет принцип суперпозиции в квантовой механике. Уравнение Гамильтона-Якоби, которое является основным уравнением классической механики, не является линейным в обычном смысле. Тем не менее, оно линейно над полукольцами $\mathbf{R}_{\max }$ и $\mathbf{R}_{\min }$. Похожим образом различные версии уравнения Беллмана, основного уравнения теории оптимизации, линейны над подходящими полукольцами. В этом состоит идемпотентный принцип суперпозиции В.П.Маслова (см. [119-123]). Например, конечномерное стационарное уравнение Беллмана может быть записано в виде $X=H \odot X \oplus F$, где $X, H, F$ - матрицы с коэффициентами в идемпотентном полукольце $S$, а неизвестная матрица $X$ определяется через $H$ и $F[20]$. В частности, стандартные проблемы динамического программирования и задача поиска кратчайшего пути отвечают случаям $S=\mathbf{R}_{\max }$ и $S=\mathbf{R}_{\min }$ соответственно. В работе [20] оптимизационные алгоритмы на конечном графе поставлены в соответствие стандартным методам решения систем линейных уравнений этого типа (над полукольцами). В частности, алгоритму Беллмана поиска кратчайшего пути соответствует алгоритм Якоби, алгоритму Форда отвечает итерационный метод Гаусса-Зейделя и т.д.

Линейность над $\mathbf{R}_{\min }$ и $\mathbf{R}_{\max }$ уравнения Гамильтона-Якоби (которое является результатом деквантования Маслова уравнения Шредингера) тесно связана с обычной линейностью уравнения Шредингера и может быть выведена из этой линейности. Таким образом, можно заимствовать стандартные идеи и методы из линейного анализа и применять их в новой области.

Рассмотрим классическую динамическую систему, описываемую гамильтонианом

$$
H=H(p, x)=\sum_{i=1}^{N} \frac{p_{i}^{2}}{2 m_{i}}+V(x),
$$

где $x=\left(x_{1}, \ldots, x_{N}\right)$ - обобщенные координаты, $p=\left(p_{1}, \ldots, p_{N}\right)-$ обобщенные импульсы, $m_{i}$ - массы, а $V(x)$-потенциал. В этом 
случае лагранжиан системы $L(x, \dot{x}, t)$ запишется в виде

$$
L(x, \dot{x}, t)=\sum_{i=1}^{N} m_{i} \frac{\dot{x}_{i}^{2}}{2}---V(x),
$$

где $\dot{x}=\left(\dot{x}_{1}, \ldots, \dot{x}_{N}\right), \dot{x}_{i}=d x_{i} / d t$. При этом функция значения функционала действия $S(x, t)$ имеет вид

$$
S=\int_{t_{0}}^{t} L(x(t), \dot{x}(t), t) d t,
$$

где интегрирование ведется вдоль реальной траектории системы. Классические уравнения движения выводятся из условия минимума функционала действия (принцип Гамильтона или принцип наименьшего действия).

Для фиксированных моментов времени $t$ и $t_{0}$ и произвольной траектории $x(t)$, функционал действия $S=S(x(t))$ может быть рассмотрен как функция, переводящая множество кривых (траекторий) во множество вещественных чисел, которое, в свою очередь, может быть интерпретировано как $\mathbf{R}_{\text {min. }}$ В этом случае минимум функционала действия выражается интегралом Маслова по множеству траекторий, т.е. как идемпотентный аналог эвклидовой версии фейнмановского континуального интеграла.

Минимум функционала действия соответствует максимуму функции $e^{-S}$, т.е. идемпотентному интегралу $\int_{\{p a t h s\}}^{\oplus} e^{-S(x(t))} D\{x(t)\}$ по отношению к алгебре $\mathbf{R}_{\text {max }}$. Таким образом, классический принцип наименьшего действия может рассматриваться как идемпотентная версия фейнмановской формулировки квантовой механики. Представление решения уравнения Шредингера в виде континуального интеграла Фейнмана соответствует формуле Лакса-Олейник для уравнения Гамильтона-Якоби.

Поскольку $\partial S / \partial x_{i}=p_{i}, \partial S / \partial t=-H(p, x)$, справедливо следующие уравнение Гамильтона-Якоби:

$$
\frac{\partial S}{\partial t}+H\left(\frac{\partial S}{\partial x_{i}}, x_{i}\right)=0
$$

Квантование (см., например, [48]) приводит к уравнению Шредингера

$$
-\frac{\hbar}{i} \frac{\partial \psi}{\partial t}=\widehat{H} \psi=H\left(\hat{p}_{i}, \hat{x}_{i}\right) \psi
$$

где $\psi=\psi(x, t)$ - волновая функция, т.е. зависящий от времени элемент гильбертового пространства $L^{2}\left(\mathbf{R}^{N}\right)$, а $\widehat{H}$ - оператор энергии, полученный из классической функции Гамильтона заменой переменных $p_{i}$ операторами импульсов $\widehat{p}_{i}=\frac{\hbar}{i} \frac{\partial}{\partial x_{i}}$, и переменных $x_{i}$ - операторами 
координат: $\widehat{x}_{i}: \psi \mapsto x_{i} \psi$. Уравнение Шредингера линейно в обычном смысле (квантовый принцип суперпозиции).

В стандартной процедуре предельного перехода от уравнения Шредингера к уравнению Гамильтона-Якоби используется следующее представление для волновой функции в виде $\psi(x, t)=a(x, t) \cdot e^{i S(x, t) / \hbar}$ и выделение главного члена при $\hbar \rightarrow 0$ (квазиклассический предел).

Вместо этого мы заменим постоянную Планка $\hbar$ мнимой величиной $h=i \hbar$, выбирая $h>0$. Тогда уравнение Шредингера (4) перейдет в обобщенное уравнение теплопроводности:

$$
h \frac{\partial u}{\partial t}=H\left(-h \frac{\partial}{\partial x_{i}}, \hat{x}_{i}\right) u
$$

в котором вещественнозначная функция $u$ соответствует волновой функции $\psi$ (точнее, ее модулю). Похожая идея (переход к мнимому времени) используется в эвклидовой квантовой теории поля (см., например, [130]). Напомним, что время и энергия - дуальные величины.

Линейность уравнения (4) ведет к линейности уравнения (5). Поэтому, если $u_{1}$ и $u_{2}$ - решения уравнения (5), то их линейная комбинация

$$
u=\lambda_{1} u_{1}+\lambda_{2} u_{2}
$$

также является решением уравнения (5). Положим $S=h \ln u$ или $u=e^{S / h}$, как это было сделано выше в разделе 2 . Несложно проверить, что после такой замены уравнение (5) примет вид

$$
\frac{\partial S}{\partial t}=V(x)+\sum_{i=1}^{N} \frac{1}{2 m_{i}}\left(\frac{\partial S}{\partial x_{i}}\right)^{2}+h \sum_{i=1}^{n} \frac{1}{2 m_{i}} \frac{\partial^{2} S}{\partial x_{i}^{2}} .
$$

Таким образом, мы перешли от (4) к (7) при помощи замены переменных $\psi=e^{S / h}$. При этом $|\psi|=e^{\operatorname{Re} S / h}$, где $\operatorname{Re} S-$ вещественная часть $S$. Будем рассматривать теперь $S$ как вещественную переменную. Уравнение (7) нелинейно в обычном смысле. Однако, если $S_{1}$ и $S_{2}-$ его решения, то функция

$$
S=\lambda_{1} \odot S_{1} \oplus_{h} \lambda_{2} \odot S_{2},
$$

полученная из (6) заменой $S=h \ln u$, также является решением уравнения $(7)$. В этом случае обобщенное умножение $\odot$ совпадает с обычным сложением, а обобщенное сложение $\oplus_{h}$ определяется выбранной заменой переменных. При $h \rightarrow 0$, мы получим операции идемпотентного полукольца $\mathbf{R}_{\max }$, то есть, $\oplus=\max$ и $\odot=+$, а уравнение (7) перейдет в уравнение Гамильтона-Якоби (3), так как третье слагаемое в правой части уравнения (7) исчезает.

Естественно рассматривать предельную функцию $S=\lambda_{1} \odot S_{1} \oplus$ $\lambda_{2} \odot S_{2}$ как решение уравнения Гамильтона-Якоби и ожидать, что 
это уравнение можно рассматривать как линейное над $\mathbf{R}_{\max }$. Подобная аргументация (на эвристическом уровне) может быть применена и к уравнениям более общего вида. Строгое обоснование линейности этих уравнений над полукольцами приводится в [52,96, 122, 123] а также в [120]. Отметим, что если $h$ заменить на $-h$, то в результате мы получим линейность уравнения Гамильтона-Якоби над полукольцом $\mathbf{R}_{\text {min }}$.

Идемпотентный принцип суперпозиции показывает, что ряд важных нелинейных (в обычном смысле) задач может быть сведен к задачам, линейным над идемпотентными полукольцами. Таким образом, линейный идемпотентный функциональный анализ (см. ниже) является естественным инструментом для исследования нелинейных бесконечномерных задач, обладающих этим свойством.

\section{7. СВЕРТКА И ПРЕОБРАЗОВАНИЕ ФУРЬЕ-ЛЕЖАНДРА}

Пусть $G$ - некоторая группа. Тогда пространство $B\left(X, \mathbf{R}_{\max }\right)$ всех ограниченных функций $G \rightarrow \mathbf{R}_{\max }$ (см. выше) является идемпотентным полукольцом относительно следущего аналога обычной операции свертки $\circledast$ :

$$
(\varphi(x) \circledast \psi)(g)=\int_{G}^{\oplus} \varphi(x) \odot \psi\left(x^{-1} \cdot g\right) d x=\sup _{x \in G}\left(\varphi(x)+\psi\left(x^{-1} \cdot g\right)\right) .
$$

Разумеется, можно также использовать и другие функциональные пространства (и другие базовые полукольца вместо $\mathbf{R}_{\max }$ ). В работах [96,122] групповые полукольца этого типа называются сверточными полукольиами.

Пусть $G=\mathbf{R}^{n}$, где $\mathbf{R}^{n}$ понимается как топологическая группа относительно векторного сложения. Обычное преобразование ФурьеЛапласа определяется формулой

$$
\varphi(x) \mapsto \tilde{\varphi}(\xi)=\int_{G} e^{i \xi \cdot x} \varphi(x) d x,
$$

где $e^{i \xi \cdot x}$ является характером группы $G$ и решением следующего функционального уравнения

$$
f(x+y)=f(x) f(y) .
$$

Идемпотентный аналог этого уравнения имеет вид

$$
f(x+y)=f(x) \odot f(y)=f(x)+f(y),
$$

поэтому "непрерывные идемпотентные характеры" являются линейными функциями вида $x \mapsto \xi \cdot x=\xi_{1} x_{1}+\cdots+\xi_{n} x_{n}$. В результате преобразование (8) 
переходит в преобразование

$$
\varphi(x) \mapsto \tilde{\varphi}(\xi)=\int_{G}^{\oplus} \xi \cdot x \odot \varphi(x) d x=\sup _{x \in G}(\xi \cdot x+\varphi(x)) .
$$

Преобразование (9) есть не что иное, как преобразование Лежандра (с точностью до обозначений) [121]. Преобразования этого вида устанавливают связь между гамильтоновым и лагранжевым формализмом в классической механике. Преобразование Лежандра порождает идемпотентную версию гармонического анализа в пространстве выпуклых функций (подробнее см., например, [118]).

Разумеется, описанную конструкцию можно обобщить на различные классы групп и полуколец. Преобразования указанного типа переводят обобщенную операцию свертки в поточечное произведение (обобщенное), сохраняя при этом ряд важных свойств обычного преобразования Фурье. Для случая полукольца множеств Парето, соответствующая версия преобразования Фурье сводит задачу многокритериальной оптимизации к семейству однокритериальных задач [152].

Примеры, обсуждаемые в данном разделе, могут рассматриваться как фрагменты идемпотентной теории представлений, см., например, [111]. В частности, "идемпотентные" представления групп можно трактовать как представления соответствующих сверточных полуколещ (т.е. идемпотентных групповых полуколец) в идемпотентных полумодулях.

\section{8. ПРИЛОЖЕНИЯ К СТОХАСТИКЕ И ДВОЙСТВЕННОСТЬ МЕЖДУ ТЕОРИЕЙ ВЕРОЯТНОСТЕЙ И ТЕОРИЕЙ ОПТИМИЗАЦИИ}

Идемпотентные меры Маслова являются неотрицательными (в смысле стандартного порядка), как и вероятностные меры. Аналогия между идемпотентными и вероятностными мерами определяет важную взаимосвязь между теорией оптимизации и теорией вероятностей. K настоящему времени исследован целый ряд идемпотентных аналогов вероятностных конструкций, например макс-плюс мартингалы, максплюс стохастические дифференциальные уравнения и др. Например, полученные результаты позволяют перенести мощные стохастические методы в теорию оптимизации. Это было отмечено и исследовано многими авторами (Г. Салю, П. Дел Морал, М. Акиан, Ж.-П. Квадра, В. П. Маслов, В. Н. Колокольцов, П. Бернар, У. А. Флеминг, У. М. Макэнэни, А. А. Пухальский и др.), см обзорную статью У. А. Флеминга и У. М. Макэнэни [53] и [1, 6, 13, 28, 35-38, 50-52, 69, 122, 141, 143, 144]. По поводу связей и приложений к теории больших уклонений см. [1,35-38, 142], и особенно книгу А. А. Пухальского [141]. 


\section{9. ИДЕМПОТЕНТНЫЙ ФУНКЦИОНАЛЬНЫЙ АНАЛИЗ}

Для многих конструкций и результатов традиционной математики можно указать интересные идемпотентные аналоги. В частности, это относится к основным конструкциям и теоремам функционального анализа. Идемпотентный функциональный анализ является абстрактной версией идемпотентного анализа. Для простоты изложения положим $S=\mathbf{R}_{\max }$, и пусть $X-$ произвольное множество. Идемпотентное интегрирование задается формулой (1), написанной выше. Функционал $I(\varphi)$ линеен над $S$, и его значения соответствуют предельным значениям соответствующих аналогов сумм Лебега (или Римана). Идемпотентное скалярное произведение двух функций $\varphi$ и $\psi$ определяется формулой

$$
\langle\varphi, \psi\rangle=\int_{X}^{\oplus} \varphi(x) \odot \psi(x) d x=\sup _{x \in X}(\varphi(x) \odot \psi(x)) .
$$

Поэтому естественно построить идемпотентные аналоги интегральных операторов в виде

$$
\varphi(y) \mapsto(K \varphi)(x)=\int_{Y}^{\oplus} K(x, y) \odot \varphi(y) d y=\sup _{y \in Y}\{K(x, y)+\varphi(y)\},
$$

где $\varphi(y)$ - элемент пространства функций, определенных на множестве $Y$, а $K(x, y)$ - функция, заданная на $X \times Y$, и принимающая значения в $S$. Как известно, выражения подобного типа стандартны для теории оптимизации.

Напомним, что описанные выше определения и конструкции могут быть успешно обобщены на случай идемпотентных полуколец, которые условно полны в смысле стандартного порядка. Используя интеграл Маслова, можно сконструировать различные функциональные пространства, а также идемпотентную версию теории обобщенных функций (распределений). Для некоторых конкретных идемпотентных функциональных пространств доказано, что каждый “хороший” линейный (в идемпотентном смысле) оператор может быть представлен в виде (10). Это утверждение является идемпотентной версией теоремы Л. Шварца о ядре; результаты такого рода были получены В. Н. Колокольцовым, П. С. Дудниковым, и С. Н. Самборским, И. Зингером, М. А. Шубиным и другими авторами, см.,например, [44,96,122,123,158]. Таким образом, каждый "хороший" линейный функционал представим в виде $\varphi \longmapsto\langle\varphi, \psi\rangle$, где $\langle$,$\rangle - идемпотентное скалярное произведение.$

В рамках идемпотентного функционального анализа результаты этого типа могут быть доказаны в очень общей ситуации. В работах [108-112] развита алгебраическая версия идемпотентного функционального анализа. Это означает, что основные топологические понятия и 
результаты моделируются в чисто алгебраических терминах. Построенная теория охватывает предмет, начиная с основных понятий и результатов (например, идемпотентных аналогов знаменитых теорем Хана-Банаха, Банаха-Штейнгауза, Рисса и Рисса-Фишера) и включая идемпотентные аналоги определений и результатов А.Гротендика (A.Grothendieck) по топологическим тензорным произведениям, ядерным пространствам и операторам. Сформулирована абстрактная версия теоремы о ядре. Отметим, что переход от обычной теории к идемпотентному функциональному анализу может быть весьма нетривиальным. Так, например, существует много неизоморфных идемпотентных гильбертовых пространств. Важные результаты идемпотентного функционального анализа (теоремы о двойственности и отделимости) недавно опубликовали Г. Коэн, С. Гобер, и Ж.-П. Квадра [26]; конечномерная версия теоремы об отделимости опубликована в [183]. Последнее время идемпотентный функциональный анализ привлекает повышенное внимание, см., например, [2-5,27,68,105,113,149,158,159,178] и работы, цитированные выше.

\section{0. ПРЕОБРАЗОВАНИЕ ДЕКВАНТОВАНИЯ И ОБОБЩЕНИЕ МНОГОГРАННИКОВ НЬЮТОНА}

В этом разделе мы кратко обсудим результаты, опубликованные в работе [113]. Для функций, определенных на $\mathbf{C}^{n}$ почти всюду, можно построить преобразование деквантования $f \rightarrow \hat{f}$, порожденное деквантованием Маслова. Для полиномиальной функции $f$ субдифференциал $\partial \hat{f}$ функции $\hat{f}$ совпадает с многогранником Ньютона полинома $f$. Для полукольца полиномов с неотрицательными коэффициентами преобразование деквантования является гомоморфизмом этого полукольца в идемпотентное полукольцо выпуклых многогранников относительно хорошо известных операций Минковского. Эти результаты могут быть обобщены на широкий класс функций и выпуклых множеств.

10.1. Преобразование деквантования. Рассмотрим топологическое пространство $X$. Для функций $f(x)$, определенных на $X$, будем говорить, что некоторое свойство выполняется почти всюду (п.в.), если оно справедливо для всех элементов $x$ из открытого всюду плотного подмножества в $X$. Выберем в качестве $X$ множество $\mathbf{C}^{n}$ или $\mathbf{R}^{n}$; обозначим через $\mathbf{R}_{+}^{n}$ множество $x=\left\{\left(x_{1}, \ldots, x_{n}\right) \in X\right.$ $x_{i} \geq 0$, где $\left.i=1,2, \ldots, n\right\}$. Для $x=\left(x_{1}, \ldots, x_{n}\right) \in X$ положим $\exp (x)=\left(\exp \left(x_{1}\right), \ldots, \exp \left(x_{n}\right)\right)$; таким образом, если $x \in \mathbf{R}^{n}$, то $\exp (x) \in \mathbf{R}_{+}^{n}$. 
Обозначим через $\mathcal{F}\left(\mathbf{C}^{n}\right)$ множество всех функций, непрерывных на открытом всюду плотном подмножестве $U \subset \mathbf{C}^{n}$, причем $U \supset$ $\mathbf{R}_{+}^{n}$. Во всех ниже приведенных примерах мы рассмотрим даже более регулярные функции, которые голоморфны в $U$. Очевидно, что $\mathcal{F}\left(\mathbf{C}^{n}\right)$ - кольцо (и алгебра над $\mathbf{C}$ ) по отношению к обычному сложению и умножению функций.

Для $f \in \mathcal{F}\left(\mathbf{C}^{n}\right)$ определим функцию $\hat{f}_{h}$ по следующей формуле:

$$
\hat{f}_{h}(x)=h \log |f(\exp (x / h))|,
$$

где $h$ (малый) вещественный параметр, а $x \in \mathbf{R}^{n}$. Положим

$$
\hat{f}(x)=\lim _{h \rightarrow 0} \hat{f}_{h}(x),
$$

если предел в правой части равенства (12) существует почти всюду. Назовем функцию $\hat{f}(x)$ деквантованием функции $f(x)$, а преобразование $f(x) \mapsto \hat{f}(x)$ - преобразованием деквантования. По построению $\hat{f}_{h}(x)$ и $\hat{f}(x)$ могут быть рассмотрены как функции, принимающие значения в $\mathbf{R}_{\text {max }}$. Отметим, что на самом деле $\hat{f}_{h}(x)$ и $\hat{f}(x)$ зависят только от сужения функции $f$ на подмножество $\mathbf{R}_{+}^{n}$; поэтому фактически преобразование деквантования задается для функций, определенных только на $\mathbf{R}_{+}^{n}$. Понятно, что преобразование деквантования порождено деквантованием Маслова и отображением $x \mapsto|x|$. Разумеется, аналогичные определения могут быть даны и для функций, заданных на $\mathbf{R}^{n}$ и $\mathbf{R}_{+}^{n}$.

Обозначим через $V$ множество $\mathbf{R}^{n}$, рассматриваемое как линейное эвклидово пространство (со скалярным произведением $(x, y)=x_{1} y_{1}+$ $\left.x_{2} y_{2}+\cdots+x_{n} y_{n}\right)$ и положим $V_{+}=\mathbf{R}_{+}^{n}$. Назовем функцию $f \in$ $\mathcal{F}\left(\mathbf{C}^{n}\right)$ деквантуемой, если ее деквантование $\hat{f}(x)$ существует (и определено на открытом всюду плотном подмножестве в $V)$. Обозначим через $\mathcal{D}\left(\mathbf{C}^{n}\right)$ множество всех деквантуемых функций и пусть $\widehat{\mathcal{D}}(V)$ означает множество $\left\{\hat{f} \mid f \in \mathcal{D}\left(\mathbf{C}^{n}\right)\right\}$. Напомним, что функции из $\mathcal{D}\left(\mathbf{C}^{n}\right)$ (и $\left.\widehat{\mathcal{D}}(V)\right)$ определены почти всюду и равенство $f=g$ означает, что $f(x)=g(x)$ для любого $x$ из открытого всюду плотного подмножества в $\mathbf{C}^{n}$ (соответственно в $V$ ). Обозначим через $\mathcal{D}_{+}\left(\mathbf{C}^{n}\right)$ множество всех функций $f \in \mathcal{D}\left(\mathbf{C}^{n}\right)$ таких, что $f\left(x_{1}, \ldots, x_{n}\right) \geq 0$, если $x_{i} \geq 0$ для $i=1, \ldots, n$; тогда $f \in \mathcal{D}_{+}\left(\mathbf{C}^{n}\right)$, если сужение $f$ на $V_{+}=\mathbf{R}_{+}^{n}$ является неотрицательной функцией. Обозначим полученный в результате деквантования образ множества $\mathcal{D}_{+}\left(\mathbf{C}^{n}\right)$ через $\widehat{\mathcal{D}}_{+}(V)$. Говорят, что функции $f, g \in \mathcal{D}\left(\mathbf{C}^{n}\right)$ находятся в общем положении, если $\hat{f}(x) \neq \widehat{g}(x)$ для элементов $x$, пробегающих открытое всюду плотное множество в $V$. 
Для функций $f, g \in \mathcal{D}\left(\mathbf{C}^{n}\right)$ и ненулевой константы $c$, верны следующие равенства:

1) $\widehat{f g}=\hat{f}+\widehat{g}$

2) $|\hat{f}|=\hat{f} ; \widehat{c f}=f ; \widehat{c}=0$;

3) $(\widehat{f+g})(x)=\max \{\hat{f}(x), \widehat{g}(x)\}$ п.в., если $f$ и $g$ неотрицательны на $V_{+}$(то есть $\left.f, g \in \mathcal{D}_{+}\left(\mathbf{C}^{n}\right)\right)$, или $f$ и $g-$ функции общего положения.

Левые части этих уравнений определены автоматически.

Множество $\mathcal{D}_{+}\left(\mathbf{C}^{n}\right)$ имеет естественную структуру полукольца относительно обычного сложения и умножения функций, принимающих значение в С. Множество $\widehat{\mathcal{D}}_{+}(V)$ имеет естественную структуру идемпотентного полукольца относительно операций $(f \oplus g)(x)=$ $\max \{f(x), g(x)\},(f \odot g)(x)=f(x)+g(x) ;$ элементы из $\widehat{\mathcal{D}}_{+}(V)$ можно рассматривать как функции, принимающие значения в $\mathbf{R}_{\max }$. Преобразование деквантования порождает гомоморфизм из $\mathcal{D}_{+}\left(\mathbf{C}^{n}\right)$ в $\widehat{\mathcal{D}}_{+}(V)$.

10.2. Простые функции. Для любого ненулевого числа $a \in \mathbf{C}$ и любого вектора $d=\left(d_{1}, \ldots, d_{n}\right) \in V=\mathbf{R}^{n}$ положим $m_{a, d}(x)=$ $a \prod_{i=1}^{n} x_{i}^{d_{i}} ;$ функции такого вида будем называть обобщенными мономами. Обобщенные мономы определены п.в. на $\mathrm{C}^{n}$ и на $V_{+}$, но не на $V$, исключая случай, когда $d_{i}$ являются целыми или подходящими рациональными числами. Назовем функцию $f$ обобщенным полиномом, если она представляет собой конечную сумму линейно независимых обобщенных мономов. Например, полиномы Лорана являются обобщенными полиномами.

Как обычно, для $x, y \in V$ положим $(x, y)=x_{1} y_{1}+\cdots+x_{n} y_{n}$. Легко показать, что если $f$ - обобщенный моном $m_{a, d}(x)$, то $\hat{f}-$ линейная функция $x \mapsto(d, x)$. Если $f-$ обобщенный полином, то $\hat{f}$ - сублинейная функция.

Напомним, что вещественная функция $p$, определенная на $V=$ $\mathbf{R}^{n}$, сублинейна, если $p=\sup _{\alpha} p_{\alpha}$, где $\left\{p_{\alpha}\right\}-$ семейство линейных функций. Сублинейные функции, определенные всюду на $V=\mathbf{R}^{n}$, выпуклы; следовательно, они непрерывны. В дальнейшем мы будем рассматривать только такие сублинейные функции. Пусть $p-$ непрерывная функция на $V$, тогда $p$ сублинейна в точности тогда, когда

1) $p(x+y) \leq p(x)+p(y)$ для всех $x, y \in V$;

2) $p(c x)=c p(x)$ для всех $x \in V, c \in \mathbf{R}_{+}$.

Если $p_{1}, p_{2}-$ сублинейные функции, то $p_{1}+p_{2}$ также является сублинейной функцией.

Назовем функцию $f \in \mathcal{F}\left(\mathbf{C}^{n}\right)$ простой, если ее деквантование $\hat{f}$ существует и п.в. совпадает с некоторой сублинейной функцией. 
Допуская вольность речи, будем обозначать эту (однозначно определенную всюду на $V$ ) сублинейную функцию тем же символом $\hat{f}$.

Напомним, что простые функции $f$ и $g$ являются функциями в общем положении, если $\hat{f}(x) \neq \widehat{g}(x)$ для всех $x$ из открытого всюду плотного множества в $V$. В частности, обобщенные мономы находятся в общем положении тогда и только тогда, когда они линейно независимы.

Обозначим через $\operatorname{Sim}\left(\mathbf{C}^{n}\right)$ - множество всех простых функций, определенных на $V$, и обозначим через $\operatorname{Sim}_{+}\left(\mathbf{C}^{n}\right)$ множество $\operatorname{Sim}\left(\mathbf{C}^{n}\right) \cap \mathcal{D}_{+}\left(\mathbf{C}^{n}\right)$. Через $\operatorname{Sbl}(V)$ обозначим множество всех (непрерывных) сублинейных функций, определенных на $V=\mathbf{R}^{n}$, а через $S b l_{+}(V)$ обозначим образ $\widehat{\operatorname{Sim}_{+}}\left(\mathbf{C}^{n}\right)$ множества $\operatorname{Sim}_{+}\left(\mathbf{C}^{n}\right)$ при преобразовании деквантования.

Множество $\operatorname{Sim}_{+}\left(\mathbf{C}^{n}\right) \quad$ является подполукольцом в $\mathcal{D}_{+}\left(\mathbf{C}^{n}\right)$, и $S b l_{+}(V)$ является идемпотентным подполукольцом в $\widehat{\mathcal{D}_{+}}(V)$. Преобразование деквантования порождает эпиморфизм полукольца $\operatorname{Sim}_{+}\left(\mathbf{C}^{n}\right)$ на $S b l_{+}(V)$. Множество $S b l(V)$ является идемпотентным полукольцом относительно операций $(f \oplus g)(x)=\max \{f(x), g(x)\},(f \odot g)(x)=$ $f(x)+g(x)$.

Конечно, полиномы и обобщенные полиномы являются простыми функциями.

Будем говорить, что функции $f, g \in \mathcal{D}(V)$ асимптотически эквивалентны, если $\hat{f}=\widehat{g}$; простую функцию $f$ назовем асимптотическим мономом, если $\hat{f}$ - линейная функция. Простая функция $f$ будет называться асимптотическим полиномом, если $\hat{f}$ является суммой конечного числа неэквивалентных асимптотических мономов. Каждый асимптотический полином является простой функцией.

Пример. Примерами асимптотических полиномов служат обобщенные полиномы, логарифмические функции от (обобщенных) полиномов, произведения полиномов и логарифмических функций. Это следует из наших определений и формулы (11).

\section{3. Субдифференциалы сублинейных функций и множества} Ньютона для простых функций. Хорошо известно, что совокупность всех выпуклых компактных подмножеств в $\mathbf{R}^{n}$ образует идемпотентное полукольцо $\mathcal{S}$ относительно операций Минковского: для $A, B \in \mathcal{S}$ сумма $A \oplus B$ является выпуклой оболочкой объединения $A \cup B$; произведение $A \odot B$ определяется следующим образом: $A \odot B=\{x \mid$ $x=a+b$, где $a \in A, b \in B\}$. На самом деле множество $\mathcal{S}$ является идемпотентным линейным пространством над $\mathbf{R}_{\max }$ (см., например, работу [110]). Разумеется, многогранники Ньютона в пространстве $V$ образуют подполукольцо $\mathcal{N}$ в $\mathcal{S}$. 
Воспользуемся некоторыми элементарными результатами из выпуклого анализа. Эти результаты можно найти, например, в книге [118].

Для любой функции $p \in \operatorname{Sbl}(V)$ положим

$$
\partial p=\{v \in V \mid(v, x) \leq p(x) \forall x \in V\} .
$$

Из выпуклого анализа хорошо известно, что для любой сублинейной функции $p$ множество $\partial p$ есть в точности субдифференииал от $p$ в нулевой точке. Следующее утверждение также хорошо известно из выпуклого анализа:

Предложение 1. Пусть $p_{1}, p_{2} \in S b l(V)$, тогдa

$$
\begin{gathered}
\partial\left(p_{1}+p_{2}\right)=\partial p_{1} \odot \partial p_{2}= \\
\left\{v \in V \mid v=v_{1}+v_{2}, \text { zдe } v_{1} \in \partial p_{1}, v_{2} \in \partial p_{2}\right\} ; \\
\partial\left(\max \left\{p_{1}(x), p_{2}(x)\right\}\right)=\partial p_{1} \oplus \partial p_{2} .
\end{gathered}
$$

Пусть $p \in \operatorname{Sbl}(V)$. Тогда $\partial p$ - непустое выпуклое компактное подмножество в $V$.

Следствие 1. Отображение $p \mapsto \partial p$ является гомоморфизмом идемпотентного полукольиа $\operatorname{Sbl}(V)$ в идемпотентное полукольцо $\mathcal{S}$ всех выпуклых компактных подмножеств множества $V$.

Для любой простой функции $f \in \operatorname{Sim}\left(\mathbf{C}^{n}\right)$ обозначим через $N(f)$ множество $\partial(\hat{f})$. Назовем $N(f)$ множеством Ньютона для функции $f$. Из приведенного утверждения следует, что для любой простой функции $f$ ее множество Ньютона $N(f)$ является непустым выпуклым компактным подмножеством в $V$.

Теорема. Пусть $f$ и $g$ - простые функции. Тогда

1) $N(f g)=N(f) \odot N(g)=\left\{v \in V \mid v=v_{1}+v_{2}\right.$, где $v_{1} \in$ $\left.N(f), v_{2} \in N(g)\right\}$

2) $N(f+g)=N(f) \oplus N(g)$, если $f_{1}$ и $f_{2}-$ функиии в общем положении или $f_{1}, f_{2} \in \operatorname{Sim}_{+}\left(\mathbf{C}^{n}\right)$ (напомним, что $N(f) \oplus$ $N(g)$ есть выпуклая оболочка множества $N(f) \cup N(g))$.

Следствие 2. Преобразование $f \mapsto N(f)$ порождает гомоморфизм из $\operatorname{Sim}_{+}\left(\mathbf{C}^{n}\right)$ в $\mathcal{S}$.

Предложение 2. Пусть $f=m_{a, d}(x)=a \prod_{i=1}^{n} x_{i}^{d_{i}}-$ (обобщенный) моном; здесь $d=\left(d_{1}, \ldots, d_{n}\right) \in V=\mathbf{R}^{n}$ и а-ненулевое комплексное число. Тогда $N(f)=\{d\}$.

Следствие 3. Пусть $f=\sum_{d \in D} m_{a_{d}, d}-$ (обобщенный) полином. Тогда $N(f)$ - многогранник $\bigoplus_{d \in D}\{d\}$, т.е. линейная оболочка конечного множества D. 
Этот вывод следует из Теоремы и Предложения 2. В этом случае $N(f)$ - хорошо известный классический многогранник Ньютона полинома $f$. Поэтому следующее следствие очевидно:

Следствие 4. Пусть $f$ - обобщенный или асимптотический полином. Тогда его множество Нъютона $N(f)$ является выпуклым многогранником.

Пример. Рассмотрим одномерный случай, т.е. $V=\mathbf{R}$ и положим $f_{1}=a_{n} x^{n}+a_{n-1} x^{n-1}+\cdots+a_{0}$ и $f_{2}=b_{m} x^{m}+b_{m-1} x^{m-1}+\cdots+b_{0}$, где $a_{n} \neq 0, b_{m} \neq 0, a_{0} \neq 0, b_{0} \neq 0$. Тогда $N\left(f_{1}\right)$ совпадает с отрезком $[0, n]$ и $N\left(f_{2}\right)$ - с отрезком $[0, m]$. Поэтому преобразование $f \mapsto N(f)$ соответствует преобразованию $f \mapsto \operatorname{deg}(f)$, где $\operatorname{deg}(f)-$ степень полинома $f$. При этом в соответствии с Теоремой $\operatorname{deg}(f g)=\operatorname{deg} f+$ $\operatorname{deg} g$ и $\operatorname{deg}(f+g)=\max \{\operatorname{deg} f, \operatorname{deg} g\}=\max \{n, m\}$, если $a_{i} \geq 0$, $b_{i} \geq 0$ или если $f$ и $g$ - находятся в общем положении.

\section{1. ДЕКВАнтовАнИЕ ГЕОМЕТРИИ}

Идемпотентная версия вещественной алгебраической геометрии была открыта О. Виро и представлена в его докладе на конгрессе в Барселоне [172]. Исходя из идемпотентного принципа соответствия, О. Виро построил кусочно-линейную геометрию многогранников специального вида в конечномерных эвклидовых пространствах как результат деквантования Маслова обычной вещественной алгебраической геометрии. Он указал на важные приложения к вещественной алгебраической геометрии (например, в рамках 16-ой проблемы Гильберта о построении вещественного алгебраического многообразия с предписанными свойствами и параметрами) и на связь с комплексной алгебраической геометрией и амебами в смысле И. М. Гельфанда, М. М. Капранова и А. В. Зелевинского (см. их книгу [61] и статью О. Виро [173]). Затем комплексная алгебраическая геометрия была деквантована Г. Михалкиным с тем же результатом; эта новая "идемпотентная" (или асимптотическая) геометрия теперь часто называется тропической алгебраической геометрией, см., например, [47, 72, 126-129, 146, 155, 164, 166].

Существует естественная связь между деквантованием Маслова и амебами. Пусть $\left(\mathbf{C}^{*}\right)^{n}-$ комплексный тор , где $\mathbf{C}^{*}=\mathbf{C} \backslash\{0\}-$ группа ненулевых комплексных чисел по умножению. Для $z=$ $\left(z_{1}, \ldots, z_{n}\right) \in\left(\mathbf{C}^{*}\right)^{n}$ и положительного вещественного числа $h$ обозначим через $\log _{h}(z)=h \log (|z|)$ элемент

$$
\left(h \log \left|z_{1}\right|, h \log \left|z_{2}\right|, \ldots, h \log \left|z_{n}\right|\right) \in \mathbf{R}^{n} .
$$

Рассмотрим комплексное алгебраическое многообразие $V \subset\left(\mathbf{C}^{*}\right)^{n}$; обозначим через $\mathcal{A}_{h}(V)$ множество $\log _{h}(V)$. Если $h=1$, то множество $\mathcal{A}(V)=\mathcal{A}_{1}(V)$ называется амебой в $V$ в смысле книги [61], см. 


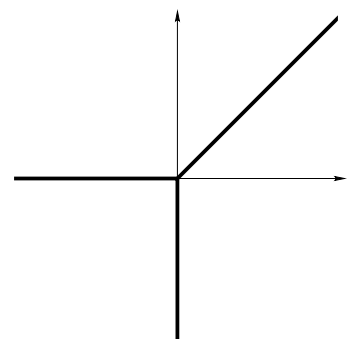

(a)

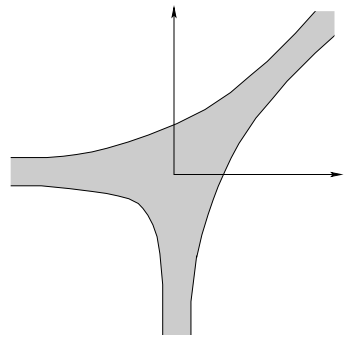

(b)

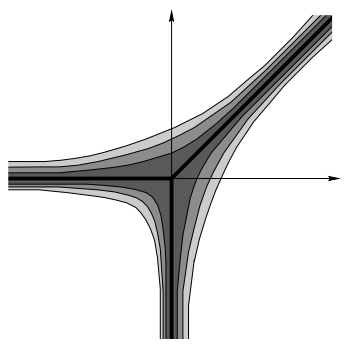

(c)

Рис. 3. Тропическая прямая и амебы.

также $[7,126,128,129,139,155,161,173]$. Амеба $\mathcal{A}(V)$ является замкнутым подмножеством в $\mathbf{R}^{n}$ с непустым дополнением. Отметим, что приведенная конструкция зависит от выбора системы координат.

Для простоты выберем в качестве $V$ гиперповерхность в $\left(\mathbf{C}^{*}\right)^{n}$, определяемую полиномом $f$; тогда существует деформация этого полинома $h \mapsto f_{h}$, порожденная деквантованием Маслова, и $f_{h}=f$ для $h=1$. Пусть $V_{h} \subset\left(\mathbf{C}^{*}\right)^{n}$ является множеством нулей полинома $f_{h}$, и $\mathcal{A}_{h}\left(V_{h}\right)=\log _{h}\left(V_{h}\right)$. Тогда существует тропическое многообразие $\operatorname{Tro}(V)$, такое что подмножества $\mathcal{A}_{h}\left(V_{h}\right) \subset \mathbf{R}^{n}$ сходятся к $\operatorname{Tro}(V)$ в метрике Хаусдорфа при $h \rightarrow 0$, см. [126,151]. Тропическое многообразие $\operatorname{Tro}(V)$ является результатом деформации амебы $\mathcal{A}(V)$ и деквантования Маслова многообразия $V$. Множество $\operatorname{Tro}(V)$ получило название скелета амебы $\mathcal{A}(V)$.

Пример [126]. Для прямой $V=\left\{(x, y) \in\left(\mathbf{C}^{*}\right)^{2} \mid x+y+1=0\right\}$ кусочно линейный граф $\operatorname{Tro}(V)$ представляет собой тропическую прямую, см. рис. 3(a). Амеба $\mathcal{A}(V)$ показана на рис. 3(b), тогда как рис. $3(\mathrm{c})$ демонстрирует соответствующую деформацию амебы.

В важной работе [80] (см. также $[47,126,128,146])$ тропические многообразия возникают как амебы над неархимедовыми полями.

В 2000 году М. Концевич заметил, что возможно использование неархимедовых амеб в перечислительной геометрии, см. [126, раздел 2.4, замечание 4]. Методы тропической геометрии имеют важные приложения в алгебраической перечислительной геометрии, инвариантах Громова-Виттена и Вельшенже, см. [59,72-75, 126-129, 155, 156]. В частности, Г. Михалкин представил и доказал в [127,129] формулу, перечисляющую кривые произвольного рода на торической поверхности (см. также работы $[60,72,73,131,155]$ ).

В последнее время появилось много других работ по тропической алгебраической геометрии и ее приложениям к обычной (например, комплексной) алгебраической геометрии, а также к другим областям, 
см., например $[7,55,56,76,131,134,135,168,169,171]$. Дело в том, что некоторые трудные традиционные задачи могут быть сведены к их тропическим версиям, которые, как можно надеяться, не так трудны.

Заметим, что тропическая геометрия тесно связана с известной программой М. Концевича и Я. Сойбельмана, см., например, [98, 99].

Введение в тропическую алгебраическую геометрию изложено в работе [146] (см. также [166]). Тем не менее, в целом сделаны лишь первые шаги в тропической/идемпотентной геометрии, и задача систематического построения идемпотентных версий алгебраической и аналитической геометрии остается открытой.

\section{2. ПРИНЦИП СООТВЕТСТВИЯ ДЛЯ АЛГОРИТМОВ И ИХ КОМПЬЮТЕРНАЯ РЕАЛИЗАЦИЯ}

В идемпотентной математике имеется большое количество важных прикладных алгоритмов, см., например, [9, 18, 21, 30, 31, 49, 52, 53, 67-69, 72, 84, 87, 93, 96, 102, 104, 106, 107, 114-116, 127, 129, 146, 150, $166,174-176,179,186,187]$. Идемпотентный принцип соответствия справедлив как для алгоритмов, так и для их программной и аппаратной реализации [102-104, 106, 107]. В частности, благодаря принципу суперпозиции, особую важность приобретают алгоритмы линейной алгебры. Хорошо известно, что алгоритмы линейной алгебры удобны для параллельных вычислений; их идемпотентные аналоги также допускают распараллеливание. Поэтому имеется регулярный способ использовать параллельные вычисления для решения многих задач, включая основные задачи оптимизации. При этом удобно использовать универсальные алгоритмы, не зависящие от конкретного полукольца и от его конкретной компьютерной модели. Программная реализация полукольцевых универсальных алгоритмов строится на объектноориентированном и обобщенном (generic) программировании; программные модули имеют дело с абстрактными (переменными) операциями и типами данных, см. [102, 104, 106, 107, 116].

Наиболее важные и стандартные алгоритмы имеют много аппаратных реализаций в виде технических устройств или специальных процессоров. Такие устройства могут стать прототипами новых аппаратных устройств, порожденных заменой традиционных арифметических операций на их полукольцевые аналоги, см. [102,104,107]. Удачные и эффективные технические идеи и решения могут быть перенесены из прототипов в новые аппаратные устройства. Таким образом принцип соответствия 
порождает регулярный эвристический метод для конструирования многочисленных устройств.

\section{3. ИДЕМПОТЕНТНЫЙ ИНТЕРВАЛЬНЫЙ АНАЛИЗ}

Идемпотентная версия традиционного интервального анализа изложена в работах $[114,115]$. Пусть $S$ - идемпотентное полукольцо, наделенное стандартным порядком. Замкнутым интервалом в $S$ назовем множество вида $\mathbf{x}=[\underline{\mathbf{x}}, \overline{\mathbf{x}}]=\{x \in S \mid \underline{\mathbf{x}} \preceq x \preceq \overline{\mathbf{x}}\}$, где элементы $\underline{\mathbf{x}} \preceq \overline{\mathbf{x}}$ называются нижней и верхней границами интервала х. Слабым интервальным расширением $I(S)$ полукольца $S$ назовем множество всех замкнутых интервалов $S$ с операциями $\oplus$ и $\odot$, определенными следующим образом: $\mathbf{x} \oplus \mathbf{y}=[\underline{\mathbf{x}} \oplus \underline{\mathbf{y}}, \overline{\mathbf{x}} \oplus \overline{\mathbf{y}}], \mathbf{x} \odot \mathbf{y}=[\underline{\mathbf{x}} \odot \underline{\mathbf{y}}, \overline{\mathbf{x}} \odot$ $\overline{\mathbf{y}}$. Множество $I(S)$ является новым идемпотентным полукольцом относительно этих операций. Доказано, что основные интервальные задачи идемпотентной линейной алгебры имеют полиномиальную сложность, тогда как в обычном интервальном анализе задачи такого типа в общем случае имеют NP-сложность. Точные интервальные решения для дискретного стационарного уравнения Беллмана (см. матричные уравнения, рассмотренные выше, в разделе 6) и для соответствующих оптимизационных задач построены Г. Л. Литвиновым и А. Н. Соболевским $[114,115]$. Близкие результаты были получены в работе [22].

\section{4. СВЯЗЬ С КАМ ТЕОРИЕЙ И ОПТИМАЛЬНЫМ ТРАНСПОРТОМ}

Предмет теории Колмогорова-Арнольда-Мозера (KAM) можно формулировать как изучение инвариантных подмножеств в фазовых пространствах неинтегрируемых гамильтоновых динамических систем, имеющих ту же динамику и ту же степень регулярности, что и интегрируемые системы (квазипериодическое поведение). В последнее время заметный прогресс был достигнут благодаря вариационному подходу, в котором динамика задается не гамильтонианом, а лагранжианом. Соответствующая теория была инициирована работами С. Обри (S. Aubry) и Дж. Н. Мезера (J. N. Mather) и недавно названа слабой KAM теорией в работах А. Фати (A. Fathi) (готовится к выходу его монография "Weak KAM Theorems in Lagrangian Dynamics" , см., также работы $[82,83,159,160])$. Минимизация некоторого функционала вдоль траекторий движущихся частиц является центральным пунктом другой теории, а именно, теории оптимального транспорта, которая интенсивно развивается. Эта теория восходит к работе Г. Монжа "О выемках и насыпях" (1781). Современная версия теории носит название теория оптимального транспорта Монжа-Ампера-Канторовича 
(MAK) (название возникло после работы Л. В. Канторовича [79]). Имеется сходство между этими двумя теориями и имеются взаимосвязи с задачами идемпотентного функционального анализа (например, с задачей о собственных функциях “идемпотентных" интегральных операторов, см. [159]). Приложения теории оптимального транспорта к теории обработки данных в космологии рассматриваются, например, в работах $[15,58]$.

\section{5. СВЯЗЬ С ЛОГИКОЙ, НЕЧЕТКИМИ МНОЖЕСТВАМИ И ТЕОРИЕЙ ВОЗМОЖНОСТЕЙ}

Пусть $S$ - идемпотентное полукольцо с нейтральными элементами $\mathbf{0}$ и 1 (напомним, что $\mathbf{0} \neq \mathbf{1}$, см. разд. 2). Тогда булева алгебра $\mathbf{B}=\{\mathbf{0}, \mathbf{1}\}$ является естественным подполукольцом в $S$. Поэтому $S$ может рассматриваться как обобщенная (расширенная) логика с логическими операциями $\oplus$ (дизъюнкция) и $\odot$ (конъюнкция). Идеи такого рода обсуждаются во многих статьях и монографиях, посвященных обобщенным версиям классической и, особенно, квантовой логики, см., например, [42, 64, 90, 147, 148].

Пусть $\Omega$ является так называемым универсумом, состоящим из “элементарных событий”. Обозначим через $\mathcal{F}(S)$ множество функций, заданных на $\Omega$ и принимающих значения в $S$; тогда $\mathcal{F}(S)$ представляет собой идемпотентное полукольцо относительно поточечного сложения и умножения функций. Назовем элементы из $\mathcal{F}(S)$ обобщенными нечеткими множествами, см. работы [64,100]. Если $S=\mathbf{P}$, где $\mathbf{P}$ - отрезок $[0,1]$ с операциями $\oplus=\max$ и $\odot=\min$, то мы получим классическое определение нечеткого множества (Л. А. Заде [180]). Разумеется, функции из $\mathcal{F}(\mathbf{P})$, принимающие значения в булевой алгебре $\mathbf{B}=\{0,1\} \subset \mathbf{P}$ соответствуют обычным множествам из $\Omega$, а полукольцевые операции отвечают стандартным операциям над множествами. В общем случае функции из $\mathcal{F}(S)$, принимающие значения в $\mathbf{B}=\{\mathbf{0}, \mathbf{1}\} \subset S$, могут рассматриваться как подмножества в $\Omega$. Если $S-$ решетка (т.е. $x \odot y=\inf \{x, y\}$ и $x \oplus y=\sup \{x, y\}$ ), то обобщенные нечеткие множества совпадают с $L$-нечеткими множествами в смысле Дж. А. Гогена [63]. Множество интервалов $I(S)$ является идемпотентным полукольцом, (см. раздел. 11), поэтому элементы из $\mathcal{F}(I(S))$ могут рассматриваться как интервальные (обобщенные) нечеткие множества.

Как хорошо известно, классическая теория нечетких множеств лежит в основе теории возможностей [43, 181]. Разумеется, исходя из обобщенной теории нечетких множеств, можно аналогичным образом развить обобщенную теорию возможностей (см., например, 
[43, 90, 100]. Обобщенные теории могут быть некоммутативными; они выглядят более качественными и менее количественными по сравнению с обычной теорией, представленной в работах [180,181]. Мы видим, что идемпотентный анализ и теория (обобщенных) нечетких множеств имеют дело с одними и теми же объектами, а именно с функциями, принимающими значения в полукольцах. Тем не менее, основные задачи и методы для обоих теорий могут отличаться (как это происходит с теорией меры и теорией вероятностей).

\section{6. ПРИЛОЖЕНИЯ К ДРУГИМ ОБЛАСТЯМ И К СМЕЖНЫМ HAYKAM}

Выше обсуждались некоторые приложения идемпотентной математики к различным теоретическим и прикладным областям математической науки и взаимосвязи идемпотентной математики с другими областями. Разумеется, очень естественной областью для приложений идей и методов идемпотентной математики являются теория оптимизации и теория оптимального управления. По этой теме имеется очень хорошая обзорная статья В. Н. Колокольцова [93]; см., также работы $[9,18,21,25,28-31,35,37,38,50-53,67-69,102,104,114,115,117,119-$ $124,144,174-176,179,186,187]$.

Существует много интересных приложений к дифференциальным уравнениям и к стохастическим дифференциальным уравнениям, см., например, [50-53, 69, 91, 92, 94, 96, 119-123, 138, 159, 160].

Приложения к теории игр обсуждаются, например, в [95,96,122]. Существуют интересные приложения в биологии (биоинформатике), см., например, $[49,135,150]$. Связь с математической морфологией и возможные приложения рассматриваются в статье П. Дел Морала и М. Дуази [38] и особенно в расширенной препринтной версии этой работы. Имеется много интересных взаимосвязей с физикой и соответствующих приложений (квантовая и классическая физика, статистическая физика, космология и т.д.) см., например, раздел 6 выше и работы $[23,92,96,110,111,117,133,145]$.

Ряд важных взаимосвязей и приложений относится и к чисто математическим областям. Так называемая тропическая комбинаторика обсуждается в большой обзорной статье А.Н.Кириллова [87], см. также $[18,187]$. Интересные приложения тропических полуколец к традиционной теории представлений рассматриваются в работах $[11,12,87]$. Тропическая математика тесно связана с весьма популярной теорией кластерных алгебр, основанной С. Фоминым и А. Зелевинским, см. их обзорную работу [57]. В обоих случаях прослеживается связь с традиционной теорией представлений групп Ли и с близкими 
задачами. Имеются важные связи с выпуклым анализом и с дискретным выпуклым анализом, см., например, [2, 27, 30, 32, 40, 113, 118, 123, 157, 183-185]. Некоторые результаты по сложности идемпотентных и тропических вычислений могут быть найдены в работах $[86,114$, $115,170]$. Интересные приложения тропической алгебры к теории 
кос и к преобразованиям Янга-Бакстера (в смысле [16]) можно найти в работах $[34,45,46]$.

Начиная с Н. Н. Воробьева [174-176], многие авторы используют, явно или неявно, конструкции и результаты идемпотентной математики в математической экономике, см., например, [33, 95, 123, 182, 187].

\section{СПИСОК ЛИТЕРАТУРЫ}

[1] M. Akian, Densities of idempotent measures and large deviations, Trans. Amer. Math. Soc. 351 (1999), 4515-4543.

[2] M. Akian and S. Gaubert, Spectral theorem for convex monotone homogeneous maps and ergodic control, Nonlinear Analysis 52 (2003), 637-679. See also arXiv:math.SP/0110108.

[3] M. Akian, S. Gaubert, and V. Kolokoltsov, Set Coverings and Invertibility of Functional Galois Connections. - In [105], p. 1952.

[4] M. Akian, S. Gaubert, and C. Walsh, The max-plus Martin boundary, arXiv:math.MG/0412408, 2004.

[5] M. Akian, S. Gaubert, and C. Walsh, Discrete Max-Plus Spectral Theory. - In [105], p. 53-78.

[6] M. Akian, J. P. Quadrat, and M. Viot, Duality between probability and optimization. - In [69], p. 331-353.

[7] D. Alessandrini, Amoebas, tropical varieties and compactification of Teichmüller spaces, arXiv:math.AG/0505269, 2005.

[8] S. M. Avdoshin, V. V. Belov, V. P. Maslov, and A. M. Chebotarev, Design of computational media: mathematical aspects. - In: [124], p. $9-145$.

[9] F. Baccelli, G. Cohen, G. J. Olsder, and J.-P. Quadrat, Synchronization and Linearity: An Algebra for Discrete Event Systems, John Wiley \& Sons Publishers, New York e.a., 1992.

[10] M. Bardi, I. Capuzzo-Dolcetta, Optimal Control and Viscosity Solutions of Hamilton-Jacobi-Bellman Equations, Birkhäuser, Boston-Basel-Berlin, 1997.

[11] A. Berenstein, S. Fomin, and A. Zelevinsky, Parametrizations of canonical bases and totally positive matrices, Adv. Math. 122 (1996), 49-149.

[12] A. Berenstein and A. Zelevinsky, Tenzor product multiplicities, canonical bases and totally positive varieties, Invent. Math. 143 (2001), 77-128.

[13] P. Bernhard, Minimax versus stochastic partial information control, Proceedings of the 33rd Conference on Decision and Control, Lake Buena Vista, FL, December 1994, IEEE, 1994, p. 2572-2577. 
[14] F. Block and J. Yu, Tropical convexity via cellular resolutions, arXiv:math.MG/0503279, 2005.

[15] Y. Brenier, U. Frisch, M. Hénon, G. Loeper, S. Matarrese, R. Mohayaee, and A. Sobolevski1. Reconstruction of the early Universe as a convex optimization problem, Mon. Nat. R. Astron. Soc. 346 (2003), 501-524.

[16] B. М. Бухштабер, Отображения Янга-Бакстера, Успехи Матем. Наук 53 (1998), no. 6, 241-242.

[17] P. Butkovič, Strong regularity of matrices - a survey of results, Discrete Applied Math. 48 (1994), 45-68.

[18] P. Butkovič, On the combinatorial aspects of max-algebra. - In [105], p. 93-104.

[19] I. Capuzzo Dolcetta, P.-L. Lions (Eds.), Viscosity solutions and applications, Lectures given at the 2nd Session of the C.I.M.E. held in Montecatini Terme, Italy, June 12-20, 1995. Lecture Notes in Mathematics 1660, 1997.

[20] B. A. Carré, An algebra for network routing problems, J. Inst. Appl. 7 (1971), 273-294.

[21] B. A. Carré, Graphs and networks, The Clarendon Press/Oxford University Press, Oxford, 1979.

[22] K. Cechlárová and R. A. Cuninghame-Green, Interval systems of max-separable linear equations, Linear Algebra and its Applications 340 (2002), 215-224.

[23] Weiren Chou and R. J. Duffin, An additive eigenvalue problem of physics related $H J B$ equation to linear programming, Adv. in Applied Mathematics 8 (1987), 486-498.

[24] G. Choquet, Theory of capacities, Ann. Inst. Fourier 5 (1955), 131-295.

[25] G. Cohen, S. Gaubert, and J. P. Quadrat, Max-plus algebra and system theory: where we are and where to go now, Annual Reviews in Control 23 (1999), 207-219.

[26] G. Cohen, S. Gaubert, and J.-P. Quadrat, Duality and separation theorems in idempotent semimodules, Linear Algebra and its Applications 379 (2004), 395-422. Also arXiv:math.FA/0212294.

[27] G. Cohen, S. Gaubert, J.-P. Quadrat, and I. Singer, Max-plus convex sets and functions. - In [105], p. 105-130.

[28] G. Cohen and J.-P. Quadrat (Eds.), 11th International Conference on Analysis and Optimization Systems, Springer Lecture Notes on Control and Information Systems 199, 1994.

[29] R. A. Cuninghame-Green, Minimax algebra, Springer Lect. Notes in Economics and Mathematical Systems 166, Berlin et al., 1979. 
[30] R. A. Cuninghame-Green, Minimax algebra and applications, Advances in Imaging and Electron Physics 90 (1995), 1-121. (Academic Press, New York).

[31] R. Cuninghame-Green and P. Meijer, An algebra for piesewiselinear minimax problems, Dicsrete Appl. Math. 2 (1980), 267-294.

[32] В. И. Данилов, Г. А. Кошевой, Дискретная выпуклость, Записки научных семинаров ПОМИ 312 (2004).

[33] V. Danilov, G. Koshevoi, and K. Murota, Discrete convexity and equilibria in economics with indivisible goods and money, Math. Soc. Sci. 11 (2001), 251-273.

[34] P. Dehornoy, I. Dynnikov, D. Rolfsen, and B. Wiest, Why are braids orderable? Panoramas et Synthèses 14, SMF, 2002.

[35] P. Del Moral, A survey of Maslov optimization theory. - In: V. N. Kolokoltsov and V. P. Maslov, Idempotent Analysis and Applications, Kluwer Acad. Publ., Dordrecht, 1997, p. 243-302 (Appendix).

[36] P. Del Moral, Feynman-Kac formulae. Genealogical and interacting particle systems with applications, Springer, New York e.a., 2004.

[37] P. Del Moral and M. Doisy, Maslov idempotent probability calculus, I, II, Theory of Probability and its Applications 43 (1998), no. 4, 735-751 and 44 (1999), no. 2, 384-400.

[38] P. Del Moral and M. Doisy, On the applications of Maslov optimization theory, Mathematical Notes 69 (2001), no. 2, 232-244.

[39] M. Develin, The moduli space of $n$ tropically collinear points in $R^{d}$, arXiv:math.CO/0401224, 2004.

[40] M. Develin and B. Sturmfels, Tropical covexity, arXiv:math.MG/0308254, 2003.

[41] M. Develin, F. Santos, and B. Sturmfels, On the rank of a tropical matrix, arXiv:math.CO/0312114v2, 2004.

[42] A. Di Nola, B. Gerla, Algebras of Lukasiewicz's Logic and Their Semiring Reducts.. - In [105], p. 131-144.

[43] D. Dubois, H. Prade, and R. Sabbadin, Decision-theory foundations of qualitative possibility theory, European Journal of Operational Research 128 (2001), 459-478.

[44] П. С. Дудников и С. Н. Самборский, Эндоморфизмы полумодулей над полукольцами с идемпотентной операцией, препринт Математического Института АН УССР, Киев, 1987; Известия АН СССР, сер. мат. 55 (1991), по. 1, 93-109.

[45] И. А. Дынников, Об отображениях Янга-Бакстера и упорядочении Деорнуа, Успехи Мат. Наук 57 (2002), nо. 3, 151152. 
[46] I. A. Dynnikov and B. Wiest, On the complexity of braids, arXiv: math.GT/0403177, 2004.

[47] M. Einsiedler, M. Kapranov, and D. Lind, Non-archimedean amoebas and tropical varieties, arXiv:math.AG/0408311, 2004.

[48] R. Feynman and A. Hibbs, Quantum mechanics and path integrals, McGraw-Hill, New-York, 1965.

[49] A. V. Finkelstein and M. A. Roytberg, Computation of biopolymers: a general approach to different problems, BioSystems 30 (1993), 1-20.

[50] W. H. Fleming, Max-Plus Stochastic Control. - In: B. PasikDuncan, Ed., Stochastic Theory and Control, Lecture Notes in Control and Information Science 280 (2002), 111-119.

[51] W. H. Fleming, Max-plus stochastic processes, Applied Math. And Optim. 48 (2004), 159-181.

[52] W. H. Fleming and W. M. McEneaney, A max-plus-based algorithm for a Hamilton-Jacobi-Bellman equation of nonlinear filtering, SIAM J. Control Optim. 38 (2000), no. 3, 683-710.

[53] W. H. Fleming and W. M. McEneaney, Max-plus approaches to continuous space control and dynamic programming. - In [105], p. $145-160$.

[54] W. H. Fleming and H. M. Soner, Controlled Markov processes and viscosity solutions, Springer, New York, 1993.

[55] V. V. Fock, A. B. Goncharov, Moduli spaces of local systems and higher Teichmuller theory, arXiv:math.AG/0311149, 2003.

[56] V. V. Fock, A. B. Goncharov, Cluster ensembles, quantization and the dilogarithm, arXiv:math.AG/0311245, 2003.

[57] S. Fomin and A. Zelevinsky, Cluster algebras: Notes for the CDM-03 Conference, Conf. "Current Developments in Mathematics 2003" held at Harvard University on November 21-22, 2004, arXiv:math.RT/0311493, v. 2, 2004.

[58] U. Frisch, S. Matarrese, R. Mohayaee, and A. Sobolevskiǔ. A reconstruction of the initial conditions of the Universe by optimal mass transportation, Nature, 417 (May 2002), 260-262.

[59] A. Gathmann and H. Markwig, The Caporaso-Harris formula and plane relative Gromov-Witten invariants in tropical geometry, arXiv:math.AG/0504392,2005.

[60] A. Gathmann and H. Markwig, The numbers of tropical plane curves through points in general position arXiv:math.AG/0406099, 2005.

[61] I. M. Gelfand, M. M. Kapranov, and A. Zelevinsky, Discriminants, resultants, and multidimensional determinants, Birkhäuser, Boston, 1994. 
[62] K. Glazek, A guide to the literature on semirings and their applications in mathematics and information sciences: with complete bibliography, Kluwer Acad. Publ., Dordrecht e.a., 2002.

[63] J. A. Goguen, L-fuzzy sets, J. of Math. Anal. Appl. 18 (1967), no. 1, 145-174.

[64] J. S. Golan, Semirings and their applications, Kluwer Acad. Publ., Dordrecht, 1999.

[65] J. S. Golan, Power algebras over semirings, Kluwer Acad. Publ., Dordrecht, 1999.

[66] J. S. Golan, Semirings and affine equations over them: thery and applications, Kluwer Acad. Publ., Dordrecht, 2003.

[67] M. Gondran and M. Minoux, Graphes et algorithmes, Editions Eyrolles, Paris, 1979, 1988.

[68] M. Gondran and M. Minoux, Graphes, dioüdes et semi-anneaux, Editions TEC\&DOC, Paris e.a., 2001.

[69] J. Gunawardena (Ed.), Idempotency, Publ. of the Newton Institute, Vol. 11, Cambridge University Press, Cambridge, 1998.

[70] J. Gunawardena, An introduction to idempotency. - In [69], p. $1-49$.

[71] E. Hopf, The partial differential equation $u_{t}+u u_{x}=\mu u_{x x}$, Comm. Pure Appl. Math. 3 (1950), 201-230.

[72] I. Itenberg, V. Kharlamov, and E. Shustin, Welschinger invariant and enumeration of real rational curves, International Mathematics Research Notices 49 (2003), 26-39.

[73] I. Itenberg, V. Kharlamov, E. Shustin, Appendix to "Welschinger invariants and enumeration of real rational curves, arXiv:math.AG/0312142v2, 2003.

[74] И. В. Итенберг, В. М. Харламов, и Е. И. Шустин, Логарифмическая эквивалентность инвариантов Вельшенже и Громова-Виттена, Успехи Матем. Наук 59 (2004), no. 6, 85-110.

[75] I. Itenberg, V. Kharlamov, E. Shustin, Logarithmic asymptotics of the genus zero Gromov-Witten invariants of the blown up plane, Geometry \& Topology 9 (2005), 483-491; see also arXiv:math.AG/0412533, 2004.

[76] Z. Izhakian, Duality of tropical curves, arXiv:math.AG/0503691, 2005.

[77] Z. Izhakian, Tropical arithmetic \& algebra of tropical matrices, arXiv:math.AG/0505458, 2005.

[78] M. Joswig, Tropical halfspaces, arXiv:math.CO/0312068, 2004.

[79] L. V. Kantorovich, On the translocation of masses, Doklady AN SSSR 37 (1942), 227-229. 
[80] M. M. Kapranov, Amoebas over non-Archimedian fields, Preprint, 2000.

[81] Y. Katsov, On flat semimodules over semirings, Algebra Universalis 51 (2004), 287-299.

[82] K. Khanin, D. Khmelëv, and A. Sobolevskiŭ, A blow-up phenomenon in the Hamilton-Jacobi equation in an unbounded domain In [105], p. 161-180.

[83] K. Khanin, D. Khmelëv, and A. Sobolevskiŭ, On velocities of lagrangian minimizers. Moscow Math. J., 2005 (in print).

[84] K. H. Kim and F. W. Roush, Inclines and incline matrices: a survey, Linear Algebra and its Applications 379 (2004), 457-473.

[85] K. H. Kim and F. W. Roush, Kapranov rank vs. tropical rank, arXiv:math.CO/0503044, 2005.

[86] K. H. Kim, F. W. Roush, Factorization of polynomials in one variable over the tropical semiring, arXiv:math.CO/0501167, 2005.

[87] A. N. Kirillov, Introduction to tropical combinatorics. - In: A. N. Kirillov and N. Liskova (Eds.), Physics and Combinatorics 2000, Proc. of the Nagoya 2000 Intern. Workshop, World Scientific, 2001, p. 82-150.

[88] S. C. Kleene, Representation of events in nerve sets and finite automata. - In: J. McCarthy and C. Shannon (Eds), Automata Studies, Princeton University Press, Princeton, 1956, pp. 3-40.

[89] E. P. Klement, R. Mesiar, and E.Pap, Triangular Norms, Kluwer Acad. Publ., Dordrecht, 2000.

[90] E. P. Klement and E. Pap (Eds.), Mathematics of Fuzzy Systems, 25th Linz Seminar on Fuzzy Set Theory, Linz, Austria, Feb. 3-7, 2004. Abstracts. J. Kepler Univ., Linz, 2004.

[91] V. N. Kolokoltsov, Stochastic Hamilton-Jacobi-Bellman equations and stochastic Hamiltonian systems, Journal of Control and Dynamic Systems 2 (1996), no. 3, 299-319.

[92] V. N. Kolokoltsov, Semiclassical analysis for diffusions and stochastic processes, Springer Lecture Notes in Math. 1724, 2000.

[93] V. N. Kolokoltsov, Idempotency structures in optimization, Journal Math. Sci. 104 (2001), no. 1, 847-880.

[94] V. N. Kolokoltsov, Small diffusion and fast dying out asymptotics for superprocesses as non-Hamiltonian quasiclassics for evalution equations, Electronic Journal of Probability 6 (2001), paper 21 (see http://www.math.washington.edu/ ejpecp/).

[95] V. N. Kolokoltsov and O. A. Malafeyev, A turnpike theorem in conflict-control processes with many participants. - In: O. Malafeyev (Ed.), Conflict Models in Economics and Finance, St. Petersburg Univ. Press, 1997. 
[96] V. Kolokoltsov and V. Maslov, Idempotent analysis and applications, Kluwer Acad. Publ., 1997.

[97] V. Kolokoltsov and A. Tyukov, Small time amd semiclassical asymptotics for stochastic heat equation driven by Levi noise, Stochastics and Stochastics Reports 75 (2003), no. 1-2, 1-38.

[98] M. Kontsevich and Y. Soibelman, Homological mirror symmetry and torus fibration. - In: Symplectic geometry and mirror symmetry (Seoul, 2000), World Sci. Publ., River Edge, N.J., 2001, pp. 203-263.

[99] M. Kontsevich and Y. Soibelman, Affine structures and nonarchimedean analytic spaces, arXiv:math.AG/0406564, 2004.

[100] G. L. Litvinov, Dequantization of mathematics, idempotent semirings and fuzzy sets. - In [90], p. 113-117.

[101] G. L. Litvinov, The Maslov dequantization, idempotent and tropical mathematics: a very brief introduction. - In [105], p. 1-17.

[102] G. L. Litvinov and V. P. Maslov, Correspondence principle for idempotent calculus and some computer applications, (IHES/M/95/33), Institut des Hautes Etudes Scientifiques, Buressur-Yvette, 1995. Also arXiv:math.GM/0101021

[103] G. L. Litvinov and V. P. Maslov, Idempotent mathematics: correspondence principle and applications, Russian Mathematical Surveys 51 (1996), no. 6, 1210-1211.

[104] G. L. Litvinov and V. P. Maslov, The correspondence principle for idempotent calculus and some computer applications. - In [69], p. 420-443.

[105] G. L. Litvinov and V. P. Maslov (Eds.), Idempotent mathematics and mathematical physics, Contemporary Mathematics, Vol. 377, AMS, Providence, RI, 2005.

[106] G. L. Litvinov and E. V. Maslova, Universal numerical algorithms and their software implementation, Programming and Computer Software 26 (2000), no. 5, 275-280. Also arXiv:math.SC/0102114.

[107] G. L. Litvinov, V. P. Maslov, and A. Ya. Rodionov, A unifying approach to software and hardware design for scientific calculations and idempotent mathematics, International Sophus Lie Centre, Moscow 2000. Also arXiv:math.SC/0101069.

[108] Г. Л. Литвинов, В. П. Маслов и Г. Б. Шпиз, Линейные функииональ на идемпотентных пространствах. Алгебрачческий подход, Доклады АН 363 (1998), по. 3, 298-300. 
[109] Г. Л. Литвинов, В. П. Маслов и Г. Б. Шпиз, Тензорные произведения идемпотентных полумодулей. Алгебраический подход, Матем. заметки 65 (1999), по. 4, 572-585.

[110] Г. Л. Литвинов, В. П. Маслов и Г. Б. Шпиз, Идемпотентный функииональный анализ. Алгебрачческий подход, Матем. заметки 69 (2001), по. 5, 758-797.

[111] G. L. Litvinov, V. P. Maslov, and G. B. Shpiz, Idempotent (asymptotic) analysis and the representation theory. - In: V. A. Malyshev and A. M. Vershik (Eds.), Asymptotic Combinatorics with Applications to Mathematical Physics. Kluwer Academic Publ., Dordrecht et al, 2002, p. 267-278. Also arXiv:math.RT/0206025.

[112] Г. Л. Литвинов и Г. Б. Шпиз, Ядерные полумодули и теоремы о ядре. Алгебрачческий подход, Доклады АН 386 (2002), nо. 3, 300-303.

[113] G. L. Litvinov and G. B. Shpiz, The dequantization transform and generalized Newton polytopes. - In [105], p. 181-186.

[114] Г. Л. Литвинов и А. Н. Соболевский, Точные интервальные решения дискретного уравнения Беллмана и полиномиалъная сложность задач интервальной идемпотентной линейной алгебры, Доклады АН 374 (2000), nо. 2, 304-306.

[115] G. L. Litvinov and A. N. Sobolevskiǔ, Idempotent interval analysis and optimization problems, Reliable Computing 7 (2001), no. 5, 353-377. Also arXiv:math.SC/0101080.

[116] P. Loreti and M. Pedicini, An object-oriented approach to idempotent analysis: integral equations as optimal control problems. In [105], p. 187-208.

[117] P. Lotito, J.-P. Quadrat, and E. Mancinelli, Traffic assignment \& Gibbs-Maslov semirings. - In [105], p. 209-220.

[118] G. G. Magaril-Il'yaev and V. M. Tikhomirov, Convex analysis: theory and applications, Translations of Mathematical Monographs, vol. 222, American Math. Soc., Providence, RI, 2003.

[119] V. P. Maslov, New superposition principle for optimization problems. - In: Seminaire sur les Equations aux Dérivées Partielles 1985/86, Centre Math. De l'Ecole Polytechnique, Palaiseau, 1986, exposé 24 .

[120] В. П. Маслов, $О$ новом приниипе суперпозиции для оптимизационных задач, Успехи Матем. Наук, 42 (1987), no. 3, 39-48.

[121] V. P. Maslov, Méthodes opératorielles, Mir, Moscow, 1987.

[122] В. П. Маслов и В. Н. Колокольцов, Идемпотентный анализ и его применение в оптимальном управлении, М: Наука, 1994. 
[123] V. P. Maslov and S. N. Samborskiı̌ (Eds), Idempotent analysis, Adv. in Sov. Math., vol. 13, AMS, RI, 1992.

[124] V. P. Maslov and K. A. Volosov (Eds.), Mathematical aspects of computer engineering, MIR Publ., Moscow, 1988.

[125] D. McCaffrey, Viscosity solutions on Lagrangian manifolds and connections with tunneling operators. - In [105], p. 221-238.

[126] G. Mikhalkin, Amoebas of algebraic varieties, Notes for the Real Algebraic and Analytic Geometry Congress, June 11-15, 2001, Rennes, France. Also arXiv:math.AG/0108225, 2001.

[127] G. Mikhalkin, Counting curves via lattice path in polygons, C.R. Acad. Sci. Paris 336 (2003), no. 8, 629-634.

[128] G. Mikhalkin, Amoebas of algebraic varieties and tropical geometry, to be published in volume "Different faces in Geometry." Also arXiv:math.AG/0403015, 2004.

[129] G. Mikhalkin, Enumerative tropical algebraic geometry in $\mathbf{R}^{2}$, Journal of the ACM, 2005 (in press). Also arXiv:math.AG/0312530.

[130] E. Nelson, Probability theory and Euclidean field theory, Constructive quantum field theory, vol. 25, Springer, Berlin, 1973.

[131] T. Nishinou and B. Siebert, Toric degenerations of toric varieties and tropical curves, arXiv:math.AG/0409060, 2004.

[132] M. Noumi, Y. Yamada, Tropical Robinson-SchenstedKnuth correspondence and birational Weyl group actions, arXiv:math-ph/0203030, 2002.

[133] R. D. Nussbaum, Convergence of iterates of a nonlinear operator arising in statistical mechanics, Nonlinearity 4 (1991), 1223-1240.

[134] L. Pachter and B. Sturmfels, Tropical geometry of statistical models, arXiv:q-bio.QM/0311009v2, 2004.

[135] L. Pachter and B. Sturmfels, The mathematics of phylogenomics, arXiv:math.ST/0409132, 2004.

[136] S. N. N. Pandit, A new matrix calculus, SIAM J. Appl. Math. 9 (1961), 632-639.

[137] E. Pap, Pseudo-additive measures and their applications. - In: E. Pap, ed., Handbook of measure theory, Elsevier, Amsterdam, 2002, p. 1403-1465.

[138] E. Pap, Applications of the generated pseudo-analysis to nonlinear partial differential equations. - In [105], p. 239-260.

[139] M. Passare and A. Tsikh, Amoebas: their spines and their contours. - In [105], p. 275-288.

[140] J. E. Pin, Tropical semirings. - In [69], p. 50-60.

[141] A. A. Puhalskii, Large Deviations and Idempotent Probability, Chapman and Hall/CRC Press, London/Boka Raton, FL., 2001. 
[142] A. A. Puhalskii, On large deviations convergence of invariant measures, Journal of Theoretical Probability 16 (2003), 689-724.

[143] J.-P. Quadrat, Théorèmes asymptotiques en programmation dynamique, Comptes Rendus Acad. Sci., Paris 311, (1990), 745-748.

[144] J.-P. Quadrat and Max-Plus working group, Max-plus algebra and applications to system theory and optimal control,- In: Proc. of the Internat. Congress of Mathematicians, Zürich, 1994.

[145] J.-P. Quadrat and Max-Plus working group, Min-plus linearity and statistical mechanics, Markov Processes and Related Fields 3 (1997), no. 4, 565-587.

[146] J. Richter-Gebert, B. Sturmfels, and T. Theobald, First steps in tropical geometry. - In [105], p. 289-318. Also arXiv:math.AG/0306366.

[147] K. I. Rosenthal, Quantales and their applications, Pitman Research Notes in Mathematics Series, Longman Sci.\&Tech., 1990.

[148] K. I. Rosenthal, The theory of quantaloids, Pitman Research Notes in Mathematics Series 348, LongmanHarlow, 1996.

[149] I. V. Roublev, On minimax and idempotent generalized weak solutions to the Hamilton-Jacobi Equation. - In [105], p. 319-338.

[150] M. A. Roytberg, Fast algorithm for optimal aligning of symbol sequences, DIMACS Series in Mathematics and Theoretical Computer Science, 8 (1992), 113-126.

[151] H. Rullgård, Polynomial amoebas and convexity, Preprint, Stokholm University, 2001.

[152] S. N. Samborskii, A.A. Tarashchan, The Fourier transform and semirings of Pareto sets. - In: [123], p. 139-150.

[153] E. Schrödinger, Quantization as an eigenvalue problem, Annalen der Physik 364 (1926), 361-376 [in German].

[154] Г. Б. Шпиз, Решение алгебраических уравнений $в$ идемпотентных полуполях, Успехи Матем. Наук 55 (2000), no. $5,185-186$.

[155] E. Shustin, Patchworking singular algebraic curves, non Archimedian amoebas and enumerative geometry, arXiv:math.AG/0211278.

[156] E. Shustin, A tropical calculation of the Welschinger invariants of real toric Del Pezzo surfaces, arXiv:math.AG/0504390, 2004.

[157] I. Singer, Abstract convex analysis, John Wiley\&Sons Inc., New York, 1997.

[158] I. Singer, Some relations between linear mappings and conjugations in idempotent analysis, J. Math. Sci. 115 (2003), no. 5, 26102630 . 
[159] A. N. Sobolevskiŭ, Aubry-Mather theory and idempotent eigenfunctions of Bellman operator, Commun. Contemp. Math. 1 (1999), no. 4, 517-533.

[160] A. N. Sobolevskiı̌, Periodic solutions of the Hamilton-Jacobi equation with a periodic nonhomogeneity, and the Aubry-Mather theory, Mat. Sb. 190 (1999), no. 10, 87-104.

[161] F. Sottile, Tropical interpolation, arXiv:math.AG/0501146, 2005.

[162] D. E. Speyer, Tropical linear spaces, arXiv:math.CO/0410455, 2004.

[163] D. Speyer, B. Sturmfels, The tropical Grassmannian, arXiv:math.AG/0304218, 2003.

[164] D. Speyer and B. Sturmfels, Tropical mathematics, arXiv:math.CO/0408099, 2004.

[165] D. Speyer, L. K. Williams, The tropical totally positive Grassmannian, arXiv:math.CO/0312297, 2003.

[166] B. Sturmfels, Solving systems of polynomial equations, CBMS Regional Conference Series in Mathematics, AMS, Providence, RI, 2002.

[167] A. I. Subbotin, Generalized solutions of first order PDEs: The dynamic optimization perspective. Birkhäuser, Boston, 1996.

[168] A. Szenes and M. Vergne, Mixed toric residues and tropical degenerations, arXiv:math.AG/0410064, 2004.

[169] J. Tevelev, Tropical compactifications, arXiv:math.AG/0412329, 2004.

[170] T. Theobald, On the frontiers of polynomial computations in tropical geometry, arXiv:math.CO/0411012, 2004.

[171] M. D. Vigeland, The group law on a tropical elliptic curve, arXiv:math.AG/0411485, 2004.

[172] O. Viro, Dequantization of real algebraic geometry on a logarithmic paper. - In: 3rd European Congress of Mathematics, Barcelona, 2000. Also arXiv:math/0005163.

[173] O. Viro, What is an amoeba?, Notices of the Amer. Math, Soc. 49 (2002), 916-917.

[174] Н. Н. Воробьев, Экстремальная матричная алгебра, Доклады АН 152 (1963), № 1, 1220-1223.

[175] Н. Н. Воробьев, Экстремальная алгебра положительных матрuи, Elektronische Informationsverarbeitung und Kybernetik 3 (1967), 39-57.

[176] Н. Н. Воробьев, Экстремальная алгебра неотрицательных матрич, Elektronische Informationsverarbeitung und Kybernetik 6 (1970), 302-312. 
[177] E. Wagneur, Dequantization: semi-direct sums of idempotent semimodules. - In [105], p. 339-357.

[178] C. Walsh, Minimum representing measures in idempotent analysis, arXiv:math.MG/0503716, 2005.

[179] J. van der Woude and G. J. Olsder, On (min, max, +)inequalities.-In [105], p. 358-363.

[180] L. A. Zadeh, Fuzzy sets, Information and Control 8 (1965), 338353.

[181] L. A. Zadeh, Fuzzy sets as a basis for a theory of possibility, Fuzzy Sets and Systems, 1 (1978), 3-28.

[182] K. Zimmermann, Extremální Algebra, Ekonomický ùstav ČSAV, Praha 46 (1976). (in Czech).

[183] K. Zimmermann, A general separation theorem in extremal algebras, Ekonom.-Mat. Obzor 13 (1977), no. 2, 179-210.

[184] K. Zimmermann, Extremally convex functions, Wiss. Z. Päd. Hochschule "N. K. Krupskaya" 17 (1979), 147-158.

[185] K. Zimmermann, A generalization of convex functions, Ekonom.Mat. Obzor 15 (1979), no. 2, 147-158.

[186] K. Zimmermann, Solution of some max-separable optimization problems with inequality constraints. - In [105], p. 363-370.

[187] U. Zimmermann, Linear and combinatorial optimization in ordered algebraic structures, Ann. Discrete Math., 10 (1981), 1-380.

НЕЗАВИСИМЫЙ МОСКОВСКИЙ УНИвеРСИТет, Б. ВЛАСьЕВСКИЙ ПЕР., 11, MOCKвA 121002, РосСия

E-mail address: islc@dol.ru 